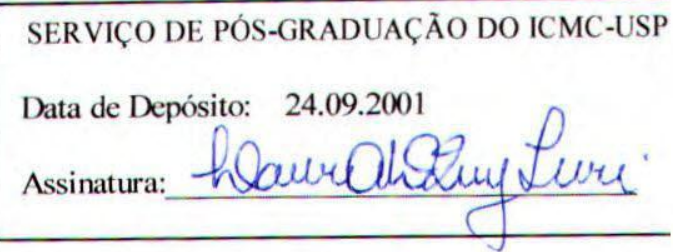

\title{
Gramática de unificação funcional: \\ levantamento de requisitos para a geração sentencial de português
}

\author{
Alexsandro Santos Soares
}

Orientadora: Profa. Dra. Maria das Graças Volpe Nunes

Dissertação apresentada ao Instituto de Ciências Matemáticas e de Computação - ICMC-USP, como parte dos requisitos para obtenção do título de Mestre em Ciências de Computação e Matemática Computacional.

\author{
USP - São Carlos \\ Setembro/2001
}


A Comissão Julgadora:

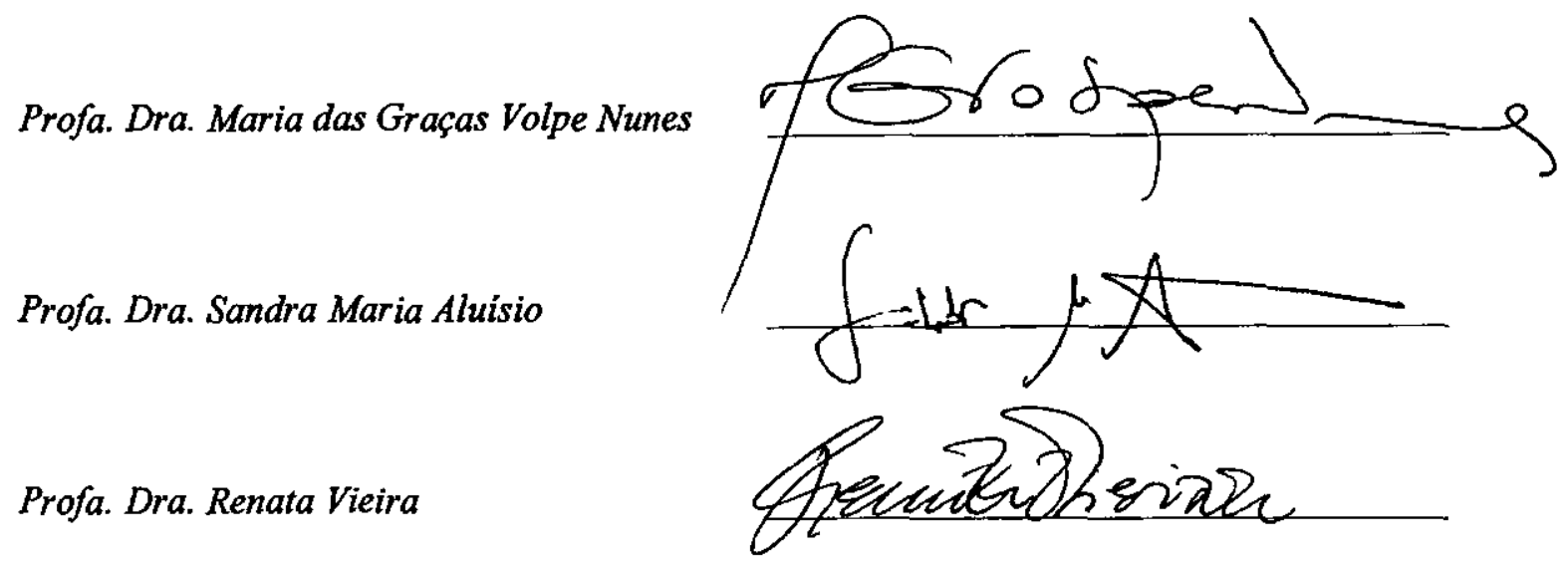


Para a minha Elzilaine, com amor. 


\section{Agradecimentos}

Em primeiro lugar, gostaria de agradecer à minha orientadora Graça, pela ajuda, pelo incentivo e por acreditar que este mestrado chegaria ao fim.

Agradeço às pessoas do Núcleo Interinstitucional de Lingüística Computacional (NILC) pela ajuda que forneceram. Em especial, a Ricardo Hasegawa e Ronaldo Martins pelas vezes que interromperam suas atividades para que a minha caminhasse.

Agradeço também à minha familía e aos meus amigos, pela paciência e constante motivação.

Por último, mas não menos importante, gostaria de agradecer a todas as pessoas que gentilmente disponibilizaram suas publicações e seus programas (muitos com código fonte) na Internet. Sem este espírito verdadeiramente cicntífico este trabalho nāo seria o mesmo. Também este trabalho ficará disponível na grande rede, pois esta obra non mihi, non tibi, sed nobis. 


\section{Abstract}

This work has as its main goal to specify the linguistic and computational resources necessary for the implementation of a portuguese monosentencial generator from a semantic representation language. For the development of such a generator it is necessary that a linguistic theory describes the resources of the language in question, and also a computational formalism that represents and manipulates these linguistic resources in a computational framework. In this dissertation we will show how these requirements can be made functional, through the use of constraint-based linguistic theories, and the use of an unification-based generation system. UNL (Universal Networking Language) is the semantic representation language used in this work. Therefore, the generator proposed here should convert on a sentence by sentence basis from the UNL into well-formed portuguese sentences. 


\section{Resumo}

Neste trabalho especificam-se os recursos lingüísticos e computacionais necessários à implementação de um realizador monosentencial para o português a partir de uma linguagem de representação semântica. Para desenvolver este gerador necessita-se de uma teoria lingüística que descreva os recursos da língua em questão, e também de um formalismo computacional que represente e manipule estes recursos lingüísticos em um ambiente computacional. Nesta dissertação, com o intuito de atender a estes requisitos, será proposto o uso de teorias lingüísticas baseadas em restrições e o uso de um sistema de geração baseado em unificação. A linguagem de representação semântica utilizada é a UNL (Universal Networking Language). Sendo assim, o gerador aqui proposto deverá converter, uma por vez, cada uma das sentenças da UNL em oraçöes gramaticalmente corretas do português. 


\section{Sumário}

Abstract $\quad$ v

Resumo vi vi vis

Lista de Abreviaturas $\quad$ ix

Índice de Tabelas $\quad$ ix

Índice de Figuras $\quad$ x

1 Introdução 1

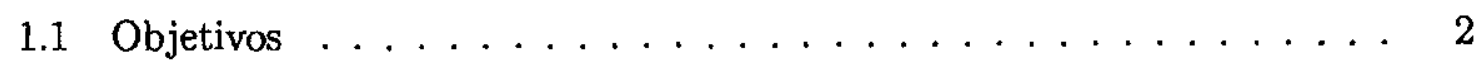

1.2 Motivação . . . . . . . . . . . . . . . . 3

1.3 Organização do trabalho . . . . . . . . . . . 5

2 Visão Geral do Processamento das Línguas Naturais 6

2.1 Introdução. . . . . . . . . . . . . . . 6

2.2 Compreensão . . . . . . . . . . . . . . . . 8

2.3 Geração . . . . . . . . . . . . . . . . . . 10

2.4 Diferenças entre a geração e a compreensão de língua natural . . . . . . 11

3 Os Sistemas de Geração de Língua Natural 14 
3.1 As entradas e as saídas da geração de língua natural . . . . . . . . . . 15

3.1.1 A língua como forma de comunicação dirigida por objetivos . . 15

3.1.2 As entradas para a geração de língua natural . . . . . . . . . . 15

3.1.3 A saída da geração de língua natural . . . . . . . . . . 16

3.2 A arquitetura de um sistema de GLN . . . . . . . . . . . . 17

3.3 Problemas e limitações . . . . . . . . . . . . . . . . 20

4 UNL - Universal Networking Language 24

4.1 Introdução . . . . . . . . . . . . . . . . . . 24

4.2 A representação interna do significado em UNL . . . . . . . . . 25

4.3 O léxico na perspectiva da UNL ................. 25

4.4 O vocabulário da UNL . . . . . . . . . . . . . 27

4.4.1 As palavras universais (UW) . . . . . . . . . . 27

4.4 .2 Os rótulos de relação $(\mathrm{RL}) \ldots \ldots \ldots . \ldots . \ldots 27$

4.4 .3 Os rótulos de atributos $(\mathrm{AL}) \ldots \ldots \ldots$

4.5 O codificador UNL . . . . . . . . . . . . . . . 32

4.6 O decodificador $\mathrm{UNL} \ldots \ldots \ldots \ldots \ldots \ldots \ldots \ldots$

4.6 .1 O funcionamento do DeCo . . . . . . . . . . . 34

5 Formalismos Gramaticais usados em GLN 36

5.1 Formalismo de Unificação Funcional - FUF . . . . . . . . . . . . 38

5.2 Formalismo Sistêmico . . . . . . . . . . . . . . . 39

5.3 Formalismo procedimental . . . . . . . . . . . . . 40

5.4 Comparação entre os três formalismos . . . . . . . . . . . . . . . 41

6 Gramática de Unificação Funcional 43 
6.1 Introdução . . . . . . . . . . . . . . . . . 43

6.2 Estruturas de traços .................... 43

6.2.1 Ordem parcial das estruturas de traços ........... 45

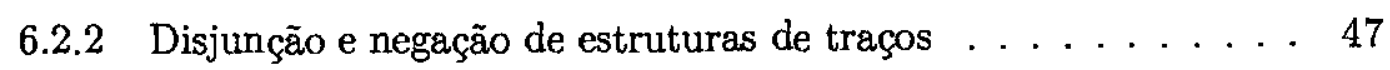

6.3 Unificação de estruturas de traços . . . . . . . . . . . . . . . . 48

6.4 Gramática de Unificaçāo Funcional . . . . . . . . . . . . . . . 49

7 Especificação dos Recursos Linguísticos e Computacionais $\quad 56$

7.1 Introdução . . . . . . . . . . . . . . . . 56

7.2 A arquitetura Geral do Sistema . . . . . . . . . . . . . 57

7.2.1 Mapeamento do Grafo UNL para Árvore UNL . . . . . . . . . 57

7.2.2 Mapeamento da Árvore UNL para uma Descrição Funcional . . 62

7.2 .3 o Gerador Sentencial . . . . . . . . . . . 63

7.2.4 Os Processadores Morfológico e Ortográfico . . . . . . . . 66

7.3 Implementação do Protótipo . . . . . . . . . . . . . . 67

7.3.1 Estruturas de traços e unificação . . . . . . . . . . . 69

7.3.2 O Dicionário UW-Português $\ldots \ldots \ldots$. . . . . . 69

7.3.3 Os Processadores Morfológico e Ortográfico . . . . . . . . . 70

7.3.4 Problemas e Limitaçöes . . . . . . . . . . . . . . . 70

8 Conclusão $\quad 72$

8.1 Resumo das contribuições ................... 73

8.2 Sugestões para trabalhos futuros . . . . . . . . . . . . . 74

$\begin{array}{ll}\text { A Gramática Funcional do Português } & 76\end{array}$

A.1 GUF para um recorte do português . . . . . . . . . . . . 76 
A.2 Excmplos de entradas . . . . . . . . . . . . . . . . 84

Referências 


\section{Lista de Abreviaturas}

CLN Compreensão de Língua Natural

DF Descrição Funcional

ET Estrutura de Traços

FUF Formalismo de Unificação Funcional

GBR Gramática Baseada em Restrições

GCG Gramática Computacional de Geração

GLN Geração de Língua Natural

GUF Gramática de Unificação Funcional

MAV Matriz Atributo-Valor

TAG Gramática de Adjunção de Árvores

UNL Universal Networking Language 


\section{Lista de Tabelas}

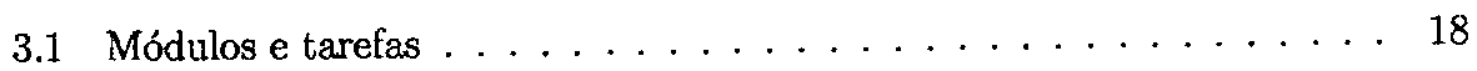




\section{Lista de Figuras}

2.1 Estágios na produção da representação interna. $\ldots \ldots \ldots \ldots$

3.1 Arquitetura de um sistema de GLN segundo Reiter e Dale. . . . . . . 17

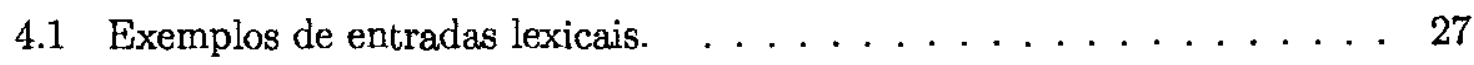

4.2 Arquitetura do decodificador UNL-Português. . . . . . . . . . 33

4.3 Configuração do DeCo para gerar O povo construiu uma torre imensa. . 35

6.1 Uma notação de grafo dirigido para estruturas de traços. . . . . . . 44 45

6.2 Descrição funcional da sentença $O$ sistema salva os documentos. . . . 51

6.3 Uma gramática de unificação funcional G. . . . . . . . . . . 52

6.4 DF da entrada enriquecida pela gramática G. . . . . . . . 53

6.5 A saída do processo de linearização. $\ldots \ldots \ldots \ldots \ldots \ldots \ldots$

6.6 DF da entrada resultante da unificação com a gramática G. . . . . . 55

7.1 Arquitetura do sistema de geração UNL-Português. . . . . . . . 57

7.2 Módulo responsável pelo mapeamento de um grafo UNL para uma

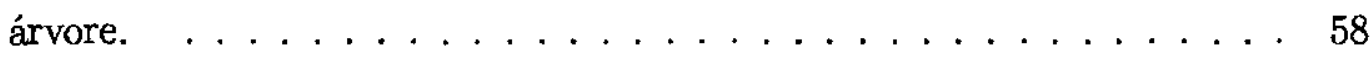

7.3 Algoritmo de conversão de grafo UNL para árvore UNL [SB00]. $\quad \ldots \quad \ldots 9$

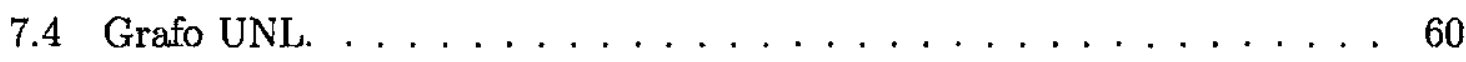

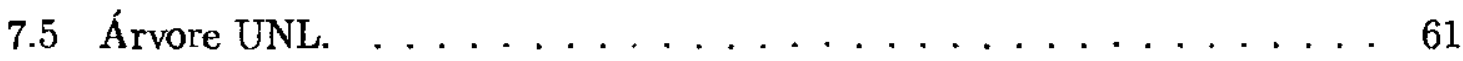


7.6 o gerador sentencial. $\ldots \ldots \ldots \ldots \ldots \ldots$

7.7 Estruturas de traços em Prolog. . . . . . . . . . . . . . . . . . 69

7.8 Programa Prolog para a unificação de ET [FL93]. . . . . . . . . . . 70 


\section{Capítulo 1}

\section{Introdução}

... escrevia de modo comum, com as palavras $e$ o jeito de hoje, em seguida invertia as orações, picava o período com virgulas e substituia incomodar por molestar, ao redor por derredor, isto por esto, quão grande ou tão grande por quamanho, sarapintava tudo de ao invés, empós, $e$ assim obtinha o seu estilo classico que começava a causar admiração aos seus pares e ao público em geral.

Lima Barreto, Triste Fim de Policarpo Quaresma

A geração de língua natural (GLN) é uma subárea da inteligência artificial e da lingüística computacional que se ocupa dos sistemas computacionais capazes de produzir textos compreensíveis em português ou em outras línguas humanas [RD00]. $O$ processo de geração geralmente inicia-se com a utilização de algurn formalismo de representação semântica, contendo a informaçāo a ser passada, e termina com a construção do texto em alguma língua natural.

Uma das etapas da GLN é a chamada geração sentencial ou lexicalização, que consiste na geração do texto propriamente dito, isto é, na escolha das palavras e construções sintáticas que efetivamente veiculem a mensagem a ser transmitida. As abordagens existentes para a modelagem desta etapa variam de sistemas simples e com pouca flexibilidade, valendo-se de textos pré-fabricados, até sistemas mais sofisticados com a utilização de gramáticas computacionais de geração (GCG). 
As GCGs permitem grande flexibilidade aos geradores sentenciais. Esta flexibilidade não é, no entanto, sem custo, pois a construção e a manutenção de tais gramáticas envolvem teorias lingüísticas e formalismos computacionais variados.

As teorias lingüísticas permitem-nos descrever os recursos das línguas naturais, assim como construir modelos que expliquem como uma língua natural funciona. Estes modelos são as gramáticas formais da língua que ajudaräo a responder perguntas, tais como, por que certas combinaçōes de palavras formam orações e outras não, e por qual razão uma oração pode ter determinados significados e não outros.

Os formalismos computacionais fornecem métodos e notações diferentes para representar os recursos linguísticos em um computador sem depender exclusivamente da teoria lingüística utilizada. Este último ponto é importante, pois embora as teorias lingüísticas pareçam estar comprometidas com um formalismo particular, é necessário abstrair e separar as noçöes da teoria lingüística daquelas presentes no formalismo [Elh92]. Isto possibilita a codificação de gramáticas fundamentadas em teorias lingüísticas diferentes (e até mesmo divergentes) utilizando o mesmo formalismo computacional, mutatis mutandis, uma mesma teoria linguiística poderia ser implementada em vários formalismos computacionais diferentes.

Os ambientes de desenvolvimento de gramáticas contribuem para a minimização do esforço necessário para a construção, ampliação e adaptação de gramáticas computacionais. Exemplos destes sistemas são: FUF [Elh92], GENESYS [KTIT94], WAG [O'D94, O’D95], KPML [Bat97] e XLE [BKNS99].

\subsection{Objetivos}

O presente trabalho tem por objetivo investigar os requisitos necessários para geração de sentenças simples do português a partir de uma representação semântica. Para alcançar este objetivo serão utilizadas, para efeito ilustrativo das técnicas, as seguintes hipóteses:

- A línguagem de representação semântica utilizada será a UNL (Universal Networking Language);

- As gramáticas baseadas em restrições (GBR), ou mais especificamente as gramáticas de unificação funcional (GUF), serão utilizadas como o formalismo computaci- 
onal adequado para a implementação das GCGs.

A utilização da UNL persegue um objetivo secundário, mas não menos importante, que consiste no detalhamento dos tipos de conhecimento necessários à construção de um gerador sentencial (ou usando o termo dos projetistas da UNL, um decodificador) para as sentenças UNL, usando, nesta tarefa, as GBRs.

Com o propósito de validar e testar o estudo realizado, foi desenvolvido um protótipo do sistema. Como veremos no capítulo 7, o protótipo possui grandes limitações sendo as principais: a pequena cobertura gramatical oferecida pela GUF do português e a dificuldade de realizar um mapeamento completo dos elementos constituintes da sentença UNL em funções sintáticas, tais como sujeito, objeto, etc. Apesar destas deficiências o protótipo cumpre a função de demonstrar a viabilidade do empreendimento.

\subsection{Motivação}

Os trabalhos de pesquisa no Brasil envolvendo geração sentencial estão, em sua grande maioria, centrados em torno de aplicações específicas. Assim, as gramáticas desenvolvidas são ou específicas demais, sendo utilizáveis apenas nos domínios para os quais foram construídas, ou apresentam um alto grau de simplificação, não tratando de vários fenômenos linguísticos importantes. Um exemplo ilustrativo é o trabalho de Quental [Que95], que especifica uma gramática computacional utilizada por um sistema de interface entre usuários e sistemas baseados em conhecimento. Tal gramática mostra-se pouco flexível à adaptação em outros ambientes e o uso desta gramática em geração apresenta problemas que são devidos, em grande parte, a sua natureza bidirecional, tentando servir tanto para a compreensão quanto para a geração. Isto, como veremos, causará alguns inconvenientes devido às necessidades diferenciadas dos dois processos.

A grande maioria dos trabalhos em lingüística computacional focaliza a compreensão ou a tradução automática de textos. Isso é explicado, segundo Silva [Sil96], pelo fato de que, em geral, os sistemas de processamento automático de língıas naturais são projetados visando-se finalidades práticas, onde há um maior comprometimento com a precisão e eficiência no processo de recepção do que com o processo de produção de mensagens. A produção de mensagens nesses sistemas resume-se à utilização de um conjunto fixo de padrões previamente armazenados que, embora reduza o grau de 
naturalidade dos textos, não chega a comprometer a sua legibilidade.

As gramáticas desenvolvidas para análise mostram-se pouco adaptáveis ao processo de geração, não tratando de forma satisfatória fenômenos linguísticos como paráfrases, referências anafóricas, coordenação e elipse, etc., cujo entendimento são essenciais para a produção de textos de qualidade. Como exemplos nacionais de gramáticas construídas com essas finalidades podemos citar [Kip94, Agu97] que utilizam o formalismo das gramáticas de adjunção de árvores (TAG, do inglês Tree-Adjoining Grammars), e [Cam97] que utiliza o formalismo das gramáticas independentes de contexto estendidas.

Gramáticas desenvolvidas especificamente para a GLN já existem há algum tempo para outras línguas. Há que ressaltar que a construção de tais gramáticas é uma tarefa complexa, exigindo-se o empenho de pessoas especializadas e leva um tempo relativamente grande para ser completada (algumas gramáticas de GLN para o inglês, por exemplo, estão sob desenvolvimento desde a década de 70). Merecem destaque, pela abrangência e impacto entre os pesquisadores de GLN, as seguintes gramáticas inglesas: NIGEL [MM83] e SURGE [ER97], ambas desenvolvidas sob a mesma teoria lingüística, a lingüística sistêmico-funcional, porém implementadas usando dois formalismos computacionais diferentes. Também de interesse são as gramáticas de GLN escritas para o turco e descritas em [Hak96] e [Kor96], respectivamente.

Descrições de gramáticas para GLN adequadas à língua portuguesa são raras na literatura. Entretanto, encontramos o trabalho de André Eliseu e seu grupo em Portugal [Eli99] e os trabalhos realizados na Universidade Federal de Pernambuco por Jacques Robin, Rosely Lacerda e Eloi Favero, para os quais, infelizmente, não possuímos referências bibliográficas.

Devido a esta escassez na literatura de trabalhos envolvendo GLN e a língua portuguesa é que decidimos investigar quais recursos seriam necessários para a construção de uma gramática computacional para o português e que fosse adequada para a GLN. Cabe lembrar que muitas aplicações, além da UNL que utilizaremos neste texto, poderão beneficiar-se do uso de tal gramática. Para citar somente algumas [Sil96]:

- Sistemas de manipulação de bases de dados;

- Sistemas de ensino assistido por computador, também conhecidos como sistemas tutores;

- Sistemas de automação de tarefas administrativas e gerenciais; 
- Sistemas de processamento automático de textos científicos;

- Sistemas especialistas;

- Sistemas de tradução automática.

\subsection{Organização do trabalho}

No Capítulo 2 é feita uma revisão da área de processamento de línguas naturais. Este capítulo também explica a diferença entre geração e compreensão de língua naturais, mostrando que uma não é necessariamente o inverso da outra.

O Capítulo 3 descreve em linhas gerais os sistemas de geração de línguas naturais. As entradas e saídas são explicadas e uma arquitetura geral para estes sistemas é proposta. O capítulo se encerra discutindo os problemas e limitações dos sistemas de geração.

No Capítulo 4 são apresentados a UNL (Universal Networking Language) e os dois sistemas que acompanham esta linguagem: o codificador e o decodificador.

A apresentação e o contraste entre três dos formalismos gramaticais mais usados em GLN são apresentados no Capítulo 5. O Capítulo 6 explica mais detalhadamente um deles: a gramática de unificação funcional. Neste capítulo também é visto o funcionamento deste formalismo na geração, usando uma gramática simplificada para o português.

No Capítulo 7 é proposta uma arquitetura para a geração de sentenças a partir da UNL. Um protótipo implementando desta arquitetura é detalhado, assim como seus problemas e limitações.

Finalmente, o Capítulo 8 apresenta as conclusões e propostas de possíveis direções para uma pesquisa posterior. $\mathrm{O}$ apêndice $\mathrm{A}$ contém a gramática exemplo usada neste trabalho e também alguns exemplos de entrada. 


\title{
Capítulo 2
}

\section{Visão Geral do Processamento das Línguas Naturais}

\author{
Dê-me um cigarro \\ Diz a gramática \\ Do professor e do aluno \\ $E$ do mulato sabido \\ Mas o bom negro e o bom branco \\ Da Naçāo Brasileira \\ Dizem todos os dias \\ Deixa disso camarada \\ Me dá um cigarro
}

Oswald de Andrade, pronominais

\subsection{Introdução}

Língua é um fenômeno complicado, envolvendo processos tão variados quanto o reconhecịmento de sons ou cartas impressas, análise sintática, inferências semânticas de alto nível e mesmo a comunicação de conteúdo emocional através de ritmo e inflexão. Com o objetivo de gerenciar esta complexidade, os lingüistas definiram diferentes níveis de análise para as línguas naturais: 
1. A prosódia lida com o ritmo e entonação da língua. Este nível de análise é difícil de ser formalizado e é freqüentemente negligenciado. Entretanto, sua importância é evidente nos poderosos efeitos da poesia ou dos cantos religiosos, como no papel desempenhado pelo ritmo nos trocadilhos das crianças e o balbucio dos bebês.

2. A fonologia examina como os sons são combinados para formar a língua. Este ramo da lingüística é importante para o trabalho sobre geração e reconhecimento de fala computadorizados.

3. A morfologia está preocupada com os componentes (morfemas) de que são constituídas as palavras. Isto inclui as regras governando a formação das palavras, tais como o efeito dos prefixos (in-, des-, anti-, etc.) e sufixos( -ndo, -mente, etc.) que modificam o significado da raiz das palavras. A análise morfológica é importante na determinação do papel de uma palavra em uma sentença, incluindo sua categoria, tempo e número.

4. A sintaxe estuda as regras de combinação entre palavras para formar sentenças e orações, e o uso de tais regras para analisar e gerar sentenças. Isto tem sido o mais bem formalizado e consequentemente o mais bem sucedido nivel de análise lingüística automatizado.

5. A semântica considera o significado das palavras, frases e orações e os modos nos quais o significado é transmitido em língua natural.

6. A pragmática é o estudo dos modos nos quais a língua é usada e seu efeito sobre o ouvinte. Por exemplo, a pragmática poderia se ocupar das razōes do porquê de "Sim" ser usualmente uma resposta inapropriada para a pergunta "Você sabe que horas são?".

7. O conhecimento de mundo inclui o conhecimento do mundo físico, o mundo das interações humanas e o papel dos objetivos e intenções na comunicação. Este conhecimento geral é essencial para se compreender o completo significado de um texto ou conversação.

Embora esses níveis de análise pareçam naturais e sejam suportados por evidência psicológica, eles são, em algum sentido, divisões artificiais que foram impostas à língua. Todos eles interagem extensivamente, até mesmo com entonações e variações rítmicas afetando o significado de uma proposição, como por exemplo, o sarcasmo. 
Esta interação ć evidente no relacionamento entre a sintaxe e a semântica. Embora algumas divisōes ao longo dessas linhas sejam essenciais, o limite exato é difícil de se caracterizar. Conversamente, a sintaxe afeta a semântica como é ilustrado pelo papel da estrutura da sentença na interpretação de seu significado. Embora a exata natureza da distinção entre a sintaxe e a semântica seja freqüentemente turva e debatida, tanto a evidência psicológica quanto a sua utilidade para gerenciar a complexidade do problema impedem que ela seja dispensada [LS93].

O processamento automático das línguas naturais se ocupa do estudo dos sistemas computacionais capazes de compreender e gerar línguas naturais. O campo é assim dividido em duas subáreas:

a compreensão ou interpretação, cujo objetivo é a transformação da sentença na língua origem em uma forma intermediária chamada de representação semântica;

a geração, que seria o inverso do processo de interpretação, ou seja, o objetivo é transformar uma sentença representada semanticamente em uma sentença na língua destino.

\subsection{Compreensão}

Embora a organização específica de programas de compreensão de línguas naturais (CLN) varie com diferentes filosofias e aplicações (por exemplo, uma interface para um banco de dados, um sistema de tradução automática ou um programa de compreensão de histórias) todos eles devem traduzir a sentença original em uma representação interna de seus significados. Geralmente, a compreensão de língua natural segue os estágios da Figura 2.1.

O primeiro estágio é o de análise sintática, que analisa a estrutura sintática da sentença. A análise sintática não somente verifica que as sentenças são sintaticamente bem formadas mas também determina suas estruturas lingüísticas. Identificando as maiores relações lingüísticas tais como sujeito-verbo, verbo-objeto e nome-modificador, o analisador fornece um quadro de trabalho para a interpretação semântica. Isto é freqüentemente representado como uma árvore sintática. $\mathrm{O}$ analisador emprega conhecimento da língua quanto à sintaxe, morfologia e alguma semântica. 
ANÁLISE SINTÁTICA

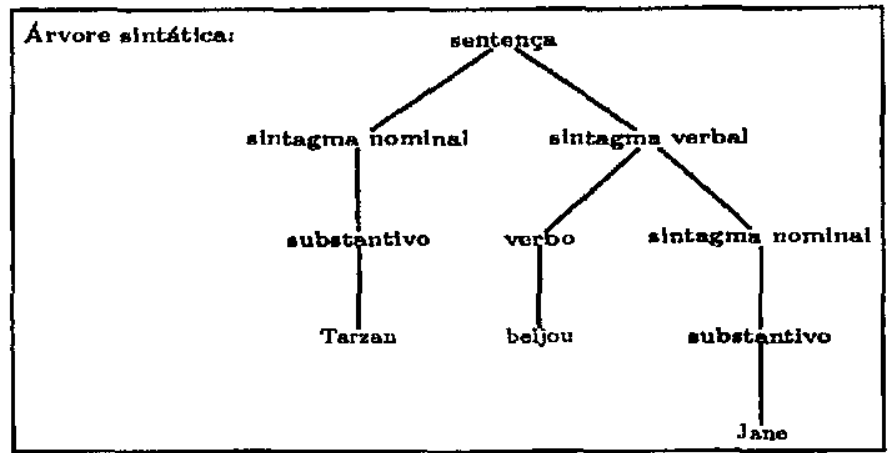

INTERPRETAÇÃO SEMÂNTICA

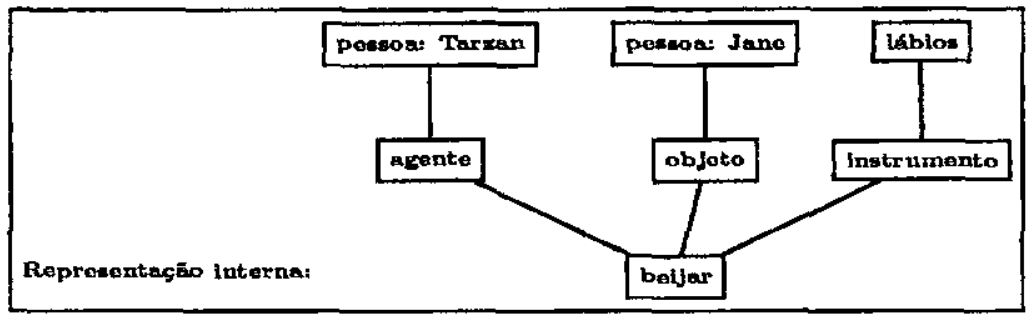

INTERPRETAÇÃo DO CONHECIMENTO DO MUNDO/ CONTEXTUAL

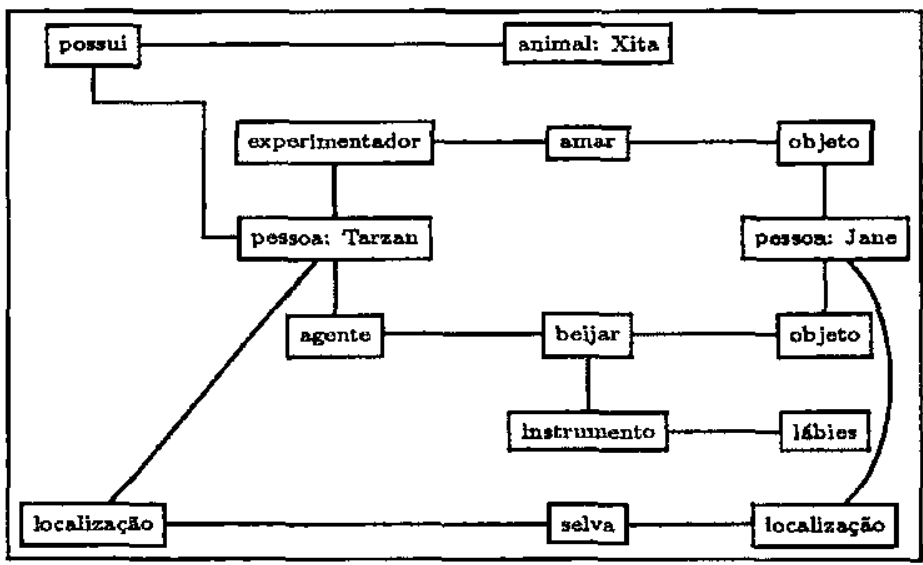

Figura 2.1: Estágios na produção da representação interna [LS93]. 
O segundo estágio é a análise semântica, que produz uma representação do significado do texto. Na Figura 2.1 isto é mostrado como um grafo conceitual. Outras representações comumente usadas incluem dependência conceitual, frames e representações baseadas em lógica. A interpretação semântica usa conhecimento sobre o significado das palavras e suas estruturas lingüísticas, tais como os casos dos substantivos ou a transitividade dos verbos. No exemplo dado na figura, o programa usou conhecimento do significado de beijar para adicionar o valor default de lábios como o instrumento da ação. Este estágio também realiza a verificação de consistência semântica. Por exemplo, a definição do verbo beijar pode incluir restrições que requeiram que o objeto seja urna pessoa se o agente é uma pessoa, isto é, Tarzan não (normalmente) beija a Xita.

No terceiro estágio, as estruturas da base de conhecimento são adicionadas à representação interna da sentença para produzir uma representação expandida do significado da sentença. Isto adiciona o conhecimento de mundo necessário, exigido para a completa compreensão, tais como os fatos que Tarzan ama a Jane, que Jane e Tarzan vivem na selva e que Xita é o animal de estimação do Tarzan. Esta estrutura resultante representa o significado do texto na língua natural e é usado pelo sistema para um processamento posterior.

Estes estágios existem em todos os sistemas de CLN, podendo não corresponder a módulos distintos de software. Por exemplo, muitos programas não produzem uma árvore sintática explícita, entretanto geram a representação semântica interna diretamente. Todavia, a árvore está implícita na análise sintática da sentença [LS93].

\subsection{Geração}

A área de estudo chamada geraçāo de língua natural (GLN) investiga como os programas de computador podem produzir textos de alta qualidade em língua natural a partir de representações internas da informação. Essas representações internas, como citadas na seção anterior, são construídas para facilitar o processamento computacional e por isso nāo detêm o caráter de inteligibilidade para uma leitura feita por humanos. Sistemas GLN usam conhecimento sobre a língua e sobre o domínio de aplicação para automaticamente produzir documentos, relatórios, explicações, mensagens de ajuda e outros tipos de textos. 
A GLN pode ser vista tanto como área de pesquisa, quanto tecnologia emergente com muitas aplicações no mundo real. Como uma área de pesquisa, a GLN adota uma perspectiva única sobre as questões fundamentais em inteligência artificial, ciência cognitiva e interação homem-computador. Entre estas, destacam-se:

- Quanto conhecimento, lingüístico e do domínio particular, deveria ser representado e utilizado em processos de raciocínio?

- O que significa dizer que um texto está bem escrito?

- Como a informação deve ser comunicada entre homem e máquina?

De uma perspectiva prática, a tecnologia de GLN é capaz de parcialmente automatizar a criação rotineira de documentos, removendo muito do trabalho associado a tais tarefas. Em longo prazo, é provável que a GLN venha desempenhar um importante papel nas interfaces homem-computador e permita uma interação mais rica com máquinas do que é possível hoje [RD00].

Mais informações sobre o processo de geração serão fornecidas pelos capítulos seguintes, onde um maior detalhamento das questões envolvidas será apresentado. Antes, porém, faremos uma breve exposição das principais diferenças entre a compreensão e a geração de língua natural.

\subsection{Diferenças entre a geração e a compreensão de língua natural}

A geração de língua natural está intimamente relacionada à sua compreensão. Ambas se ocupam dos modelos computacionais da língua e de seu uso; elas compartilham muitas das fundamentações teóricas e são constantemente utilizadas juntas em programas de aplicação.

Em um nível mais abstrato, pode-se pensar no processo de geração de língua natural como sendo o inverso do processo de compreensão. Assim, pelo menos em termos gerais, os dois processos possuem os mesmos pontos finais e a diferença entre eles recai somente na maneira com que navegam entre estes dois pontos: um navega na direção oposta à do outro. 
Entretanto, as operações internas destes processos são muito diferentes em caráter. Mais fundamentalmente, o processo de compreensão é melhor caracterizado como aquele de genenciamento de hipóteses: dada uma entrada, qual das múltiplas interpretações possíveis em qualquer estágio do processamento é a mais apropriada? A geração de língua natural é melhor caracterizada como um processo de escolha: dados os diferentes meios que estão disponíveis para se alcançar algum fim, qual deveria ser usado?

Alguns trabalhos de pesquisa [Neu98, vN93] na área têm tentado construir componentes "reversíveis" que poderiam ser usados tanto em sistemas de geração quanto nos de interpretação. Esta idéia foi explorada em particular para o mapeamento entre as representações semânticas e as sentenças na forma superficial que correspondem àquelas representações: uma gramática bidirecional [SvNPM90] usa uma representação declarativa simples da gramática da língua para realizar tanto a análise sintática nos sistemas de CLN quanto a realização lingüística nos sistemas de GLN (isto é, mapeia representações semânticas em sentenças).

Infelizmente, a despeito da elegância $e$ do apelo intuitivo da idéia, é efetivamente difícil construir sistemas bidirecionais na prática. Isto é devido em grande parte ao fato de que importantes problemas de CLN não representam problema para a GLN e viceversa. Por exemplo, um dos maiores problemas na construção de sistemas de CLN reais é a necessidade de estar apto a tratar entradas mal formadas ou gramaticalmente incorretas, o que não é um problema em GLN. Por outro lado, um dos principais problemas em GLN é assegurar que o texto gerado seja facilmente compreendido pelos humanos, o que não é um problema em CLN. Um problema relacionado aos sistemas bidirecionais é que as representações internas usadas pelos sistemas de GLN e de CLN são muito diferentes. Por exemplo, as representaçōes que muitos analisadores sintáticos usados em CLN produzem como saída são muito diferentes das representações de entrada requeridas por muitos realizadores de GLN. Esta incompatibilidade básica torna difícil construir um sistema que faça tanto a análise sintática quanto a realização.

Gramáticas bidirecionais têm sido usadas em sistemas de tradução automática, onde as representações de entrada já estão frequientemente particionadas em sentenças completas, mas elas não tem sido extensivamente usadas em sistemas de GLN, que geram texto a partir de alguma representação não lingüística da informação.

Uma importante diferença entre a GLN e a CLN vem de um aspecto mais pragmático do trabalho nas duas áreas. Em termos gerais, muito da compreensão de língua natural 
está direcionada pela necessidade de estar apto a tratar de uma grande variedade de estruturas linguísticas complexas que aparecem em qualquer língua natural. Este aspecto de cobertura é de menor importância na geração de língua natural e, de fato, os textos produzidos por muitos sistemas de geração são muito mais simples em termos lingüísticos do que os textos que sistemas de CLN aspiram processar. Para o trabalho em GLN, é, na maioria das vezes, suficiente possuir um modo de dizer algo, enquanto qualquer experimento de CLN tem que levar em conta o fato de que muitas entradas diferentes podem ser utilizadas para expressar a mesma coisa. Isto novamente enfatiza a diferença em caracterização do processo descrito anteriormente: o trabalho em CLN está frequientemente relacionado com a eliminação do que são pensadas como "diferenças superficiais", tal que, por exemplo, João comeu o biscoito e $O$ biscoito foi comido por Joāo recebem a mesma interpretação. O trabalho em GLN, ao contrário, está freqüentemente relacionado com a escolha entre tais sentenças de uma maneira sistemática [RD00]. 


\section{Capítulo 3}

\section{Os Sistemas de Geração de Língua Natural}

Chega mais perto e contempla as palauras.

Cada uma

tem mil faces secretas sob a face neutra.

e te pergunta, sem interesse pela resposta

pobre ou terrivel, que the deres:

Trouxeste a chave?

Carlos Drummond de Andrade, Procura de poesia

Como outros sistemas complexos de software, sistemas de GLN são em geral mais fáceis de construir e depurar se forem decompostos em módulos distintos, bem definidos e facilmente integráveis. Isto é especialmente verdadeiro se o software está sendo construído não por um único indivíduo, mas por uma equipe. A modularização pode também tornar mais fácil a reutilização dos componentes de diferentes aplicações, assim como a modificação de uma aplicação.

Ainda não existe concordância entre os pesquisadores de GLN sobre o que constitui a mais apropriada decomposição do processo de gerar língua natural a partir de alguma representação básica.

Este capítulo apresentará a arquitetura para os sistemas de GLN apresentada em Reiter e Dale [RD00]. Entretanto, existem outras alternativas que não serão aborda- 
das aqui tais como aquela apresentada em Matthiessen e Bateman ${ }^{1}$ ou nos sistemas baseados em revisão como em [Rob94].

\subsection{As entradas e as saídas da geração de língua natural}

\subsubsection{A língua como forma de comunicação dirigida por ob- jetivos}

De uma perspectiva teórica, o processo de geração de língua é frequientemente visto como uma forma de comunicação dirigida por objetivos. Sob tal visão, a produção de uma proposiçāo - seja ela uma palavra, uma sentença, ou um grande trecho de um texto escrito ou falado - é vista como uma tentativa de satisfazer algum objetivo comunicativo ou intenção comunicativa por parte do falante. O que conta como uma intenção ou objetivo comunicativo é deixado aberto à interpretação, entretanto a categoria de tais coisas é geralmente vista como incluindo, variadamente, os objetivos de informar ao ouvinte alguma coisa, de requerer ou persuadir o ouvinte a fazer alguma coisa e de obter algum item de informação do ouvinte. A fim de satisfazer tais objetivos, o falante (seja ele humano ou o computador) decide que algum ato comunicativo deve ser realizado, tal que o ouvinte possa compreender a intenção do falante e reagir ou responder apropriadamente.

\subsubsection{As entradas para a geração de língua natural}

Em termos gerais, podemos caracterizar a entrada em um sistema de GLN como uma quádrupla $\langle\mathbf{k}, \mathbf{c}, \mathbf{u}, \mathbf{d}\rangle$, onde $k$ é a fonte de conhecimento a ser usada, $c$ é o objetivo comunicativo a ser alcançado, $u$ é o modelo do usuário, e $d$ é a história do discurso.

A fonte de conhecimento consiste nas informações sobre o domínio, tipicamente codificadas em um ou mais bancos de dados e bases de conhecimento, que estão disponíveis para uso pelo sistema de GLN. Tanto o conteúdo quanto a representação da fonte de conhecimento são altamente dependentes da aplicação em questão.

\footnotetext{
${ }^{1}$ Matthiessen, C.M. I. and Bateman, J.A. (1991). Text Generation and Systemic-Functional Linguistics. Apud $\left[\mathrm{N}^{+99}\right]$
} 
O objctivo comunicativo descreve o propósito do texto a ser gerado. Isto deveria ser diferenciado do propósito geral de um dado sistema de GLN. Por exemplo, um tradutor automático terá como propósito geral a geração de um texto na língua nativa da pessoa que o lêe, entretanto o objetivo comunicativo pode ser o de descrever, com todas as emoções possíveis, uma partida de futebol.

O modelo do usuário é uma caracterização do ouvinte ou da audiência pretendida para a qual o texto deve ser gerado. Em muitos sistemas de GLN, o modelo do usuário não é explicitamente especificado, neste caso ele é efetivamente fundido dentro do comportamento do sistema. Onde o modelo do usuário é fornecido explicitamente, seu conteúdo dependerá do que é considerado importante no contexto de uma dada aplicação.

A história do discurso é um modelo do que foi dito no texto produzido até agora. Isto permite ao sistema rastrear as entidades e propriedades já mencionadas de maneira que possa fazer uso apropriado de recursos anafóricos tais como pronomes. Em sistemas de uma única interação, a história do discurso inicia com uma estrutura de dados vazia que durante a criação do texto sendo gerado, será eventualmente preenchida e utilizada. Em sistemas de diálogo, a história do discurso é algumas vezes chamada de história do diálogo; isto serve como um repositório de informação sobre as interações prévias entre o usuário e o sistema de GLN.

\subsubsection{A saída da geração de língua natural}

A saída do processo de geração é um texto. Do ponto de vista do usuário, um texto é algo que é lido no papel, visto on-line ou ouvido. Muitos sistemas de GLN, entretanto, não se interessam pelos detalhes da formatação para exibição on-line ou para a saída sonora. Muitos destes sistemas simplesmente produzem uma cadeia de texto ASCII para exibição em um terminal. Para aplicações reais, isto é geralmente inadequado e atenção deve ser dada à apresentação do texto em uma forma mais útil, que é, tipicamente, feita através do uso das capacidades de um pacote externo (tais como o Microsoft Word, o Nestcape Navigator ou o Lucent TTS) para de fato formatar, exibir ou ler o documento. A tarefa do sistema de GLN é então produzir representações de entrada apropriadas para o sistema de apresentação sendo usado. Estas representações geralmente consistem em seqüências lineares de tokens de palavras e símbolos de pontuação combinados com símbolos de marcação que serão compreendidos pelo sistema 


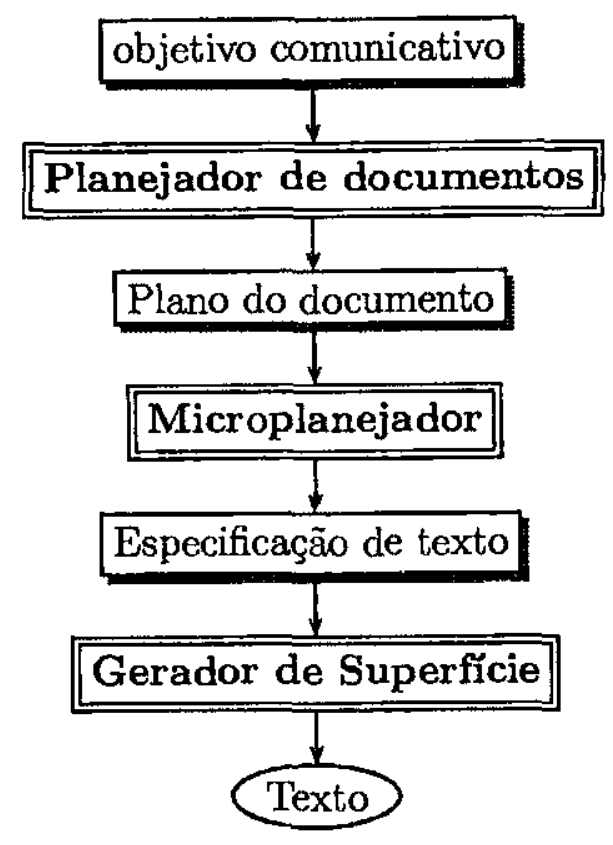

Figura 3.1: Arquitetura de um sistema de GLN segundo Reiter e Dale [RD00].

de apresentação.

\subsection{A arquitetura de um sistema de GLN}

A arquitetura proposta por Reiter e Dale [RD00] é mostrada no diagrama da Figura 3.1. Nesta seção serão descritos os módulos e representações em mais detalhes.

Entre as tarefas do planejador de documentos está a produção da especificação do conteúdo e da estrutura de um texto, usando o conhecimento do domínio e da aplicação, e a indicação da informação apropriada para o objetivo comunicativo especificado, levando em conta o modelo do usuário, e assim por diante. Isto também requer usar conhecimento sobre como os documentos são tipicamente estruturados no domínio da aplicação. Muitas das técnicas utilizadas no planejamento de documentos são similares àquelas encontradas no mundo dos sistemas especialistas. Correspondentemente, devese esperar que especialistas no domínio estejam envolvidos no projeto e na construção dos componentes do planejador de documentos.

Em alguns casos pode ser apropriado para o componente de planejamento de documentos especificar completamente o conteúdo e a estrutura de um documento. Em outros casos, entretanto, é útil para o planejador deixar abertos alguns tipos de decisão 
que dependem do conhecimento sobre a língua e sua escrita. Por exemplo, o tipo de conhecimento requerido para determinar como melhor empacotar a informação em sentenças pode ser mais convenientemente especificado separadamente e aplicado em um estágio posterior. Em tais casos, é tarefa do microplanejador completar estes detalhes faltantes.

Em alguns sistemas, a saída do microplanejador pode estar na forma de um texto real. Em muitos casos, entretanto, é novamente útil separar algum conhecimento específico tal como aquele necessário para produzir estruturas gramaticais na língua sendo gerada. O microplanejador pode então produzir uma especificação abstrata do conteúdo e da estrutura do texto, deixando para o gerador de superfície a tarefa de converter esta especificação abstrata em texto real. Por exemplo, o microplanejador pode especificar o tempo de uma sentença por meio de uma categoria abstrata tal como PASSADO, PRESENTE ou FUTURO e deixar para o realizador a escolha da flexão verbal apropriada, assim como a adição de qualquer palavra auxiliar gramaticalmente necessária. Similarmente, o microplanejador pode simplesmente enunciar que um conjunto de sentenças deveria ser agrupado em um parágrafo e pode deixar o gerador converter estas especificações nos símbolos de marcação requeridos pelo sistema de apresentação do documento alvo.

Podemos adicionalmente subdividir o processamento nestes módulos em termos de tarefas conceitualmente distintas que necessitam ser feitas. Um modo de caracterizar estas tarefas é ver algumas delas como estando primariamente interessadas no conteúdo e outras na estrutura, como resumido na Tabela 3.1 .

\begin{tabular}{|l|l|l|}
\hline Módulo & Conteúdo & Estrutura \\
\hline $\begin{array}{l}\text { Planejador de } \\
\text { documentos }\end{array}$ & Determinação do conteúdo & Estruturação do documento \\
\hline Microplanejador & $\begin{array}{l}\text { Lexicalização; } \\
\text { Geração de expressões de referência }\end{array}$ & Agregação \\
\hline Realização & Realização lingǘística & Realização da estrutura \\
\hline
\end{tabular}

Tabela 3.1: Módulos e tarefas [RD00]

Determinação do conteúdo é a tarefa de decidir qual informação deveria ser comunicada no documento de saída. Podemos pensar nisto como o aspecto do conteúdo do planejamento do documento. 
Estruturação do documento é a tarefa de decidir como as porções do conteúdo deveriam estar agrupadas no documento e como porções diferentes deveriam estar relacionadas em termos retóricos. Podemos pensar nisto como o aspecto estrutural do planejamento do documento.

Lexicalização constitui-se na tarefa de decidir quais palavras específicas (ou outros recursos lingüísticos, tais como construções sintáticas particulares) deveriam ser usadas para expressar o conteúdo selecionado pelo componente de determinação de conteúdo. Isto pode ser visto como o lado de conteúdo do microplanejamento.

Agregação é a tarefa de decidir como as estruturas criadas pelo planejador de documentos deveriam ser mapeadas nas estruturas lingüísticas, tais como sentenças e parágrafos. Os mecanismos de agregação podem também decidir em qual ordem a informação deveria ser expressa, se isto foi deixado em aberto pelo componente de estruturação do discurso. Podemos ver ista tarefa como o lado estrutural do microplanejamento.

Realização lingưística é a tarefa de converter as representações abstratas de sentenças em texto real; ela corresponde ao aspecto de conteúdo da geração de superfície.

Realização da estrutura é a tarefa de converter estruturas abstratas, tais como parágrafos e seções, nos símbolos de marcação compreendidos pelo componente de apresentação do documento; isto corresponde ao lado estrutural da geração de superfície.

As representações intermediárias passadas entre os módulos da Tabela 3.1 são explicadas abaixo:

Planos de documentos estão na saída do planejador de documentos e na entrada do microplanejador. Os planos de documentos consistem em árvore cujos nós internos especificam informação estrutural e cujos nós folhas especificam o conteúdo. Os nós folhas dos planos de documentos são chamados mensagens.

Especificações de texto estão na saída do microplanejador e na entrada do gerador. Estas estruturas novamente são árvores, cujos nós internos especificam a estrutura de um texto e cujos nós folhas especificam as sentenças de um texto. Os nós folhas de uma especificação de texto são chamados de especificaçōes de frases. 
A especificação de frase será desmembrada em vários níveis de abstração. Ela pode ser uma cadeia ortográfica, um fragmento de texto pré-fabricado, uma estrutura sintática abstrata ou uma árvore temática parcialmente lexicalizada. Misturas destas representações também são permitidas.

As cadeias ortográficas especificam uma frase como uma cadeia completa, com todas as maiúsculizações, símbolos de pontuação e outras ortografias, corretamente realizadas. Por exemplo, "O dia está chuvoso hoje.".

Texto pré-fabricado é o termo usado para as especificações de conteúdo onde a seqüência de caracteres a ser usada já foi determinada, embora algum processamento ortográfico possa ainda ser necessário. Por exemplo, "o dia está chuvoso hoje".

Para muitas aplicações, o valor da utilização das técnicas de GLN vem da habilidade de fatorar as idiossincrasias da morfologia e da sintaxe das especificações produzidas pelos estágios da GLN anteriores à geração de superfície. Uma representação que suporta esta fatoração é chamada de estrutura sintática abstrata.

Uma representação sintática abstrata descreve os elementos lingüísticos a serem usados em termos dos seus lexemas básicos (palavras não flexionadas) e constituintes sintáticos, juntamente com uma coleção de traços que especificam como as formas superficiais serão construídas.

Uma representação mais abstrata ainda para as especificações de frases é fornecida pela árvore temática parcialmente lexicalizada. Esta difere das estruturas sintáticas abstratas pois os constituintes são especificados pelos papéis semânticos (por exemplo, possuidor) ao invés do papel sintático (por exemplo, sujeito).

\subsection{Problemas e limitações}

É seguro dizer que, atualmente, pode-se facilmente construir um gerador de simples propósito para qualquer aplicação específica ou, com alguma dificuldade, adaptar um gerador de sentenças existente a uma aplicação, com resultados aceitáveis. Entretanto, não se pode ainda construir um gerador de sentenças ou um planejador de textos não experimental de propósito geral. Existem significativos problemas sem soluções suficientemente gerais [Hov97]:

- seleção lexical 
- planejamento de sentenças

- estrutura do discurso

- modelagem do domínio

- critério de escolha na geração

Seleção lexical : É um dos mais difíceis problemas em geração. Em sua forma mais simples, esta questão envolve selecionar a palavra mais apropriada para uma dada unidade de entrada. Entretanto, tão logo o modelo semântico alcance um tamanho realístico, e tão logo o léxico seja grande o bastante para permitir locuções alternativas, o problema torna-se muito complexo. Em algumas situações, teria-se que escolher entre as frases o carro de João, o carro esporte do João, sua máquina, o automóvel, o veículo vermelho ou o ferrari vermelho para se referir a um certo carro. A decisão depende do que já tenha sido dito, do que é referencialmente disponível no contexto, do que é mais saliente, qual o efeito estilístico que o falante deseja produzir, e assim por diante. Uma considerável quantidade de trabalho tem sido devotada à questão e soluções para vários aspectos do problema têm sido sugeridas na literatura. Atualmente não existe qualquer método geral para realizar a seleção lexical. A maioria dos sistemas geradores atuais contorna o problema simplesmente associando um único item lexical com cada unidade de representação. Qualquer solução proposta para este problema dependerá do desenvolvimento de teorias e implementações de algoritmos de seleção lexical, para referenciar objetos, eventos, estados, etc., bem como sua submissão a testes envolvendo grandes léxicos.

Estrutura do discurso : Um dos mais importantes desenvolvimentos em geração é o planejamento automático da estrutura de parágrafos. Até agora nenhum planejador existente pode, confiavelmente, planejar textos de muitos parágrafos, de maneira geral. Qualquer busca de solução, precisará: de teorias sobre a natureza estrutural do discurso, sobre o desenvolvimento de tema e foco no discurso e sobre a coerência e coesão; bibliotecas de relações de discurso, ob jetivos comunicativos e planos de textos; paradigmas representacionais implementados para caracterizar textos estereótipos, tais como relatórios e cartas comerciais; e planejadores de textos implementados e testados em domínios realísticos.

Planejamento de sentenças : Mesmo assumindo que o problema de planejamento de texto esteja resolvido, muitas tarefas ainda deverão ser realizadas antes que 
textos multisentenciais bem estruturados possam ser gerados. Estas tarefas, necessárias ao planejamento de estrutura e conteúdo de cada sentença, incluem: especificação pronominal, sinalização do tema, sinalização do foco, agregação do conteúdo para remover redundâncias desnecessárias, o ordenamento dos sintagmas preposicionais, adjetivos etc. Estas tarefas podem parecer relativamente insignificantes, contudo podem ter significante efeito e fazer a diferença entre um texto bem ou mal escrito. Logo, precisamos: de teorias sobre o uso pronominal, de sinalização e seleção de tema e foco, assim como de agregação de conteúdo; de planejadores de sentenças implementados com regras que realizem estas operações, novamente testados em domínios realísticos.

Modelagem do domínio : Um grande obstáculo na pesquisa sobre geração é a ausência de grandes modelos de domínios de aplicação que sejam bem motivados, ou mesmo a ausência de princípios claros através dos quais construí-los. Um problema tradicional com geradores é que as entradas são freqüentemente manuais, ou são construídas por algum outro sistema que usa elementos de representação de algum modelo restrito de domínio (também construído manualmente), tornando a entrada do gerador já altamente orientada para a língua final desejada. É muito difícil ligar um sistema de geração a uma base de conhecimento ou a um banco de dados que foi desenvolvido originalmente para algum propósito não lingüístico. A incompatibilidade entre os esquemas de representação demonstram a necessidade de princípios claramente articulados de modelagem de domínio e adequação representacional lingüisticamente apropriadas. Portanto, faz-se necessário: modelos de domínio implementados e de grandes proporções que sejam úteis tanto para uma aplicação não lingüística quanto para a geração; critérios para avaliar a consistência interna de tais modelos; teorias e experiências práticas na junção de geradores a tais modelos; léxicos de tamanhos comensuráveis.

Critério de escolha na geração : Provavelmente o problema menos considerado em sistemas geradores hoje é aquele que levará o mais longo tempo para ser resolvido. Ele consiste no problema de guiar o processo de geração através de suas escolhas quando múltiplas opções existirem para tratar uma entrada. Infelizmente uma língua, com sua flexibilidade quase infinita, demanda muito mais da entrada do gerador do que pode ser representado hoje. Desde que os geradores permaneçam pequenos em seus potenciais expressivos, este problema não virá à tona. Entretanto, quando os geradores puderem dizer a mesma coisa em vários modos, um controle adicional deve ser exercitado a fim de garantir que 
o texto apropriado seja produzido. Diferentes textos gerados da mesma entrada trazem consigo importância adicional, não semântica; as variaçōes estilísticas servem para expressar significados situacionais e interpessoais importantes (o texto pode ser formal ou informal, verborrágico ou objetivo, expressivo ou simples, etc.). Com o objetivo de garantir uma geração apropriada, o usuário do gerador deve especificar não somente o conteúdo semântico do texto desejado, mas também seus efeitos pragmáticos (ou interpessoais). Pouca pesquisa tem sido desenvolvida sobre esta questão além de estudos pilotos de menor escala. $\mathrm{O}$ que se faz necessário aqui são: classificaçōes dos tipos das características e objetivos do leitor, os tipos dos objetivos do autor e os aspectos situacionais e interpessoais que afetam a forma e o conteúdo da língua; teorias sobre como estes aspectos afetam o processo de gcracão; sistemas de planejamento e/ou regras implementadas que guiem as escolhas do sistema gerador; critérios para avaliar a adequação do texto gerado nas situações comunicativas especificadas. 


\section{Capítulo 4}

\section{UNL - Universal Networking}

\section{Language}

E havia uma gramática que dizia assim:

"Substantivo (concreto) é tudo quanto indica

Pessoa, animal ou cousa: João, sabia, caneta."

Eu gosto é das cousas. As cousas, sim!...

As pessoas atrapalham. Estão em toda parte.

Multiplicaram-se em excesso.

Mário Quintana, Prosa \& Verso

\subsection{Introdução}

A Universal Network Language (UNL) é uma língua eletrônica (interlíngua) projetada para computadores com o intuito de expressar e trocar qualquer tipo de informação [UZS99].

A UNL representa informação, isto é significado, sentença por sentença. A informação na sentença é representada como um hipergrafo tendo conceitos como nós e relações como arcos. Este hipergrafo é também representado como um conjunto de relações binárias dirigidas, entre cada dois dos conceitos presentes na sentença.

Mais especificadamente, a UNL é uma interlíngua que serve para descrever aspectos essenciais do significado das sentenças, tais como as relações semânticas que podem ser representadas por relações formais (morfológicas ou sintáticas) entre palavras de uma 
sentença. A UNL é capaz de represcntar de maneira uniforme o significado de orações que podem ser descritas e explicadas a partir de diferentes modelos gramaticais, pois se baseia na análise gramatical das mesmas e, logo, na representação superficial de suas estruturas textuais [SZRN97].

\subsection{A representação interna do significado em UNL}

A UNL permite o tratamento de aspectos semânticos de forma sistemática e independente do conhecimento profundo sobre questões não textuais. Ela se restringe, por exemplo, ao significado literal, denotativo de sentenças e trata de descrições de significados frasais seguindo a abordagem tradicional de relacionamento de papéis semânticos a entidades ou objetos componentes da frase.

A característica principal da UNL é a de privilegiar a predicação entre elementos lingüísticos, por sua caracterização individual ou relacional (com outros elementos lingüísticos) durante a ocorrência de eventos ou outras relaçöes complexas entre eventos. Neste caso, os próprios argumentos verbais ou adjuntos frasais se manifestam como predicados, sendo responsáveis por preservar a relevância da informação textual. As predicações podem, portanto, ser relativamente simples, como um simples adjetivo, ou complexas, como em uma subordinação. Privilegiando as predicações, a UNL não fornece mecanismos para tratar questões referenciais, tais como construções elípticas ou referências dêiticas introduzidas por pronomes demonstrativos (este, esta, aquele, etc.), pois ela não consegue recuperar o sentido e a referência aos componentes individuais em questão. No entanto, ela sugere uma técnica para se recuperar itens co-referentes no contexto imediato, pela co-indexação dos componentes frasais [SZRN97].

\subsection{O léxico na perspectiva da UNL}

Os componentes do léxico incluem conceitos padrões ou Universal Words (UWs) e um conjunto de relações conceituais e atributos que pode ser expresso estruturalmente, em termos de relações sentenciais. Essas relações são rotuladas adequadamente, por meio de rótulos de relações (Relation Labels - RLs) e rótulos de atributos (Attribute Labels - ALs). Há ainda uma ontologia que estrutura o léxico. Suas UWs são baseadas em palavras da língua inglesa e são relacionadas segundo as relações hierárquicas da 
taxonomia conceitual ou segundo os rótulos de relacionamento sentencial fornecidos pelo usuário especialista (no caso, um lingüista). Dessa forma, o léxico forma uma hiper-rede de relações entre UWs que abrange conceitos genéricos e específicos, indicando parte de seu inter-relacionamento semântico.

As UWs são, portanto, entradas do léxico que especificam conceitos individuais em termos de sua relação com outros conceitos, assim como a correspondência de cada conceito com a forma que ele deve tomar em determinada língua. A relação interconceitual diz respeito à semântica composicional das palavras: uma UW principal e todas as suas ramificações são definidas em termos da composição de significados que ela possa apresentar. Devido a essa característica, o léxico é, na verdade, um dicionário que faz a correspondência entre UWs e verbetes do português (dicionário UWs-português).

Assim como se faz uso de RLs para se chegar ao significado pertinente e, logo, a uma UW particular, faz-se uso dos ALs (rótulos de atributos) para limitar o significado das UWs. Desse modo, o uso dos componentes sentenciais indica a semântica lexical incorporada ao léxico: a cada UW é associado um significado particular, representativo das acepcões mais freqüentes da língua portuguesa (essas acepçōes recebem o nome de headwords) [SZRN97].

A sintaxe do dicionário de UWs-português obedece o seguinte formato:

[headword] canônica "UW" (grammatical features) 〈P,f,p>;

onde:

- headword é a palavra do português, correspondente ao significado expresso pela UW;

- canônica é a forma canônica da palavra em português;

- (grammatical features) é o conjunto de traços gramaticais e semânticos da headword;

- P: denota o idioma, no caso português;

- $\mathbf{f}$ e $\mathbf{p}$ são valores naturais que exprimem a freqüência e a prioridade de uso da headword; 
Na Figura 4.1 estão alguns exemplos de entradas no dicionário, após sua associação com o português.

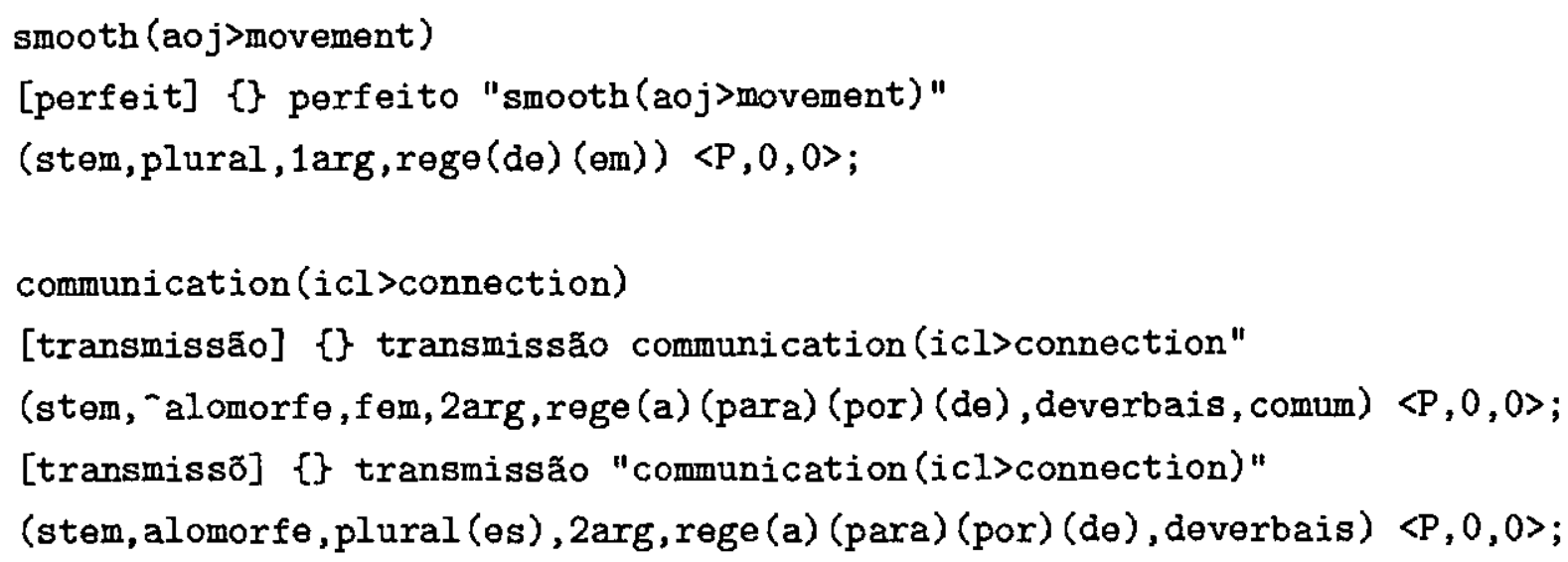

Figura 4.1: Exemplos de entradas lexicais.

\subsection{O vocabulário da UNL}

\subsubsection{As palavras universais (UW)}

A função de uma UW é denotar um significado específico. Sua representação genérica é ou um rótulo simples (que indica o significado genérico de uma palavra em inglês), ou um rótulo limitado por um intervalo específico, que denota significados distintos, quando há ambigüidades em relação à palavra original. Por exemplo, o significado de "book" permite a representação das seguintes UWs: book = (livro), book (icl>publication) $=$ (publicaçōes), book (=account) $=$ (livro comercial) e book (obj>room) = (reserva de um quarto). A primeira UW, book, é a representação mais genérica do significado. As demais limitam este significado a conceitos particulares, desfazendo, desse modo, a ambigüidade natural dessa palavra.

\subsubsection{Os rótulos de relação ( $R L)$}

RLs servem para expressar relações binárias entre significados, i.e., entre duas UWs distintas. Sua representação geral é dada por um par ordenado do tipo relation_label (UW1, UW2), onde UW1 e UW2 são duas UWs diferentes relacionadas pela relação semântica 
indicada por relation_label. Há diversas classes de RLs. Abaixo serão dados alguns exemplos e o leitor é remetido para [SZRN97] para uma melhor apreciação.

1 - RLs entre componentes intra-sentenciais (em número de trinta e três)

agt: Agente. Um agente que causa uma ação volitiva, i.e., um objeto animado com intençōes. Exemplo:

Sentença original: A lebre corre.

Representação UNL: agt (run.@entry. @pred. @present, rabbit.@def)

and: conjunção. Conjunção de objetos ou eventos. Exemplo:

Sentença original: Gatos e ratos são animais.

Representação UNL: aoj (and (cat. @generic, rat. @generic), animal)

aoj: Objeto atributivo. Um objeto de um atributo. Exemplo:

Sentença original: Folhas são verdes.

Representação UNL: aoj (green, leaf. @generic. @pl)

bas: Base. Critério para comparação. Exemplo:

Sentença original: Um gato é maior que um rato.

Representação UNL:

aoj (cat. Qgeneric, big),

bas (big,mouse. @generic)

ben: Beneficiário. Beneficiário de eventos. Exemplo:

Frase original: Trabalhar para uma família.

Representação UNL: ben(work, family. Qindef)

cau: Causa. Causa de um evento. Exemplo:

Sentença original: Ele morreu de câncer.

Representação UNL:

obj (die. Qentry. Qpred. Qpast, He), 
cau (die. Qentry. Opred. Opast, cancer. Ogeneric)

gol: Objetivo. Local (físico ou lógico) de um agente/objeto relativo a um evento. Exemplo:

Sentença original: As crianças foram para Londres.

Representação UNL:

agt (go. Qentry. Opred. Opast, child. Opl.Qdef), gol (go. Qentry. Qpred. Opast, Londres)

ins: Instrumento. Um instrumento utilizado em uma ação volitiva. Exemplo:

Sentença original: A criança se cortou com a faca.

Representrąão UNL:

agt (cut. .entry. Opred. Qpast, child.@def), ins (cut. Qentry. opred, knife.Qdef)

obj: Objeto. Um objeto de uma ação ou uma mudança que afeta o objeto. Exemplo: Sentença original 1: Pedro come maçãs.

Representação UNL:

agt (eat. Qentry. Opred. Qpresent, Pedro),

obj (eat. Qentry. Opred, apple.Qgeneric.@pl)

2 - RLs entre palavras universais (UWs)

icl: Inclusão. Representação de hiperonínima (super e subclasses) ou meronínima (relaçäo parte-todo). Exemplo:

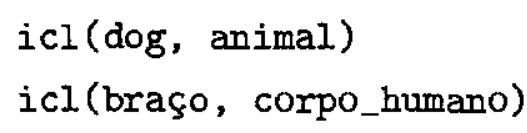

equ: Sinonímia. Representação de significados equivalentes entre UWs, como em equ (book, accounts) 


\subsubsection{Os rótulos de atributos (AL)}

ALs servem para limitar o significado de uma UW genérica, i.e., para particularizar seu significado. Informações adicionais tais como tempo verbal, aspecto, intenção ou estrutura sentencial são exemplos de atributos específicos de uma UW. A representação genérica de um AL é dada pela UW, seguida por tantos atributos quantos forem necessários para restringir o significado do conceito genérico. Cada um dos atributos é identificado na sentença UNL pelo símbolo inicial "@". Por exemplo, a representação genérica de uma UW com $\mathrm{n}$ atributos tem a forma:

UW. Qatrib1. Qatrib2.... Qatribn

Se não houver ALs vinculados a uma UW, esta representa o significado mais genérico de sua classe. Da mesma forma que para RLs, pode haver diferentes classes de ALs. A seguir algumas delas.

a) ALs que limitam o poder de expressão de uma UW, tais como:

@generic: Representação genérica de uma UW. Exemplo:

Sentença original: Pedro come maçãs.

Representaçäo UNL:

agt (eat. Qpresent. @entry. Qpred, Pedro),

obj (eat.@present.@entry. @pred, apple.@generic.@pl)

@def: indica uma UW que já foi referenciada anteriormente. Exemplo:

Sentença original: Pedro fechou a porta.

Representação UNL:

agt (shut. @entry.@pred.@past, Pedro),

obj (shut. Qentry. Qpred.Qpast, door. Qdef)

b) ALs que expressam tempo verbal. Estes seguem a gramática da língua inglesa e incluem:

@past: Evento que aconteceu no passado. Exemplo:

Sentença original: Eu não fui ao cinema. 
Representação UNL:

agt (go. Qpast. @not. @entry. @pred, I),

gol (go. Qpast. @not. Qentry. Qpred, cinema. Qdef)

@present: Evento que está acontecendo. Exemplo:

Sentença original: Pedro fecha a porta.

Representação UNL:

agt (shut. @present. @entry.@pred, Pedro),

obj (shut. @present. @entry.@pred, door.@def)

@future. Evento que irá acontecer. Exemplo:

Sentença original: Ela virá.

Representação UNL:

agt (come. Qf uture. Qentry. Opred, She)

\section{c) ALs que expressam aspecto}

Esses ALs se referem à noçāo de aspecto da língua inglesa. Vale observar que a maioria deles se aplica também ao português, embora essa noção possa variar de uma língua para outra.

@begin-soon: evento que vai começar. Exemplo:

Sentença original: O avião está para aterrissar.

Representação UNL:

agt (land_in.@begin-soon.@entry.@pred.@present, plane.@def)

@progress: evento em progressão. Exemplo:

Sentença original: $\Lambda$ menina está chorando.

Representação UNL: 
agt (cry. Oprogress. Qentry. Qpred.Qpresent, girl. Qdef)

\section{d) Als que expressam intençōes}

Intenções do falante, tais como emoções, interpretações subjetivas e ênfase, são expressas por ALs desta classe. Como intenções podem se manifestar léxica ou estruturalmente, os ALs são divididos em duas subclasses: os associados a intenções expressas por elementos intra-sentenciais e os associados a intenções expressos pela sentença inteira.

@focus: Informação sobre o foco de uma sentença. Exemplo:

Sentença original: Foi você quem saiu?

Representação UNL:

agt (leave. Qentry.Qpred. Qinterrogation.Qpast, you. @focus)

@emphasis: Entidade sentencial enfatizada. Exemplo:

Sentença original: Do caráter dele, eu desconfio.

Representação UNL:

agt (distrust. Qentry . Qentry. Qpresent, I), obj (distrust. Qentry. Qentry. Opresent, character. Qemphasis), pos (He, character. Oemphasis)

@theme. Informação temática

Muito mais resta a ser dito sobre os vários elementos constituintes da notação UNL, entretanto a consulta a [SZRN97] é indispensável àqueles desejosos de maiores esclarecimentos. Para o propósito deste texto é suficiente a apresentação aqui esboçada.

\subsection{O codificador UNL}

Um codificador UNL é um software que automaticamente ou interativamente converte textos em língua natural para a UNL. A UNU/IAS desenvolveu um software para conversão chamado "EnCo" que se constitui de um codificador junto com um dicionário 


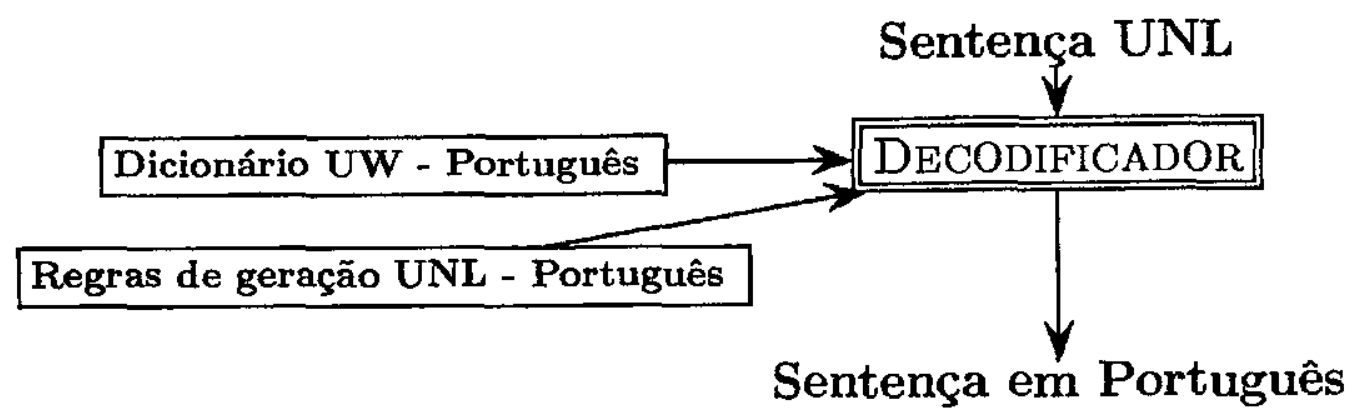

Figura 4.2: Arquitetura do decodificador UNL-Português.

de palavras, um dicionário de co-ocorrência e as regras de conversão para a língua. Este "EnCo" é um software independente de língua, assim ele é aplicável a quaisquer línguas.

No processo de codificação, a UNL permite um mapeamento de sentenças de uma dada língua natural num conjınto de relações entre significados, sem representação explícita da estrutura sintática.

\subsection{O decodificador UNL}

O decodificador faz uso de um conjunto de regras gramaticais da língua destino que, uma vez aplicadas à sentença UNL, gera uma sentença em língua natural. Um sistema de regras foi desenvolvido no NILC para o português do Brasil, que permite a decodificação de sentenças relativamente complexas [MRN98]. O sistema funciona acoplado a uma ferramenta, chamada DeCo, fornecida pela Universidade das Nações Unidas.

A Figura 4.2 mostra a arquitetura do decodificador. Uma sentença codificada em UNL é introduzida no decodificador, que emprega regras de geração de sentenças em português a partir da representação semântica em UNL. Obviamente, as UWs originais da sentença UNL precisam ser traduzidas para o português, e para tanto se emprega o dicionário UW-português $\left[\mathrm{N}^{+} 01, \mathrm{~N}^{+} 99\right]$. 


\subsubsection{O funcionamento do DeCo}

Nesta seção será explicado brevemente como o DeCo realiza o seu processamento.

Inicialmente o DeCo escolhe uma UW para ser processada, então o dicionário é pesquisado antes da aplicação de qualquer regra de geração, a fim de associar à UW informações relativas à headword correspondente e a seus atributos gramaticais. Somente após a obtenção dessas informações o DeCo inicia a busca por uma regra de geração que contemple as informações da nodelist que estão visíveis em suas janelas. As regras de geração são aplicadas apenas aos nós da nodelist, a partir de sua configuração atual e da configuração da nodenet. $\mathrm{O}$ processo de geração ocorre sob controle de dois tipos de janelas: de geraçāo (G) e de condiçāo (C) (Figura 4.3).

As janelas de geração à esquerda e à direita destinam-se a examinar os atributos gramaticais de seus respectivos nós e, portanto, decidir qual a alteração de conteúdo que a nodelist pode sofrer. As janelas de condição servem para examinar as condições dos nós da nodelist que são vizinhos das janelas de geração e, portanto, servem para verificar as condições de contexto no processo de geração. Os nós das janelas de condição são examinados também com base em suas características gramaticais.

A Figura 4.3 mostra o status da nodelist e da nodenet no início do processo de decodificação da sentença UNL que envolve os seguintes RLs (a notação a seguir é uma forma simplificada que suprime detalhes desnecessários nesta ilustração):

$$
\begin{aligned}
& \operatorname{agt}([U W=\text { build }], \quad[U W=\text { people }]) ; \\
& \operatorname{obj}([U W=\text { build }], \quad[U W=\text { tower }]) ; \\
& \operatorname{aoj}([U W=\text { tower }],[U W=\text { huge }]) ;
\end{aligned}
$$

Esta sentença, decodificada para o português, dá origem a "O povo construiu uma torre imensa". 


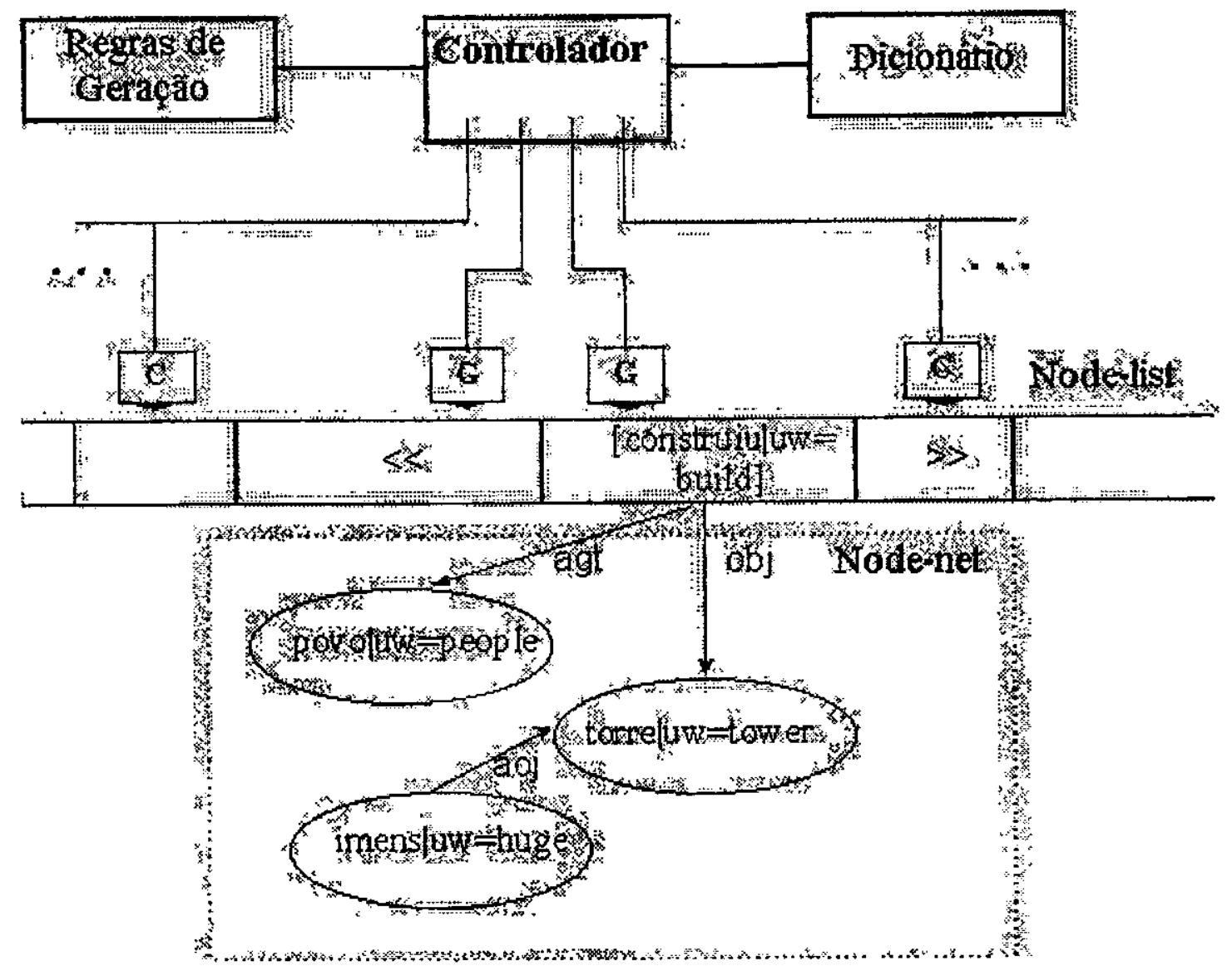

Figura 4.3: Configuração do DeCo para gerar $O$ povo construiu uma torre imensa. 


\section{Capítulo 5}

\section{Formalismos Gramaticais usados em GLN}

..., a intimidade com a gramática é tão dispensável que eu ganho a vida escrevendo apesar de minha total inocência na matéria. Sou um gigolô das palavras. Vivo às suas custas.

Luiz Fernando Veríssimo, O gigolô das palavras

A tarefa de geração de linguagem requer a manipulação de estruturas complexas: representação de constituintes lingüísticos, entradas lexicais, suas notações semânticas, as ligações entre objetos lingüísticos e suas restrições semânticas. Além disso, geração consiste em se escolher entre diferentes dispositivos lingüísticos a fim de satisfazer um objetivo comunicativo, e se construir uma estrutura lingüística que combine esses vários dispositivos numa sentença ou texto coerente. Desta forma, um formalismo de geração está envolvido em constantes atividades de escolha, de tomada de decisão e de construção de uma estrutura lingüística a partir da composição de componentes menores. Segundo Elhadad [Elh92], um conjunto de critérios para se determinar a adequação de um formalismo para a tarefa de geração inclui:

Descrição de entrada conceitual : o formalismo deve permitir especificação de característica semântica e/ou pragmática, já que a entrada para o gerador de superfície deve ser desse tipo.

Especificação parcial da entrada : o gerador deve ser capaz de funcionar na ausência 
de algumas informações semânticas ou pragmáticas, muitas vezes não previstas na gramática subjacente.

Expressividade da entrada : a entrada deve ser genérica o suficiente para ser tratada por diferentes esquemas de representação de conhecimento, permitindo o desenvolvimento de sistemas de geração portáveis.

Descrição funcional de objetos lingüísticos : deve ser possível especificar como objetos lingǘsticos se relacionam com objetos conceituais e como eles se relacionam funcionalmente com outros objetos lingüísticos.

Descrição estrutural de objetos lingüísticos : deve ser possível expressar a estrutura de objetos lingüísticos, espccificando constituintes e como estes são intercalados.

Suporte para composicionalidade : possibilidade de relacionar a construção da estrutura lingüística com a estrutura da entrada conceitual.

Declaratividade : restrições sobre como objetos lingüísticos se combinam e se relacionam com a entrada devem ser expressas declarativamente.

Ordem de tomada de decisão : a ordem de processamento, bottom-up, top-down, left-to-right, ou qualquer outra variação, pode influenciar significativamente o modo como as restrições interagem entre si.

Eficiência : o formalismo deve ser tal que permita a definiçāo de procedimentos eficientes.

Reversibilidade : é desejável, porém reconhecidamente difícil, que um sistema de LN use uma única gramática tanto para parsing quanto para geração.

Esse conjunto de características é desejável, mas difícil de ser alcançado por um único formalismo.

Apresentam-se, a seguir, três dos principais formalismos gramaticais utilizados para sistemas de geração. Cada um deles baseia-se numa teoria lingüística diferente (perspectivas funcional, sistêmica e procedimental), e deram origem a sistemas computacionais reconhecidos e constantemente citados na literatura da área, bem como utilizados em diversas aplicaçōes. 


\subsection{Formalismo de Unificação Funcional - FUF}

A gramática de unificação funcional (GUF) foi introduzida em 1979, por Martin Kay [Kay79], sendo uma instância dos formalismos baseados em unificação. O sucesso do uso da GUF para a geração é motivado principalmente por sua maior ênfase na perspectiva funcional do que na estrutural, uma vez que a geração começa com considerações funcionais (como mapear o significado para a forma) e termina com consideraçōes estruturais (como organizar a forma) [McK85], [App85], [Par88], [ME91].

Algumas características que distinguem a GUF sāo [Elh92]:

Representação uniforme : a GUF conta com uma estrutura de dados simples chamada descrição funcional (DF) para codificar uniformemente fatores sintáticos, semânticos e pragmáticos. As DFs capturam tanto aspectos funcionais quanto estruturais de uma descrição lingüística.

Unificação : GUF conta com uma operação simples chamada unificação para manipular as DFs e tomar decisões. A unificação tem sido bastante usada em teorias lingüísticas (Head Phrase Structure Grammars, General Phrase Structure Granımars, Lexical Functional Grammars [Shi86]). Devido à unificação, não há distinção entre tomada de decisão e realização, comum em outros formalismos.

Ordem de decisão flexível : sendo a unificação um processo monotônico bidirecional, é possível tomar decisōes em qualquer ordem. Esta característica torna mais fácil o processo de escrita das gramáticas (não há preocupação sobre como uma restrição interage com outras decisões) e também mais modular (cada restrição só precisa ser especificada uma vez). A flexibilidade na tomada de decisão também é importante porque permite o processamento de entrada mista, contendo tanto restrições semânticas quanto lingüísticas.

Devido a algumas limitações da GUF, como quanto a eficiência, expressividade e interação entre planejamento de conteúdo e realização, [Elh92] propõe o Formalismo de Unificação Funcional - FUF, que é uma extensão e uma implementação de GUFs. O autor apresentou FUF em conjunto com SURGE (Surface Grammar for English), que é a implementação, em FUF, de uma gramática de realização sintática do inglês, portável e independente de domínio. Nesse sentido, sua substituição por uma (sub)gramática 
do português é perfeitamente viável nesse ambiente computacional. As características e a disponibilidade do pacote de software FUF faz desse formalismo um dos candidatos naturais para implementação de um sistema de geração de português a ser contrastado com o formalismo UNL.

\subsection{Formalismo Sistêmico}

O mais conhecido exemplo de sistema baseado no formalismo sistêmico é PENMAN, um ambiente de geração construído na Southern California University, tendo um módulo gramatical denominado NIGEL, com uma gramática de superfície, um léxico e uma linguagem de especificação de entrada chamada SPL (Sentence Plann Language) [Kas89]. NIGEL é a implementação de uma aproximação sistêmica para a gramática apresentada em [Hal85]. A influência da lingüística sistêmica é particularmente forte no campo de geração devido à prioridade dada pelos primeiros sistemicistas à geração em oposição à interpretação, descrevendo a linguagem como um conjunto de recursos para satisfazer necessidades comunicativas. O processo através do qual a linguagem serve para satisfazer uma determinada função é chamado de realização.

A lingüística sistêmica deriva seu nome da função primária que as redes de sistemas desempenham no processo de realização. Uma rede sistêmica é um "grande grafo direcionado, cujos nós sāo pontos de escolha, que são chamados sistemas" [Mat88].

Cada ponto de escolha é chamado sistema e representa uma das decisões que deve ser tomada para produzir linguagem. O sistema é disparado quando uma condição de entrada é satisfeita, e uma decisão deve então ser tomada, a qual consiste na escolha de uma das características de saída. O efeito de atravessar um sistema é, portanto, o de decidir sobre uma característica da sentença final.

A distinção entre tomada de decisão e realização é a diferença mais importante entre NIGEL e as GUFs. Nas GUFs, tanto a tomada de decisão quanto a realização são desempenhadas pelo mesmo mecanismo de unificação.

A principal contribuição de NIGEL e do sistema PENMAN é especificar uma interfacc clara entre o sistema gramatical e o ambiente, definindo um framework conhecido como chooser and inquiry semantics. 


\subsection{Formalismo procedimental}

Um dos mais importantes sistemas de geração é o MUMBLE de David McDonald [McD80, McD81, McD86] e sua versão mais moderna MUMBLE-86 [M+87], ambos tendo a característica de ser um componente de realização lingüística eficiente e independente de aplicação. Desde sua concepção, MUMBLE era voltado para uma independência de representação de conhecimento. McDonald [McD81] explorou a geração de inglês com uma variedade de representações de conhecimento, incluindo Cálculo de Predicado, FRL (Frame Oriented Language) [RG77] e KL-ONE (Knowledge Language-ONE), um formalismo de rede semântica estruturada por herança [Bra85].

MUMBLE-86 constrói e atravessa uma árvore sintática de superfície (surface syntax tree). Ele conclui essa realização sintática via três processos que interagem entre si: realização, anexação e execução de estrutura sintagmática. "Classes de Realização" mapeiam subcategorias em constituintes gramaticais. Por exemplo, a classe de realização sujeito-verbo-objeto mapeia a subcategorização (agente verbo paciente) em (sujeito verbo objeto) para uma cláusula principal não marcada. "Classes de Anexação", por outro lado, governam o posicionamento de unidades na estrutura dc superfície, por exemplo, posicionando um modificador restritivo antes de um nome. Finalmente, a "execução de estrutura sintagmática" (EES) desempenha a travessia em profundidade das árvores de estrutura de superfície durante a qual são invocados procedimentos que transformam ou cumprem exceções em uma árvore parcialmente ordenada. Também faz o tratamento morfológico e a geração dos lexemas.

Uma característica importante é a orientação procedimental do MUMBLE, na qual cada nível de representação é visto como um conjunto de instruções que, quando executado por uma máquina virtual apropriada, produz o próximo nível de representação.

Durante a EES, o MUMBLE-86 pode adicionar novas unidades para a estrutura de superfície existente porque os pontos de anexação são indicados na árvore. Assim, pode-se ver o MUMBLE-86 como um empregador das gramáticas de adjunção de árvores ('TAGs), onde uma árvore de estrutura sintagmática inicial é estendida através de inclusão, em locais específicos e restritos, de uma ou mais árvores auxiliares. Joshi [Jos87] discute a relevância e os benefícios de TAGs para geração, incluindo produção incremental, controle de movimento de constituinte e variação de ordem de palavras. En MUMBLE-86, por exemplo, quando provemos descriçōes em um sistema baseado em conhecimento que contém objetos com propriedades associadas, as 
propriedades podem se tornar modificadores de objetos até mesmo se o MUMBLE-86 já tiver começado a construir um grupo nome sobre aquele objeto $\left[\mathrm{M}^{+} 87\right]$. Isto aumenta a interação (interleaving) entre o planejamento de texto e a realização lingüística, como oposição a planejar uma sentença inteira e depois realizá-la.

Visto de uma perspectiva lingüística, MUMBLE dá ênfase à estrutura da linguagem e de seus constituintes.

Além dessas, MUMBLE-86 tem uma série de outras propriedades. Primeiro, o gerador é description directed, ou seja, é guiado pela representação da entrada e pelas características da árvore de estrutura de superfície que está sendo construída. Esta característica contrasta com as gramáticas de escolha direta (como as gramáticas sistêmicas). Segundo, o processo é não reversível, ou seja, as decisões são nãoretratáveis. Terceiro, McDonald sugere que o processo seja psicologicamente motivado: o processamento é feito da esquerda para a direita, é incremental, e produz erros similares a erros humanos $\mathrm{n}_{\mathrm{a}}$ linguagem [McD86].

A título de comparação, dos três formalismos apresentados, MUMBLE é o único message-directed: o processo de geração percorre a mensagem de entrada, não a gramática.

\subsection{Comparação entre os três formalismos}

MUMBLE provê uma visão modular do processo de realização, definindo um conjunto de três níveis de representação, no qual se dá ênfase à eficiência e ao processamento determinístico, ainda que em prejuízo da flexibilidade da gramática e da especificação da entrada.

NIGEL e PENMAN implementam uma aproximação sistêmica para geração de textos, dando ênfase ao papel da gramática, que é vista como uma rede de pontos de escolha. A perspectiva é, portanto, funcional ao invés de estrutural. A tomada de decisões é modelada como uma navegação através da rede e da instanciação de características. A realização constitui uma atividade à parte da tomada de decisão e acumula a estrutura lingüística conforme procede a navegação. A ordem das decisões é fixa e determinística. Devido ao fato da rede sistêmica determinar a ordem das decisōes, NIGEI, é vista como uma gramática procedimental. A ênfase é dada à definição de uma interface transparente entre o ambiente e a gramática, através do uso de seletores (choosers) e 
averiguações (inquiries).

Em GUF vimos que a representação é uniforme e os mecanismos para manipulá-la são simples, o que permite uma representação de informações lingüísticas, semânticas e pragmáticas em todos níveis sem restrições. O formalismo é bidirecional, não havendo distinção entre decisão e realização. As entradas podem ser mistas, contendo restrições semânticas e lingüísticas, e ainda podem ser parcialmente especificadas devido ao fato de não haver necessidade de se pré-declarar aridades fixas na construção da gramática. Quanto à tomada de decisão, em GUF a ordem é flexível, deixando o desenvolvedor da gramática livre de tarefas difíceis como ordenar decisões para todas as situações.

Uma característica comum entre GUF e MUMBLE se dá no mecanismo de geração, que requer uma entrada inteiramente lexicalizada (isto é, todas as classes abertas substantivo, adjetivo, advérbio - são especificadas, e esses lexemas são o significado primário através do qual o conteúdo é especificado). 


\title{
Capítulo 6
}

\section{Gramática de Unificação Funcional}

\author{
Segundo affirmam os grammaticos, a grammatica é o \\ conjunto de regras tiradas do modo pelo qual um povo falla \\ usualmente uma língua. Ora, o povo falla sempre muito mal, \\ e escreve ainda peiormente; logo, não é de estranhar que seja \\ a grammatica a arte de fallar $e$ escrever incorrectamente \\ uma língua.
}

Mendes Fradique, Grammatica Portugueza pelo Methodo Confuso, 1928

\subsection{Introdução}

Neste capítulo examinaremos melhor a gramática de unificação funcional (GUF). Detalharemos dois conceitos básicos neste tipo de formalismo: as estruturas de traços e a unificação.

Veremos como esses conceitos podem ser combinados e exemplificaremos, no final do capílulo, o funcionamento de um gerador baseado na GUF.

\subsection{Estruturas de traços}

As estruturas de traços (ETs) descrevem ou representam um objeto pela enumeração de suas características significativas. Elas se apresentam como conjuntos de pares 
atributo-valor, onde os atributos (os traços) são símbolos atômicos retirados de um conjunto finito, e os valores podem ser símbolos atômicos ou outras estruturas de traços [JM00]. Tradicionalmente, as ETs säo ilustradas através do uso de matrizes, chamadas de matrizes atributo-valor (MAV):

$$
\left[\begin{array}{ll}
\text { Traço }_{1} & \text { Valor }_{1} \\
\text { Traço }_{2} & \text { Valor }_{2} \\
\vdots & \\
\text { Traçon }_{n} & \text { Valor }_{n}
\end{array}\right]
$$

As E'Ts nos fornecem meios de guardar informações parciais que poderão ser enriquecidas. Para tornar mais concreta nossa discussão, tomemos como exemplo a propriedade "número" de dos sintagmas nominais (SN). O fato de que um SN está no singular poderia ser descrito pela ET seguinte:

$$
\text { [número sing] }
$$

$\mathrm{Na}$ MAV acima usamos os símbolos atômicos número e sing para designar o atributo gramatical número e um possível valor, respectivamente.

Adicionando um outro par atributo-valor para capturar a noção gramatical de pessoa, leva à seguinte ET:

$$
\left[\begin{array}{ll}
\text { número } & \text { sing } \\
\text { pessoa } & 3
\end{array}\right]
$$

Devido à natureza recursiva das ETs, podemos usar a ET anterior para capturar a noção de concordância nominal em gênero, número e pessoa de um SN:

$$
\text { - }\left[\begin{array}{ll}
\text { cat } & \text { SN } \\
\text { concordância } & \left.\begin{array}{ll}
\text { gênero } & \text { masc } \\
\text { número } & \text { sing } \\
\text { pessoa } & 3
\end{array}\right]
\end{array}\right]
$$

Note na ET anterior que o valor do traço concordância é ele mesmo uma outra ET. 


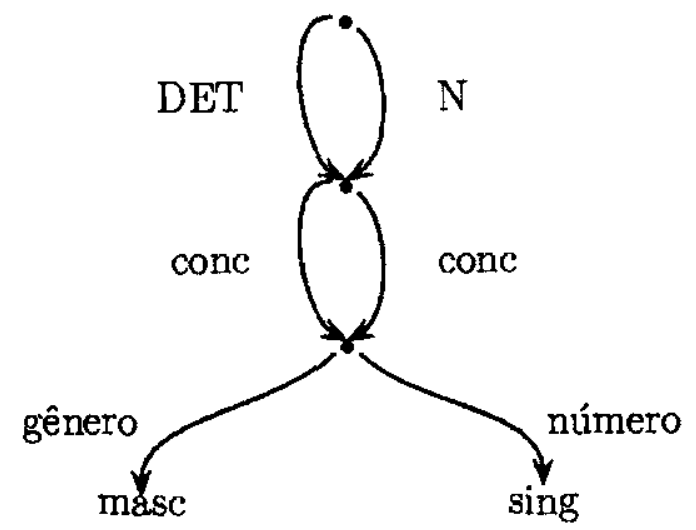

Figura 6.1: Uma notação de grafo dirigido para estruturas de traços.

Outra característica importante das ETs é que elas permitem que os valores sejam compartilhados, sendo este compartilhamento feito pela co-indexação dos valores [Bou98]. Se, por exemplo, desejarmos reforçar o fato de que em português o determinante concorda em gênero e número com o nome, poderíamos usar a ET:

$$
\left[\begin{array}{ll}
\text { DET } & {\left[\begin{array}{ll}
\text { conc } & \text { ⿴囗 }
\end{array}\right]} \\
\mathrm{N} & {\left[\begin{array}{ll}
\text { conc } & \text { @] }\left[\begin{array}{ll}
\text { gênero } & \text { masc } \\
\text { número } & \text { sing }
\end{array}\right]
\end{array}\right]}
\end{array}\right.
$$

Em uma ET, uma seqüência finita de traços denominarse caminho de traços, como em DET:conc:gênero. Um caminho de traços é somente uma lista de traços através da ET levando a um valor particular. Desta forma, o valor do caminho DET:conc:gênero na ET anterior é masc.

Formalmente, podemos identificar uma ET como um grafo dirigido conexo e acíclico, onde os traços aparecem como arcos rotulados e os valores como nós, como na Figura 6.1 .

\subsubsection{Ordem parcial das estruturas de traços}

Em função da riqueza informativa rclativa, pode-se ordenar as ETs por uma relação de subsunçāo ou, inversamente, por uma relação de extensão, como ilustram os exemplos a seguir [Bou98]:

1. 0 
2. $[$ cat $\mathrm{SV}]$

3. $\left[\begin{array}{lll}\text { cat } & \mathrm{SV} & \\ \text { núcleo } & {\left[\begin{array}{lll}\text { conc } & \text { número } & \text { sing }\end{array}\right]}\end{array}\right]$

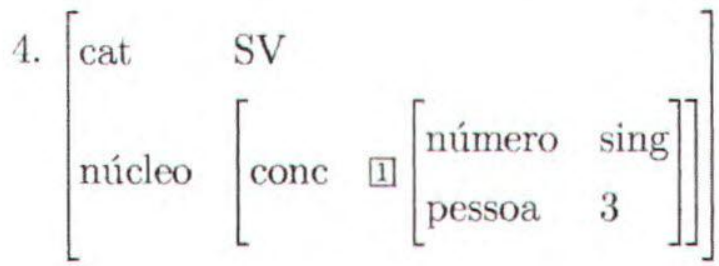

5. $\left[\begin{array}{ll}\text { cat } & \text { SV } \\ \text { núcleo } & {\left[\begin{array}{ll}\text { conc } & 1\end{array}\right]\left[\begin{array}{ll}\text { número } & \text { sing } \\ \text { pessoa } & 3\end{array}\right]}\end{array}\right]$

Nestes exemplos, a estrutura representada em (1) é a menos informativa de todas: ela não contém nenhuma informação e pode ser aplicada a todas as palavras do léxico. Já a estrutura (5), ao contrário, possui muito mais informações: ela descreve os sintagmas verbais na terceira pessoa do singular. Essa relação de ordem, chamada relação de subsunção (ou de extensão), mede a quantidade de informação contida em uma estrutura de traços.

Informalmente, considera-se que uma ET A subsume uma ET B, se as informações em A formam um subconjunto das informações em B. Neste caso dizemos que B é mais específica do que $\mathrm{A}$, isto é, $\mathrm{B}$ nos fornece mais informação do que $\mathrm{A}$.

Representamos a subsunção pelo operador $\sqsubseteq$. Voltando ao exemplo anterior, podemos notar as seguintes relações de subsunção entre as ETs: (1) $(2) \sqsubseteq(3) \sqsubseteq(4) \sqsubseteq(5)$. Formalmente, dizemos que uma ET $A$ subsume uma ET $B(A \sqsubseteq B)$, se e somente se [JM00]:

1. Para qualquer traço $x$ em $A, A(x) \sqsubseteq B(x)$, onde $A(x)$ significa "o valor do traço $x$ na estrutura de traços $A$ ".

2. Para todos os caminhos $p$ e $q$ tais que $A(p)=A(q)$, é também o caso que $B(p)=B(q)$. 
Note que a subsunção é uma relação de ordem parcial, pois existem pares de estruluras de traços que não subsumem e nem são subsumidas umas pelas outras. Para isto, considere a ETs abaixo:
1. [número sing]
2. [ [ pessoa 3 $]$

Da definição de ET, podemos ver que (1) $\nsubseteq(2)$ e que (2) $\nsubseteq(1)$.

A relação de extensão é definida como a relação inversa da subsunção, ou seja, se $A \sqsubseteq B$ então $B$ estende $A$, pois possui todas as informações de $A$ e outras que the são próprias.

\subsubsection{Disjunção e negação de estruturas de traços}

Certas operações podem ser incluídas na ET, como a disjunção e a negação [Bou98, App85].

Intuitivamente, utilizamos uma disjunção de ETs quando existe uma situação em que duas ETs podem descrever o mesmo objeto sem que possamos distinguir qual é a melhor, por nạ̃o possuirmos informações suficientes. Por exemplo, a ET abaixo pode ser aplicada a um objeto singular ou plural, como lápis. Usaremos chaves para indicar a disjunção de valores ou de estruturas de traços.

$\left[\begin{array}{lll}\text { lex } & \text { lápis } & \\ \text { conc } & {\left[\begin{array}{ll}\text { gênero } & \text { masc } \\ \text { número } & \left\{\begin{array}{l}\text { singular } \\ \text { plural }\end{array}\right.\end{array}\right\}}\end{array}\right]$

Utiliza-se a negação para indicar que certo traço é impedido de possuir determinado valor. Ela se coloca como uma maneira mais econômica de restringir valores possíveis de um traço do que enumerá-los todos disjuntivamente. Assim a ET seguinte especifica que o pronome me não pode possuir o caso nominativo.

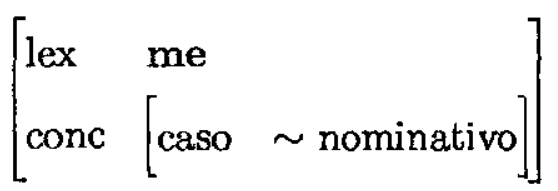




\subsection{Unificação de estruturas de traços}

As duas principais operações que realizaremos sobre ET são: fundir a informação contida em duas ET's e rejeitar a fusão de ETs que sejam incompatíveis. Estas duas operações podem ser realizadas pela mesma técnica computacional, a unificação. Esta técnica é análoga à operação de união entre conjuntos, com a diferença que a unificação é indefinida se as ETs são incompatíveis (usualmente denotada por $\perp$ ). Devido a esta semelhança, denotaremos a unificação pelo símbolo $\sqcup$.

Define-se a unificação de duas ETs A e B como a menor ET que estende A e B simultaneamente, se tal estrutura existir, ou, em caso contrário, a unificação é indefinida [GM89].

A unificação pode ser vista como uma forma de combinar a informação em cada uma das ETs envolvidas e também fornece um meio de descrever objetos que satisfazem simultaneamente um conjunto de restrições. Vista de outra forma, a unificação de duas ETs produz uma nova ET que é mais específica (contém mais informação) ou é igual a ambas ETs.

Para exemplificar a operação de unificação, considere as ET's abaixo:

1. $\left[\begin{array}{lll}\text { conc } & {\left[\begin{array}{ll}\text { número } & \text { sing }\end{array}\right]} \\ \text { sujeito } & \left.\left[\begin{array}{lll}\text { conc } & \text { número } & \text { sing }\end{array}\right]\right]\end{array}\right]$

2. $\left[\right.$ sujeito $\left[\right.$ conc $\left.\left.\left[\begin{array}{ll}\text { número } & \text { sing } \\ \text { pessoa } & 3\end{array}\right]\right]\right]$

3. $\left[\begin{array}{ll}\text { conc } & {\left[\begin{array}{ll}\text { número } & \text { sing }\end{array}\right]} \\ \text { sujeito } & {\left[\begin{array}{ll}\text { conc } & {\left[\begin{array}{ll}\text { número } & \text { sing } \\ \text { pessoa } & 3\end{array}\right]}\end{array}\right]}\end{array}\right.$

Pela definição da unificação, sabe-se que $(1) \sqcup(2)=(3)$, pois os valores dos caminhos em (1) e em (2) estão todos representados em (3).

Como exemplo de falha (indefinição) da unificação, considere as ETs: 
1. $\left[\begin{array}{ll}\text { conc } & 1\left[\begin{array}{ll}\text { número } & \text { sing } \\ \text { pessoa } & 3\end{array}\right] \\ \text { sujeito } & {\left[\begin{array}{ll}\text { conc } & 0\end{array}\right]}\end{array}\right]$

$\left[\begin{array}{ll}\text { conc } & {\left[\begin{array}{ll}\text { número } & \text { sing } \\ \text { pessoa } & 3\end{array}\right]} \\ \text { sujeito } & {\left[\text { conc }\left[\begin{array}{ll}\text { número } & \text { plural } \\ \text { pessoa } & 3\end{array}\right]\right]}\end{array}\right]$

A estrutura de traços (1) falhará em se unificar com (2), pois os valores achados no fim dos caminhos sujeito:conc:número, em cada ET, não coincidem. Assim, (1) $\cup(2)$ $=\perp$.

A unificação apresenta duas propriedades importantes [JM00]:

i. Ela é monotônica, e isto significa que se alguma descrição é verdadeira para uma estrutura de traços, unificá-la com outra estrutura de traços resultará em uma estrutura de traços que ainda satisfaz a descrição original.

ii. A sua aplicação independe de ordem. Dado que um conjunto de ETs serão unificadas, podemos fazê-las em qualquer ordem e obteremos o mesmo resultado.

\subsection{Gramática de Unificação Funcional}

A gramática de unificação funcional usa unificação para manipular e raciocinar sobre cstruturas de traços [Kay79]. $\Lambda$ idéia básica consiste em construir uma gramática de geração como uma estrutura de traços com disjunções e então unificar essa gramática com uma especificação da entrada construída usando os mesmos tipos de estruturas de traços. O processo de unificação então usa a especificação de entrada e a reconcilia com a gramática de geração, produzindo uma estrutura de traços maior, que posteriormente será enviada para o processo de linearização, que efetivamente construirá a mensagem.

$\mathrm{Na}$ GUF, as estruturas de traços usadas para descrever a gramática de geração são chamadas descriçöes funcionais (DF) e consistem de um conjunto possivelmente vazio 
de configurações (em inglês, patterns) juntamente com uma coleção de pares atributovalor [App85]. As configurações são expressões regulares que descrevem como os valores de certos traços na DF são combinados para formar uma estrutura sintática.

Dadas uma descrição funcional $D$ de uma especificação de entrada e uma descrição funcional $G$ para uma gramática de geração, a GUF calculará $D \sqcup G$. A descrição $D$ é supostamente uma coleção minimal de traços especificando uma ou mais expressōes que sejam consistentes com o objetivo comunicativo. O resultado do cálculo de $D \sqcup G$ é uma completa especificação e instanciação de todos os traços associados com a expressão, de tal forma que se torna possível extrair uma seqüência de itens lexicais consultando o traço pattern em $D \sqcup G$ [App85].

Para ilustrar o mecanismo de geração, usaremos a DF apresentada na Figura 6.2 como uma especificação de entrada, e a DF da Figura 6.3 como a GUF. Esta gramática, representada através de uma MAV, suporta frases simples com verbos transitivos diretos no presente do indicativo.

No nível superior, esta gramática fornece alternativas para sentenças (cat $S$ ), sintagmas nominais (cat SN) e sintagmas verbais (cat SV). No nível da sentença, ela suporta as funções oracionais de sujeito, verbo e objeto direto. Ela também provê a concordância entre sujeito e verbo, feita pela co-indexação do traço conc. No nível do sintagma nominal, observa-se a concordância nominal, novamente através da co-indexação, entre o determinante e o núclco, e a escolha no nível do artigo entre as formas singular e plural do artigo definido masculino.

A especificação de entrada mostrada na Figura 6.2 indica que esta sentença ( $O$ sistema salva os documentos) possui como sujeito um determinado sistema e como objeto direto os documentos. O verbo indica que o sistema está salvando os documentos no presente. 


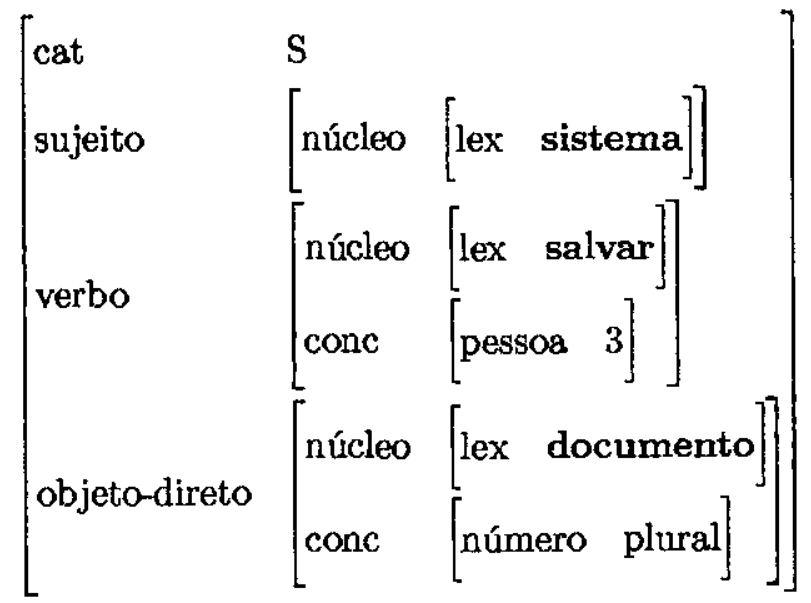

Figura 6.2: Descrição funcional da sentença $O$ sistema salva os documentos. 


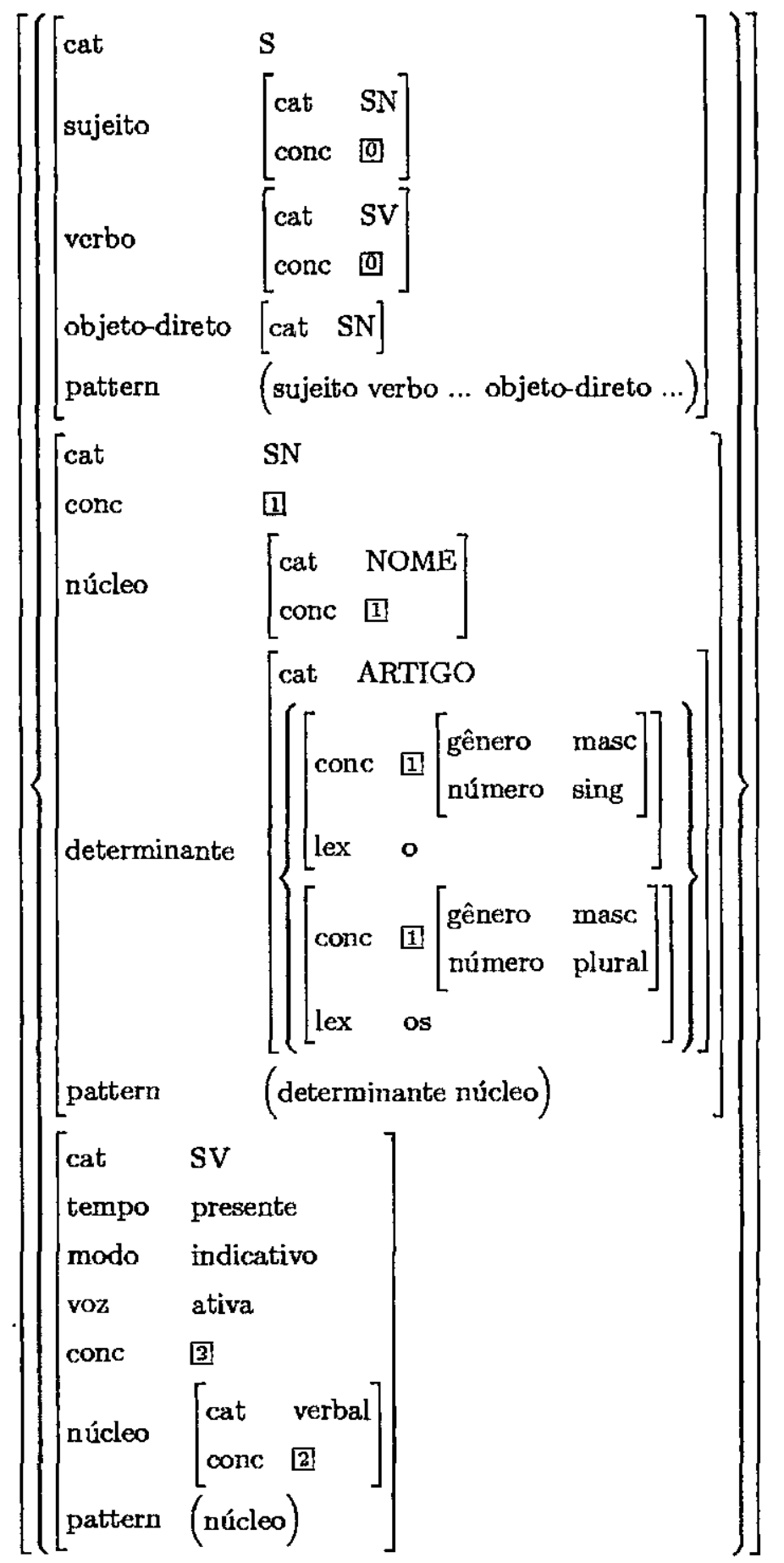

Figura 6.3: Uma gramática de unificação funcional G. 


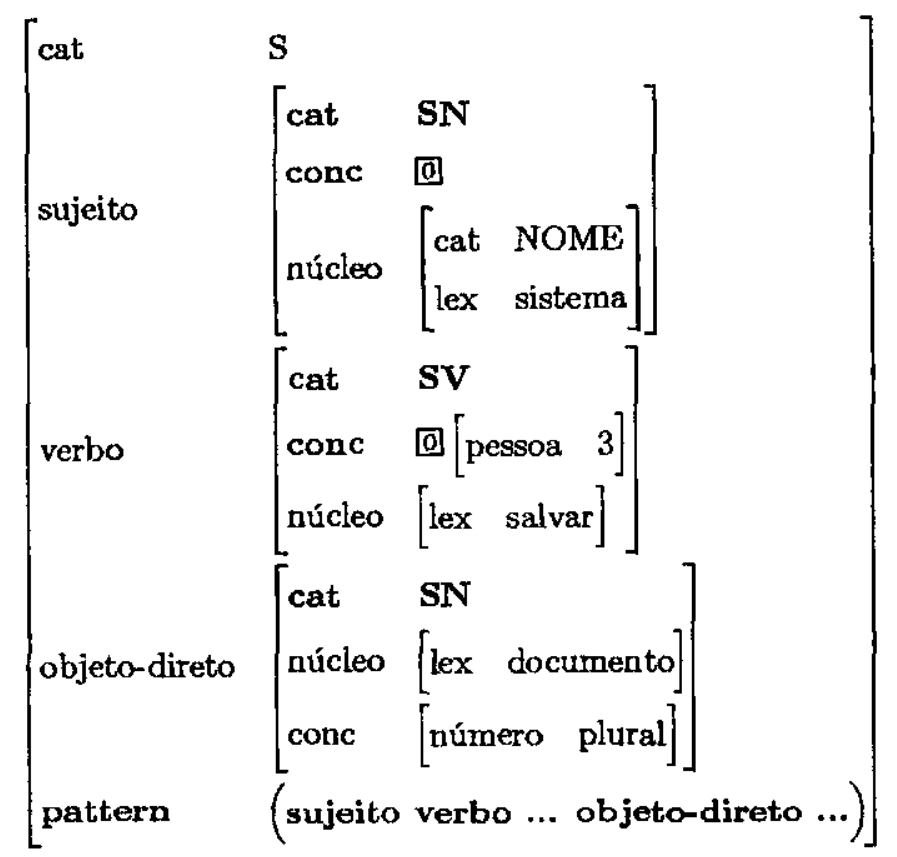

Figura 6.4: DF da entrada enriquecida pela gramática G.

Para produzir uma sentença, a especificação de entrada é unificada com a gramática $\mathrm{G}$ mostrada na Figura 6.3. Isto requer múltiplos passos através da gramática. $\mathrm{O}$ primeiro passo unifica a DF de entrada com o nível "S" da gramática. O resultado deste processo é mostrado na Figura 6.4, onde as adições feitas pela gramática à DF de entrada estāo em negrito.

Neste passo, várias informações de G que estavam no nível superior incorporam-se à DF de entrada. Por exemplo, o fato que sujeito e verbo devem concordar. Outra informação adicionada foi a maneira como a sentença deve ser linearizada, representada pelo traço patterm. Neste traço vê-se a presença de pontos. Estes pontos marcam a posiçäo dentro da sentença onde novas construçöes sintáticas poderiam ser adicionadas. $\mathrm{Na}$ configuração em questão, é indicado que após o verbo poderiam ser adicionados vários adjuntos (por exemplo, o advérbio "repetidamente"), o mesmo se dando com o objeto direto.

Da maneira como a gramática foi construída, ela necessariamente deve possuir um sujeito e sempre na primeira posição (ela inibe, por exemplo, a topicalização do objeto direto). Além disso, ela também impede que qualquer outra coisa seja entreposta entre o sujeito e o verbo. 
No próximo passo, o mecanismo de geração reentra recursivamente na gramática $G$ para cada um dos subconstituintes. Assim, ela entrará no nível do SN duas vezes (uma para o sujeito e outra para o objeto direto) e uma vez no nível do SV (para o verbo). A DF que resulta destes passos é mostrada na Figura 6.6.

A descrição funcional resultante é enviada para o processo de linearização. Esse processo, por sua vez, acessa recursivamente todos os traços pattern da DF, iniciando no nível superior. Lá ele encontra a seguinte configuração (sujeito verbo ... objetodireto ...), indicando que ele deve procurar dentro das DF de sujeito, verbo e objetodireto, nesta ordem, seus traços pattern, e assim sucessivamente. O processo de linearização termina quando não forem mais encontrados os traços pattern e, nesse caso, procura-se pelo traço lex, que indica o item lexical a ser usado, caso ele exista.

Terminado o processo de linearização, obtém-se a lista mostrada na Figura 6.5, que será enviada para o último processo que realizará a síntese ortográfica e morfológica, se necessário. Note que os itens lexicais já estão na ordem em que devem aparecer na sentença final.

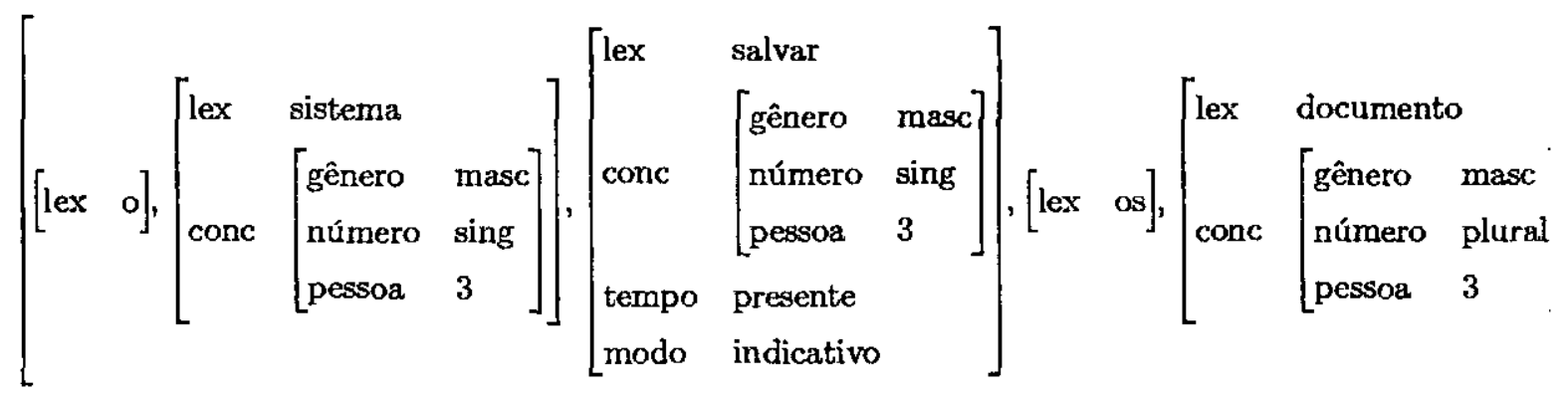

Figura 6.5: A saída do processo de linearização. 


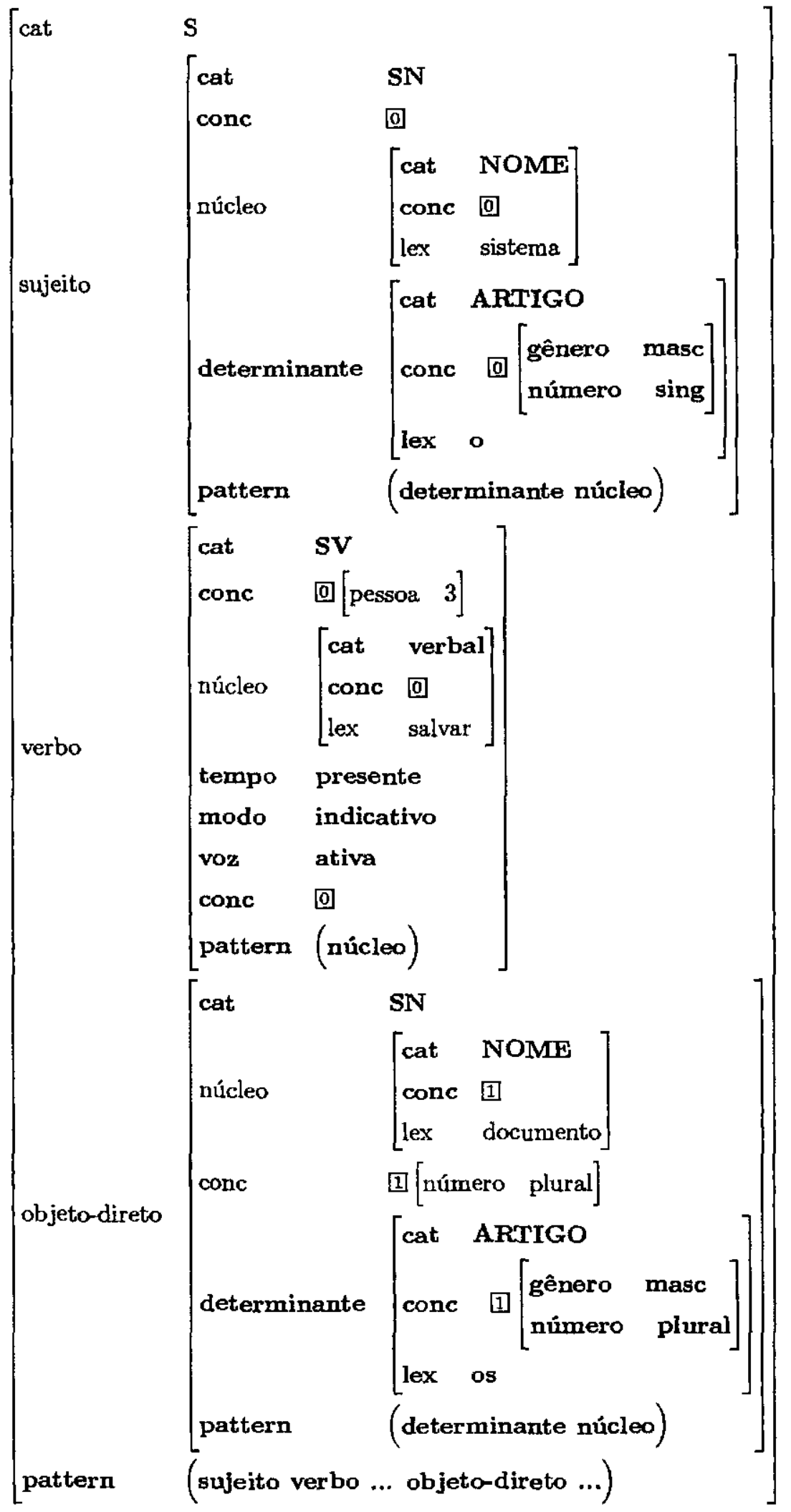

Figura 6.6: DF da entrada resultante da unificação com a gramática G. 


\title{
Capítulo 7
}

\section{Especificação dos Recursos Linguísticos e Computacionais}

\author{
Eu quase que nada não sei. Mas desconfio de muita \\ coisa. \\ ... o real não está na saída nem na chegada: ele se \\ dispõe para a gente é no meio da travessia.
}

Guimarães Rosa, Grande Sertão: Veredas

\subsection{Introdução}

Neste capítulo trataremos da especificação dos tipos de recursos lingüŕsticos e computacionais serão necessários à construção de uma gramática de geração para a língua portuguesa.

Para tornar mais concreta a argumentação, utilizaremos como modelo ilustrativo o processo de geração de português a partir da UNL (vista no capítulo 4). A escolha deste modelo por si só já apresenta grandes desafios e reflete bem os tipos de problemas encontrados quando se trabalha com geração de línguas naturais. 


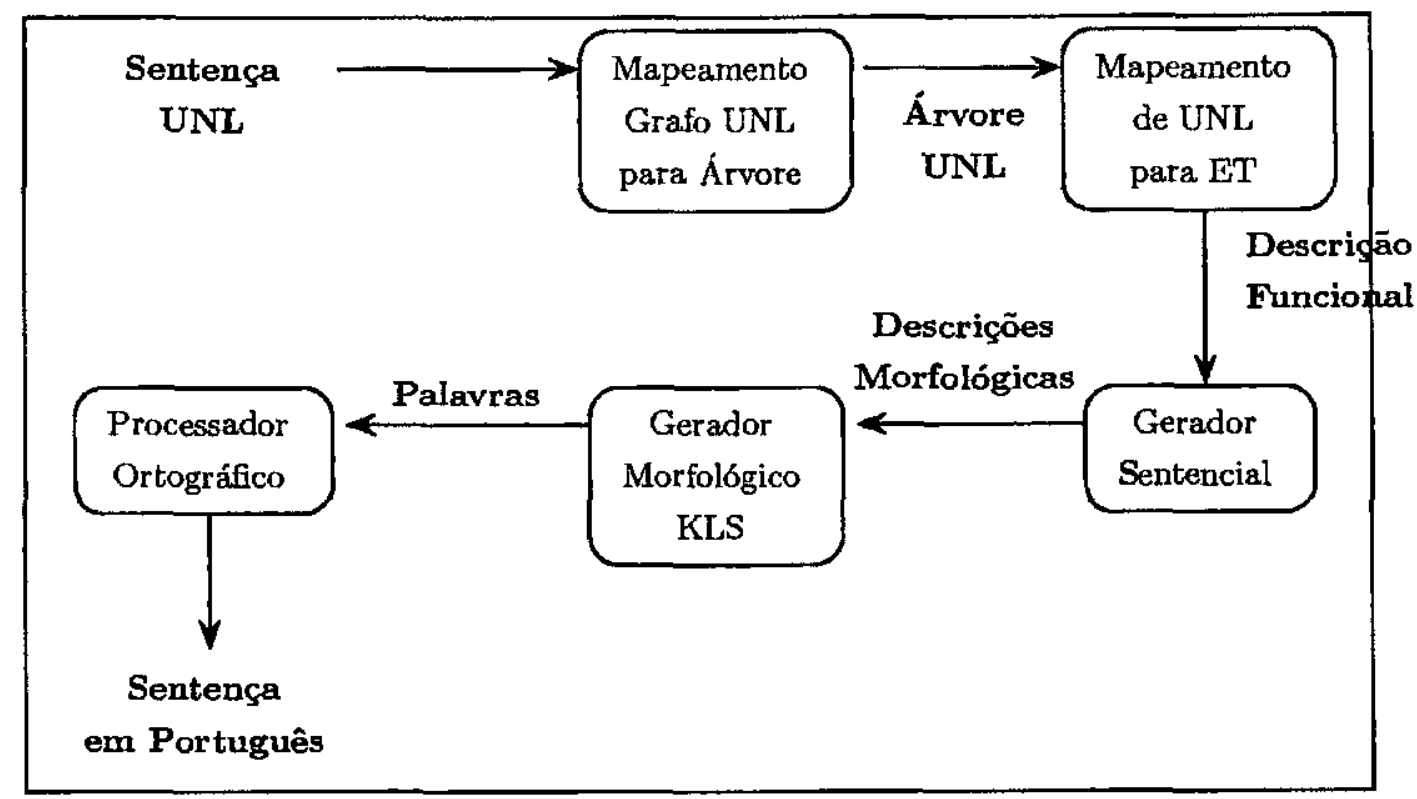

Figura 7.1: Arquitetura do sistema de geração UNL-Português.

\subsection{A arquitetura Geral do Sistema}

A Figura 7.1 apresenta a arquitetura utilizada no sistema de geração de UNL para português. A escolha desta arquitetura baseou-se naquelas citadas por Elhadad [Elh92], Temizsoy [Tem97], Korkmaz [Kor96] e Sérasset e Boitet [SB00].

\subsubsection{Mapeamento do Grafo UNL para Árvore UNL}

A UNL é um hipergrafo dirigido onde cada nó pode, ele mesmo, ser outro grafo $\left[\mathrm{M}^{+} 00\right]$. Um desses nós é marcado com "entry" e indica a entrada para este hipergrafo. O fato da UNL ser um hipergrafo nos coloca problemas, pois a maioria das técnicas e algoritmos apresentados aqui usa uma estrutura de árvore como mecanismo representacional básico. Assim, necessitamos transformar este hipergrafo em uma árvore, o que é feito pelo módulo de mapeamento do grafo UNL para uma árvore UNL (Figura 7.2), que realiza este mapeamento mantendo a direcionalidade e a rotulagem dos nós do grafo.

A primeira ação do módulo é varrer a sentença UNL de entrada fazendo a análise sintática (parser) e a validação da estrutura. A verificação da existência de um nó marcado com "entry" é feita nesta fase. Caso alguma inconformidade seja encontrada o processo todo é abortado e mensagens de erro são emitidas. Se a validação resultar correta, é gerada uma representação interna mais adequada para o processamento dos 


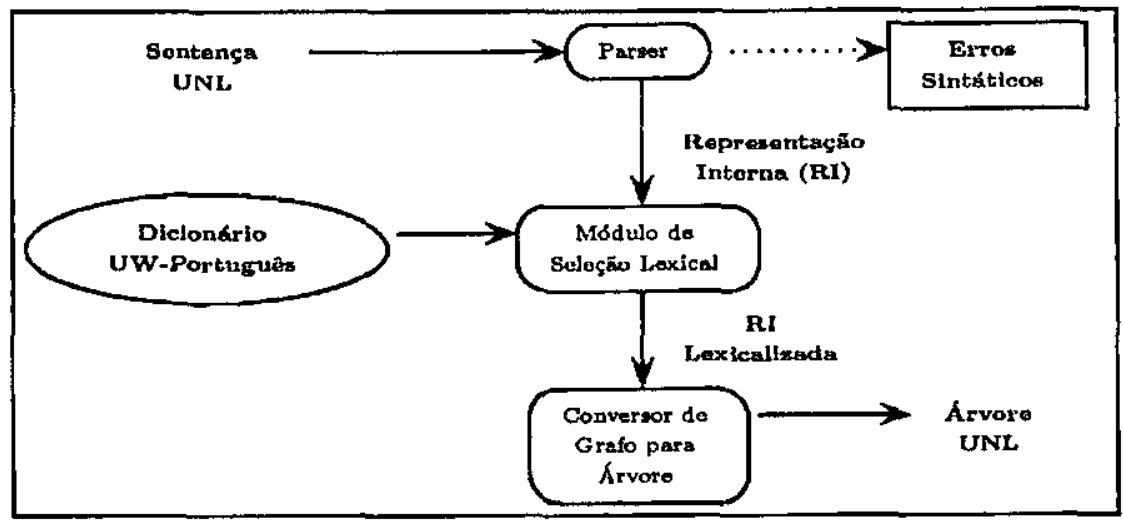

Figura 7.2: Módulo responsável pelo mapeamento de um grafo UNL para uma árvore.

outros módulos.

Em seguida, a representação interna gerada pelo parser é enviada ao módulo de seleção lexical que, consultando o dicionário UW-Português, converte as UWs nos vários lexemas candidatos. Pode haver mais que um lexema candidato porque neste ponto do processamento é impossível ter todas as considerações sintáticas e semânticas necessárias à escolha de um único lexema. Isto se dá pelo fato de uma mesma UW poder possuir interpretaçōes diferentes em português, dependendo de fatores sintáticos, semânticos ou pragmáticos. Outro fator que contribui para a multiplicidade de lexemas ocorre quando diferentes termos são usados em diferentes domínios para denotar o mesmo sentido da palavra [SB00]. O resultado desta fase é a lexicalização da representação interna, com os vários lexemas candidatos acrescidos aos nós do grafo. As entradas destes lexemas no dicionário UW-Português também contribuem com descrições morfossintáticas e semânticas dos lexemas selecionados.

A última fase do processamento deste módulo consiste em fazer a conversão de grafo lexicalizado em um árvore. Esta conversão levará em conta a direção e os rótulos presentes em cada nó do grafo original. Para este fim, usaremos o algoritmo apresentado por Sérasset e Boitet [SB00] e visto na Figura 7.3. Este algoritmo divide os nós que são alvos de mais de um nó, invertendo a direção do menor número possível de arcos. Para mostrar este algoritmo em ação, considere a sentença dada abaixo em inglês, seguida de sua tradução em português e da representação UNL. O grafo UNL representativo desta sentença é dado na Figura 7.4.

Sentença inglesa: Long ago, in the city of Babylon, the people began to build a 
Seja $\Sigma$ o conjunto de nós de $G, R$ o conjunto de rótulos, $A$ a árvore criada e $N$ o conjunto de nós de $A$.

Defina o grafo $G=\{(a, b, r) \mid a \in \Sigma, b \in \Sigma$ er $r \in R\}$ como um conjunto de arcos dirigidos rotulados e defina $L_{a}=\left\{\left(n_{G}, n_{A}\right) \mid n_{G} \in \Sigma\right.$ e $\left.n_{A} \in N\right\}$ como a lista associativa que estabelece a correspondência entre os nós da árvore e os nós do grafo.

$e_{G} \in \Sigma$ é o nó de entrada erm $G$

$e_{A} \leftarrow$ CriaNovoNoArvore $\left(e_{G}\right.$, entry)

$A \leftarrow e_{A} ; N \leftarrow\left\{e_{A}\right\} ; L_{a} \leftarrow\left\{e_{G}, e_{A}\right\}$

enquanto $G \neq \emptyset$ faça

se existe $(a, b, r)$ em $G$ tal que $\left(a, a_{A}\right) \in L_{a}$ então

$G \leftarrow G \backslash(a, b, r)$;

$b_{A} \leftarrow$ CriaNovoNoArvore $(b, r)$;

$L_{a} \leftarrow L_{a} \cup\left\{\left(b, b_{A}\right)\right\}$;

seja $a_{A} \in N$ tal que $\left(a, a_{A}\right) \in L_{a}$;

adicione $b_{A}$ aos filhos de $a_{A}$;

senão se existe $(a, b, r)$ em $G$ tal que $\left(b, b_{A}\right) \in L_{a}$ então

$G \leftarrow G \backslash(a, b, r) ;$

$a_{A} \leftarrow$ CriaNovoNoArvore $\left(a, r^{-1}\right)$;

$L_{a} \leftarrow L_{a} \cup\left\{\left(a, a_{A}\right)\right\}$;

seja $b_{A} \in N$ tal que $\left(b, b_{A}\right) \in L_{a}$;

adicione $a_{A}$ aos filhos de $b_{A}$;

senão encerre com erro ("grafo desconexo");

Figura 7.3: Algoritmo de conversão de grafo UNL para árvore UNL [SB00]. 


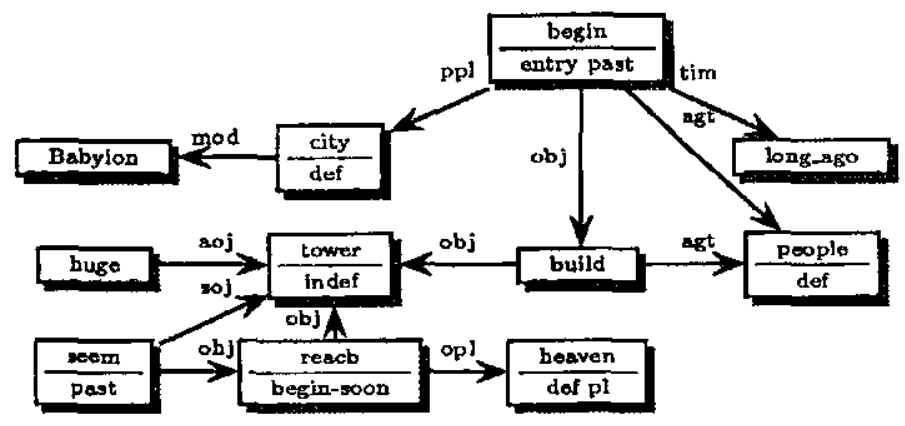

Figura 7.4: Grafo UNL.

huge tower, which seemed about to reach the heavens.

Tradução: Há muito tempo, na cidade de Babilônia, os homens começaram a construir uma imensa torre, que parecia quase atingir os céus.

Representação UNL: tim(begin. @entry. @past, long_ago)

mod(city.@def, Babylon)

ppl (begin. Qentry. Qpast, city. Qdef)

agt (begin. Qentry. Qpast, people. Qdef)

obj (begin. Qentry. Qpast, build)

obj (build, tower. Qindef)

agt (build, people.Qdef)

aoj (huge, tower. Qindef)

soj (seem. Qpast, tower. Qindef)

obj (seem. @past, reach. @begin-soon)

obj (reach.Qbegin-soon, tower.Qindef)

opl (reach.Qbegin-soon, heaven.Qdef.Qpl)

Após a aplicação do algoritmo de conversão obteremos a árvore mostrada na Figura 7.5. Note a duplicação dos nós contendo as UWs tower.@indef e people.@def, as únicas que são al vos de mais de uma RL no grafo. Note também que somente dois ramos na árvore tiveram suas direções invertidas, mantendo as mesmas orientações do grafo UNL. 


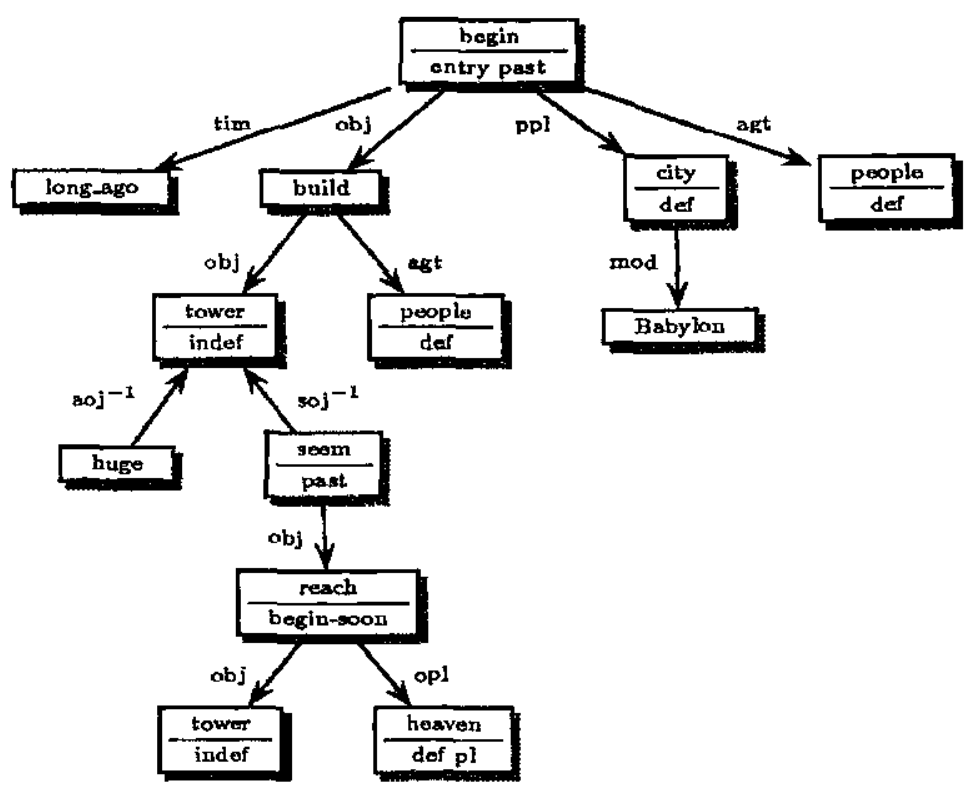

Figura 7.5: Árvore UNL. 


\subsubsection{Mapeamento da Árvore UNL para uma Descrição Fun- cional}

Depois de converter a sentença UNL em uma árvore UNL lexicalizada, temos que mapeá-la para uma estrutura de traços. Esta ET será a descrição funcional de entrada a ser utilizada pelo módulo de geração.

Do ponto de vista da geração de sentenças a partir da UNL, esta é a fase mais crítica do processo, pois é nela que encontraremos questōes que ainda não foram resolvidas a contento pela comunidade de pesquisa em GLN.

A árvore que é apresentada a este módulo é essencialmente semântica em natureza, excetuando-se as UWs que já possuem parte das informações sintáticas que serão necessárias para o seu processamento. Assim, cabe a este módulo mapear as estruturas semânticas em estruturas sintáticas. Vejamos alguns dos problemas que deverão ser tratados aqui:

- Os rótulos de relações não possuem um mapeamento bijetivo com as funções sintáticas da oração em português. A mesma RL pode ser mapeada para funções sintáticas diferentes dependendo do contexto em que ela aparece. É o caso de soj que pode se manifestar sintaticamente como sujeito, predicativo do sujeito, adjunto adnominal ou objeto direto, em virtude do contexto que o circunda. Decidir entre uma função e outra não é uma tarefa fácil, pois entram nesta discussão tanto informações sintáticas (nem sempre disponíveis no dicionário) quanto informaçōes semânticas (por exemplo, se um substantivo é concreto e animado), o que torna a construção deste módulo mais complicada. Além disto, a mesma função morfossintática pode ser exercida por RLs diferentes. O sujeito, por exemplo, se manifesta na UNL pelos RLs soj, obj, agt, cau, ins e met [SZRN97].

- Conforme notado por Martins et al. [ $\left.\mathrm{M}^{+} 00\right]$ e [SB99], a própria UNL, na sua forma atual, não possui todos os atributos multilingüísticos para ser considerada verdadeiramente independente dos pares de línguas usadas. Por problemas de localização cultural, alguma informação crucial pode estar ausente da sentença UNL, dependendo da língua fonte da mensagem (por exemplo sexo, modalidade, número, determinação, formas de tratamento, etc.).

- A multiplicidade de lexemas para as UWs deverá ser reduzida a um único lexema 
por UW, pois como sabemos, o algoritmo de unificação falhará se existirem na mesma ET valores divergentes para os traços.

Uma maior compreensão do funcionamento interno deste módulo ainda depende de uma investigação mais profunda e, por esta razão, demandará um tempo maior do que aquele gasto no entendimento dos demais módulos.

Um caminho que nos parece viável no momento é aquele seguido por Temizsoy [Tem97], que faz o mapeamento de expressões $\mathrm{TMR}^{1}$ (Text Meaning Representations) para ETs. $\mathrm{Na}$ arquitetura proposta por ele, uma sentença TMR é processada e uma estrutura sintática é construída desta sentença, selecionando os itens lexicais para os constituintes da sentença. O sistema divide-se em dois módulos: um, de selcção lexical, responsável pelo processamento dos lexemas candidatos e outro, chamado de módulo de aplicação de regras de mapeamento. Este módulo reúne todas as regras de mapeamento que são aplicadas à sentença TMR sendo processada e também à estrutura sintática sendo construída. Estas regras são compostas de condições e ações. Se as condições especificadas por elas forem satisfeitas tanto pela sentença TMR quanto pela ET representando a estrutura sintática, então as ações correspondentes são realizadas sobre a ET, atualizando-a

Um outro caminho seria deixar as tarefas de seleção lexical e de mapeamento da estrutura semântica para a sintática totalmente para a gramática [Elh92], porém isto torna o desenvolvimento da gramática muito mais complexo e pode também ter conseqüências no desempenho do gerador. Por outro lado, a entrada poderia estar em um nível semântico mais abstrato, liberando assim o aplicativo que a gerar de tomar conhecimento de questões sintáticas ou lexicais, o que certamente aumentará a modularidade e a aplicabilidade do gerador.

\subsubsection{O Gerador Sentencial}

A Figura 7.6 mostra a arquitetura interna do gerador sentencial. O seu funcionamento já foi explicado no final do capítulo 6 . Aqui somente comentaremos sobre os problemas encontrados no desenvolvimento de uma gramática de unificação funcional.

\footnotetext{
${ }^{1}$ TMR foi desenvolvida pelo projeto Microcosmos da New Mexico State University e assemelha-se a UNL, embora possua formas mais ricas para a representação dos conhecimentos lingüísticos e de mundo.
} 
Existem várias questões a serem resolvidas quando se deseja construir uma gramática computacional de geração, a saber:

1. Quais fenômenos lingüísticos serão tratados? Dito de outra forma, qual a cobertura gramatical que se pretende?

2. Uma vez respondida a questão anterior, surge outra: Qual tipo ou quais tipos de teorias lingüísticas melhor espelham esta cobertura?

3. Qual nível de abstração será exigido da entrada?

4. Existe algum formalismo computacional implementando a teoria lingüística? Qual sua eficiência? Como ele pode ser combinado com outros componentes?

A primeira questão em geral é respondida por meio do uso de um corpus de textos [RD00]. O primeiro passo é então estudar e posteriormente selecionar um conjunto de textos representativos do domínio de atuação do gerador. Mesmo nestes textos há que se examinar, cuidadosamente, quais construções da língua são gerais e recorrentes o suficiente para justificar uma investigação mais detalhada. Um fenômeno lingüístico interessante, mas pouco freqüente, pode não justificar todo o esforço que será dispendido na tentativa de cobri-lo. Em geral, a construção da GCG é um processo longo e iterativo. Começa-se com um núcleo básico cobrindo alguns fenômenos e então, paulatinamente, estende-se este núcleo básico até que se obtenha uma cobertura satisfatória. Este processo não é linear, pois a adição de novos conhecimentos a uma gramática já funcional pode ocasionar erros devido, principalmente, à interação entre as regras. Logo, uma má escolha no início poderá inviabilizar totalmente o empreendimento.

A segunda questão possui uma resposta mais subjetiva. A questão da escolha das teorias lingüísticas subjacentes dependerá, em grande medida, da experiência anterior da equipe de desenvolvimento com alguma delas. Teorias diferentes poderão tratar melhor alguns fenômenos do que outras. Não é raro o caso em que uma GCG precise usar conceitos e métodos de diferentes escolas lingüísticas. SURGE [ER97], por exemplo, possui como eixo principal a teoria lingüística sistêmica funcional, entretanto, em muitos casos, foi preciso usar conceitos da gramática tradicional, assim como conceitos de HPSG (Head-driven Phrase Structure Grammar) [PS94], para realizar muitas das construções hoje possíveis. Outro ponto a se observar é a existência de 


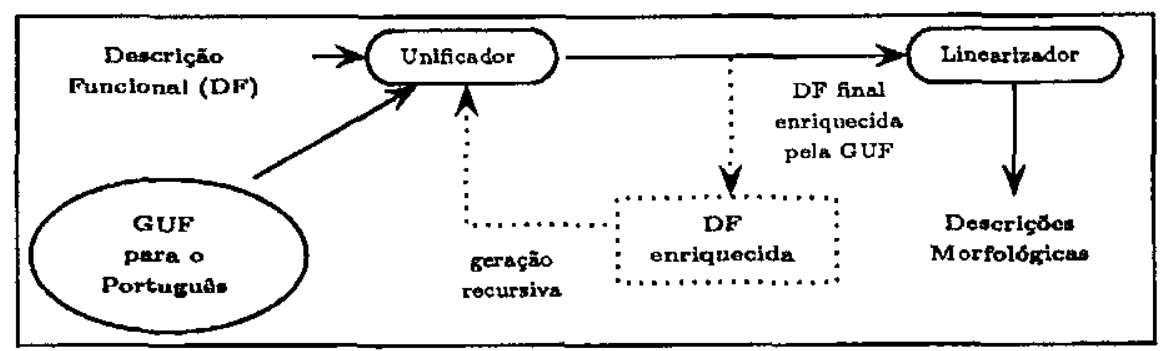

Figura 7.6: $O$ gerador sentencial.

trabalhos lingüísticos que detalhem em nível suficiente, como as gramáticas poderiam ser construidas.

É notória, entre os lingüistas, a preocupação com fenômenos relativamente raros e também a longa discussão sobre modelos gramaticais teóricos. Também é notório que estes mesmos lingüistas raríssimas vezes constroem gramáticas, aplicando suas próprias teorias, que sejam efetivamente práticas. Muitas teorias, apesar da elegância descritiva, podem ser computacionalmente intratáveis.

O lingüista Bento Carlos Dias da Silva discorria, na sua tese de doutorado [Sil96] apresentada em 1996, sobre a necessidade do trabalho cooperativo entre os "cientistas da linguagem"e os "engenheiros da linguagem", pois a desvinculação das duas áreas faz com que os pesquisadores do processamento automático das línguas naturais lutem para domar as línguas naturais, muitas vezes, sem poder contar com o auxílio de fundamentação lingüística adequada. Podemos dizer que o panorama atual melhorou, mas não muito. Poucos são os trabalhos lingüísticos no Brasil que possuem orientação mais computacional ou que detalhem o conhecimento lingüístico para que possam ser utilizados em GLN. Sob esta ótica, é importante salientar o trabalho do lingüista Mário Perini, no livro Gramática Descritiva do Português [Per96]. Este trabalho, cuja motivação é eminentemente teórica, é um exemplo de que a pesquisa teórica pode caminhar lado a lado com a pesquisa aplicada. Trabalhos, como o entendimento mais amplo da estrutura do sintagma nominal, denominado por ele como sintagma nominal máximo ${ }^{2}$, em muito facilitam a tarefa de quem deseja construir uma gramática para fins práticos.

\footnotetext{
${ }^{2}$ Este trabalho ainda está em andamento.
} 
A terceira questāo, que trata do nível de abstração exigido da representaçāo, já foi respondida no Capítulo 3, subseção 3.1.2. Vamos somente explorar este ponto dentro do processo construtivo das gramáticas de unificação funcional.

De modo geral, uma GUF é a diferença entre a DF final na saída do unificador e aquela dada inicialmente na entrada. Desta forma, tudo o que for desejado na saída e não estiver na entrada deve ser explicitamente fornecido pela gramática. De posse desta informação, podemos verificar que quanto mais alto o nível de abstração da DF de entrada, mais complexa será a gramática. Por outro lado, quanto mais sintática e lexicalizada for a DF de entrada, mais simples será a GCG. É tarefa do projetista decidir sobre a complexidade da gramática.

A quarta e última questão aborda assuntos relacionados à eficiência do formalismo, sua capacidade de integração com outros componentes e as características fornecidas pelo ambiente computacional de desenvolvimento e teste das gramáticas. As GUFs, ou mais genericamente os formalismos gramaticais baseados em restrições, contam hoje com várias ferramentas que diferem de acordo com estes pontos:

- FUF de Elhadad [Elh92], que por ser implementado em LISP conta com todo o aparato disponível há anos para os programadores, além daqueles criados especificamente para acompanhar a ferramenta. Vale notar que SURGE foi criada usando-se FUF.

- KPML [Bat97] (Komet-Penman Multilingual) é um ambiente de desenvolvimento para a escrita e desenvolvimento de gramáticas. NIGEL, a gramática de geração que o acompanha, foi desenvolvida inteiramente nele.

- Genesys [KTIT94] é um ambiente para desenvolvimento de gramáticas, possuindo editores especiais, ferramentas de depuraçāo e interface gráfica.

\subsubsection{Os Processadores Morfológico e Ortográfico}

A saída do gerador é uma lista ordenada de descrições morfológicas. Estas descrições possivelmente necessitarão de processamento morfológico e ortográfico para se tornarem efetivamente sentenças do portugucss. A ordem indicada na lista é a ordem final em que serão posicionados os lexemas após este processamento. Entre os exemplos de lexemas que precisarão de tratamento morfológico estão: 
- Os verbos, que precisarão ser flexionados em modo, tempo e pessoa;

- Os substantivos e adjetivos, que necessitaräo se adequar em número, gênero e grau;

- Os pronomes, pois podem ser apenas indicados por sua descrição morfologica e portanto serão lexicalizados nesta fase;

- As Crases e as contrações.

Terminada a fase do processamento morfológico chega a vez do processamento ortográfico. Algumas das funções do processador ortográfico são:

- Maiusculizar as letras iniciais dos nomes próprios e do início de um período;

- Acrescentar os sinais de pontuação, que podem apenas estar indicados na descrição morfológica;

- Colocar marcas de realce tais como aspas, sublinhados, negritos, ctc.

Estas duas fases são bem compreendidas e existem vários pacotes e ferramentas capazes de realizá-las para várias línguas, entre elas o português.

\subsection{Implementação do Protótipo}

Para testar a funcionalidade da arquitetura mostrada na Figura 7.1, foi desenvolvido um protótipo em Prolog, usando uma pequena GUF desenvolvida para o português (vide apêndice $\mathrm{A}$ ).

Embora o FUF seja um gerador eficiente, não encontramos razão suficiente para utilizálo em toda a sua funcionalidade neste projeto. O interpretador FUF, escrito em LISP, herda todas as vantagens e desvantagens dos ambientes de programação desta linguagem. Uma destas desvantagens é o excessivo número de parênteses, que confunde o implementador quando a gramática adquire um certo tamanho. Este problema pode ser minorado com o uso de editores especializados que provêem indentação automática. Outra desvantagem, mais séria, é a necessidade da utilização dos pesados ambientes que a linguagem necessita, o que causa ineficiência no processamento. 
Esses problemas da implementação FUF em LISP foram notados pelo seu criador, que recentemente tem conduzido pesquisas no sentido de amenizá-los. Um destes trabalhos [YE94] reimplementou um grande subconjunto das funcionalidades do interpretador FUF na linguagem de programação LIFE [AKP93]. Esta linguagem é uma integração de Prolog com programação funcional que usa estruturas de traços tipadas ao invés dc termos de primcira ordem como Prolog.

O trabalho de Barak [Bar00], sob a supervisão de Elhadad, enfatiza a definição e a busca de técnicas eficientes de compilação de FUF. Para alcançar este objetivo, ele desenvolveu uma máquina abstrata para a qual ele compila um subconjunto do FUF. Esta máquina abstrata e o respectivo compilador, segundo o autor, trazem grandes melhoramentos quanto à velocidade quando comparada com a versão FUF original feita em LISP.

Os trabalhos de Boyer, Lapalme e Fasciano [FL93, BL90] também se apóiam no mesmo formalismo (GUFs), porém usam Prolog como linguagem de implementação. A motivação no uso de Prolog provém do fato de ser ela uma melhor linguagem de implementação para um sistema de unificação.

PFUF [FL93] é a implementação, em Prolog, de um subconjunto do FUF. A implementação usada no nosso protótipo segue o PFUF, a exemplo do sistema Genesys [KTIT94]. A diferença está no compilador usado. Enquanto PFUF e Genesys baseiam-se no interpretador ISO-Prolog, nós utilizamos um compilador Prolog chamado Visual Prolog ${ }^{3}$.

Visual Prolog difere da maioria das implementações de Prolog, por várias razões:

- Visual Prolog produz programas compilados autônomos (executáveis). Em outras versões, Prolog é interpretado;

- O modelo de programação é fortemente tipado. Isto possibilita a construção de executáveis de maior eficiência pois elimina a necessidade de verificação dinâmica de tipos;

- O compilador é robusto, sendo utilizado há vários anos em aplicações comerciais;

- Possui interface amigável com aplicativos e bibliotecas escritos em outras linguagens, em especial com a linguagem $\mathrm{C}$.

\footnotetext{
${ }^{3}$ Visual Prolog é um produto do PDC Group e pode ser encontrado no site www.pdc.dk
} 
$[$ numero $\quad$ sing $]$

Prolog: [numero:sing $\mid \mathrm{X}]$

$\left[\begin{array}{ll}\text { cat } & \text { sn } \\ \text { conc } & {\left[\begin{array}{ll}\text { genero } & \text { masc } \\ \text { numero } & \text { sing } \\ \text { pessoa } & 3\end{array}\right]}\end{array}\right]$

Prolog: [cat:sn,

conc: [genero:masc,

numero:sing,

pessoa:3 $\mid \mathrm{X}]$

[ Y ]

Figura 7.7: Estruturas de traços em Prolog.

\subsubsection{Estruturas de traços e unificação}

Em PFUF as estruturas de traços são implementadas através de listas abertas. Listas abertas são listas que sempre possuem uma variável na posição final. Esta variável permite que inserções de novos traços sejam feitos de maneira eficiente e o compartilhamento de valores entre dois traços é feito pela simples unificação das listas que os representam. O compartilhamento ficará definido pelo uso da mesma variável na posição final. Na Figura 7.7 pode-se ver alguns exemplos da representação Prolog das ETs.

A unificação das estruturas de traços é feita através do programa mostrado na Figura 7.8. Na implementação, usamos o operador " $==="$ para indicar a unificação.

\subsubsection{O Dicionário UW-Português}

O dicionário UW-Portugutês foi implementado usando uma B-Tree, pré-definida em Visual Prolog, com a própria UW sendo usada como chave.

Esta implementação é provisória e, como será visto, o uso de um autômato finito será um mecanismo mais eficiente e compacto para a representação deste léxico [Jes99, 


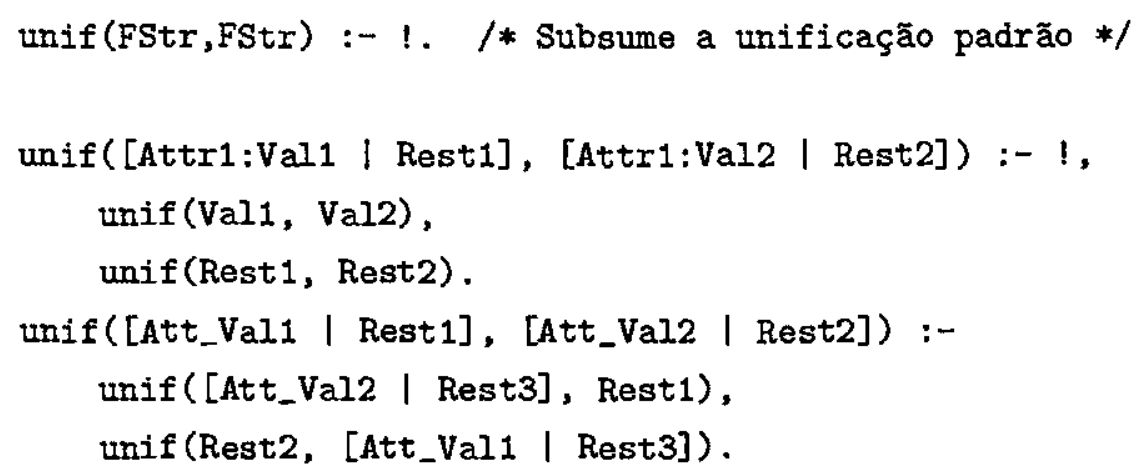

Figura 7.8: Programa Prolog para a unificação de ET [FL93].

KLS98].

\subsubsection{Os Processadores Morfológico e Ortográfico}

Usamos como processador morfológico, o KLS [KLS98, KLS95, KL93], desenvolvido por Kowaltolski, Lucchesi e Stolfi. Este processador foi concebido para uso em um aconselhador ortográfico para a língua portuguesa, usando um autômato finito como forma eficiente e compacta de representação de grandes vocabulários [Jes99].

O léxico usado no KLS foi construído pelo $\mathrm{NILC}^{4}\left[\mathrm{~N}^{+} 96\right]$ e conta com cerca de 1.500 .000 entradas (palavras com atributos sintáticos e gramaticais).

O processador ortográfico foi construído em Visual Prolog e faz operações simples como aquelas descritas na subseçāo 7.2.4.

\subsubsection{Problemas e Limitações}

Existem dois grandes problemas a serem resolvidos no protótipo: o módulo de mapeamento de árvore UNL para uma descrição funcional não foi satisfatoriamente implementado e a cobertura gramatical da GUF é pequena.

A maior dificuldade encontrada no primeiro problema, discutido na subseção 7.2 .2 , é a formulação do conjunto de regras que possibilitariam transformar a árvore UNL em

\footnotetext{
${ }^{4}$ Núcleo Interinstitucional de Lingüística Computacional
} 
uma DF. Este problema surge, em parte, da natureza da própria UNL que não possui um mapeamento bijetivo entre os RLs e as funçōes sintáticas.

O segundo problema possui suas raízes na falta de conhecimento lingüístico disponível para o português. Como exemplo, citamos a inexistência de estudos abrangentes envolvendo a lingüística sistêmica funcional, que tem sido aplicada com sucesso no desenvolvimento de outras GCGs, como é o caso de SURGE, NIGEL e outras, todas construídas tendo a língua inglesa como base.

A ausência destes estudos fez com que utilizássemos uma adaptação de uma gramática desenvolvida para a língua inglesa. Esta gramática somente consegue tratar de orações simples, e não trata adequadamente adjuntos, como os adverbiais, e também não lida com construções passivas de maneira satisfatória.

O protótipo possui limitações quando o contrastamos com FUF. Muitas das operações desenvolvidas em FUF, ou para facilitar o desenvolvimento de gramáticas, ou para aumentar a eficiência do gerador, estão ausentes na nossa implementação. Isto não representa um grande problema para a pequena gramática que usamos, porém, quando a gramática assumir um tamanho mais realístico, estas limitações se constituirão em problemas. 


\section{Capítulo 8}

\section{Conclusão}

Valeu a pena? Tudo vale a pena

se a alma näo é pequena.

Quem quer passar além do Bojador

Tem que passar além da dor.

Deus ao mar o perigo e abysmo deu,

Mas nelle é que espelhou o céu.

Fernando Pessoa, Mar Portuguez

O ponto de partida desta pesquisa foi levantar os requisitos necessários à implementação de um gerador monosentencial para o português a partir da UNL(Universal Networking Language). Os problemas que encontrei, e que parcialmente ou totalmente foram sanados no desenvolvimento dessa pesquisa, foram:

1. Entender o funcionamento da UNL e suas manifestações morfossintáticas no português.

2. Descrever como as sentenças UNL poderiam ser transformadas para servirem de entradas a algum gerador sentencial.

3. Estudar sistemas de geração alternativos e selecionar um que se adequasse à UNL.

4. Descobrir quais recursos lingüísticos seriam necessários para a geração automática de sentenças gramaticalmente corretas. 
5. Demonstrar que o modelo escolhido para os itens anteriores é viável e eficiente.

O Capítulo 4 mostrou como a UNL funciona e como as relaçōes semânticas binárias existentes entre as palavras universais poderiam ser convertidas em língua portuguesa. Vários sistemas de geração utilizados pela comunidade de pesquisadores da área de geração de línguas naturais foram examinados (Capítulos 3 e 5). Foi escolhido o formalismo das gramáticas de unificação funcional, apresentado no Capítulo 6, devido à sua natureza declarativa para a descrição lingüística, e pela existência de muitas implementaçōes disponíveis para este formalismo. Foi feita, então, uma implementação Prolog do formalismo de unificação funcional (FUF), em virtude da simplicidade notacional e também da eficiência apresentada.

No Capítulo 7 foi proposta uma arquitetura para o sistema de geração e foi descrita uma implementação parcial desta arquitetura. As principais dificuldades na utilização desta arquitetura também foram descritas e são resumidas aqui:

- A cobertura gramatical ficou restrita em razão de ausência de trabalhos mais abrangentes no campo lingüístico que sirvam de fundamento para a construção de uma gramática de geração para o português.

- O Mapeamento da sentença UNL em funções sintáticas foi parcial, em virtude da natureza da própria UNL.

\subsection{Resumo das contribuições}

As principais contribuiçōes desta pesquisa são:

1. A proposta de um modelo de geração sentencial usando-se gramáticas de unificação funcional.

2. A implementação que serviu de suporte a este modelo.

3. A descrição e comparação de vários formalismos de geração.

4. A descrição e comparação dos principais sistemas de geração existentes na atualidade. 
5. A apresentação de evidências da necessidade de estudos mais abrangentes da língua portuguesa que também possibilitem a construção de gramáticas de tamanho realístico.

6. Uma descrição das dificuldades encontradas na construção de gramáticas de geração de grande cobertura.

\subsection{Sugestões para trabalhos futuros}

O sistema PFUF, a implementação sobre a qual nos baseamos para construir o protótipo, pode ser melhorado quanto à eficiência na geração e quanto à interface com o usuário desenvolvedor de gramáticas, ao longo das seguintes linhas:

- As estruturas de traços foram implementadas usando-se listas abertas. Conforme observado por Schöter [Sch93] e Erbach [E+ 95, Erb95], esta não é a representação mais eficiente. Prolog trabalha bem com unificação de termos, e nos trabalhos destes pesquisadores demonstra-se que o uso de termos em substituição às listas abertas acelera o processo de unificação em pelo menos uma ordem de grandeza.

- O processo de unificação, no qual as GUFs estão baseadas, pode falhar. A falha acontece devido a uma inconsistência entre os valores de dois traços. Ao ocorrer esta falha, o algoritmo de unificação retrocederá e tentará encontrar um outro caminho no qual a unificação tenha sucesso. O unificador do nosso protótipo implementou este retrocesso usando o algoritmo nativo do Prolog, chamado de backtracking cronológico, pois a próxima alternativa a ser analisada é aquela que ocorreu mais próxima ao ponto em que a falha foi constatada. Entretanto, o motivo da falha pode ter sido uma escolha errada que o gerador fez em um ponto bem distante do ponto em que a falha ocorreu. Dessa forma, qualquer caminho alternativo que ocorra depois da escolha errônea deve ser descartado e o unificador deveria poder saltar direto para o ponto da escolha errônea e, a partir de lá, escolher outra alternativa ou retroceder um pouco mais se nenhuma existir. Inui, Tokunaga e Tanaka [ITT93] propõem o uso de um esquema chamado de backtracking dirigido por dependência que faz os sistemas se aproximarem deste ideal.

- Não foi implementado no protótipo nenhum tipo de ferramenta que ajudasse na depuração de gramáticas. Assim, um depurador baseado em interface gráfica, 
como aquela do Genesys [KTIT94], deverá acelerar bastante o processo de criação de gramáticas.

A GUF usada neste trabalho é muito pequena e só foi construída para justificar a viabilidade da abordagem. Em função disso, ela não cobre de maneira satisfatória muitos fenômenos importantes da língua portuguesa. Assim, o aumento da cobertura desta gramática é certamente um trabalho interessante que demandará o empenho de lingüistas computacionais na sua execução.

Finalmente, o mapeamento da UNL para o português pode demandar o uso de gramáticas probabilísticas nos moldes da PCFG (Probabilistic Context Free Grammars) [MS99]. A adição de modelos probabilísticos tornará o processo de decodificação mais robusto, mas para isto acontecer, deverão estar disponíveis grandes corpora textuais nos quais estes modelos serão treinados [Rob97]. Além disto, as gramáticas de unificação podem ser adaptadas para incorporar informaçōes estatísticas [Eis94]. 


\title{
Apêndice A
}

\section{Gramática Funcional do Português}

\begin{abstract}
Abaixo é mostrado a gramática de unificação funcional para um recorte do português. Esta gramática é uma adaptação daquelas escritas para o inglês por Elhadad [Elh92] e Fasciano [FL93]. No final deste apên dice encontram-se exemplos de entradas a serem usadas com esta gramática em nosso gerador.
\end{abstract}

\section{A.1 GUF para um recorte do português}

$\% \% \% \% \% \% \% \% \% \% \% \% \% \% \% \% \% \% \% \% \% \% \% \% \% \% \% \% \% \% \% \% \% \% \% \% \% \% \% \% \% \% \% \% \% \% \% \% \% \% \% \% \% \% \% \% \% \% \% \% \% \% \% \% \% \% \% \% \% \% \% \% \% \% \% \% \% \% \% \%$

$\% \%$

$\%$

$\%$ Descrição : Gramática de Unificação Funcional (GUF) baseada nas gramâticas: \%\%

$\%$ - GR3.L (escrita por Michael Elhadad) contido no diretorio de \%

$\%$ exemplos do FUF 5.3 ; $\%$

$\%$ - Example.PFUF (escrita por Massimo Fasciano) para ser utiliza- \%

$\%$ da na versão Prolog do FUF. $\%$

$\% \%$

$\%$ Ambas as gramáticas tratam do inglês, sendo esta uma adapatação \%

$\%$ para a sintaxe do português usado no Brasil. $\%$

$\%$ Autor : Alexsandro Santos Soares (ASS) \%

$\%$ Criado : 25 de maio de $2001 \%$

$\%$ Linguagem : Prolog \%

$\%$ Sistema : PFUF $\%$

$\% \%$

\%\%\%\%\%\%\%\%\%\%\%\%\%\%\%\%\%\%\%\%\%\%\%\%\%\%\%\%\%\%\%\%\%\%\%\%\%\%\%\%\%\%\%\%\%\%\%\%\%\%\%\%\%\%\%\%\%\%\%\%\%\%\%\%\%\%\%\%\%\%\%\%\%\%\%\%\%\%\%\%\%\%\%\%\% 
\% Processo 1: Atributiva $\rightarrow$ o estado de um objeto

$\%$ casos inerentes $\rightarrow$ portador e atributo.

$\%$ Todos estes casos devem estar presente na entrada.

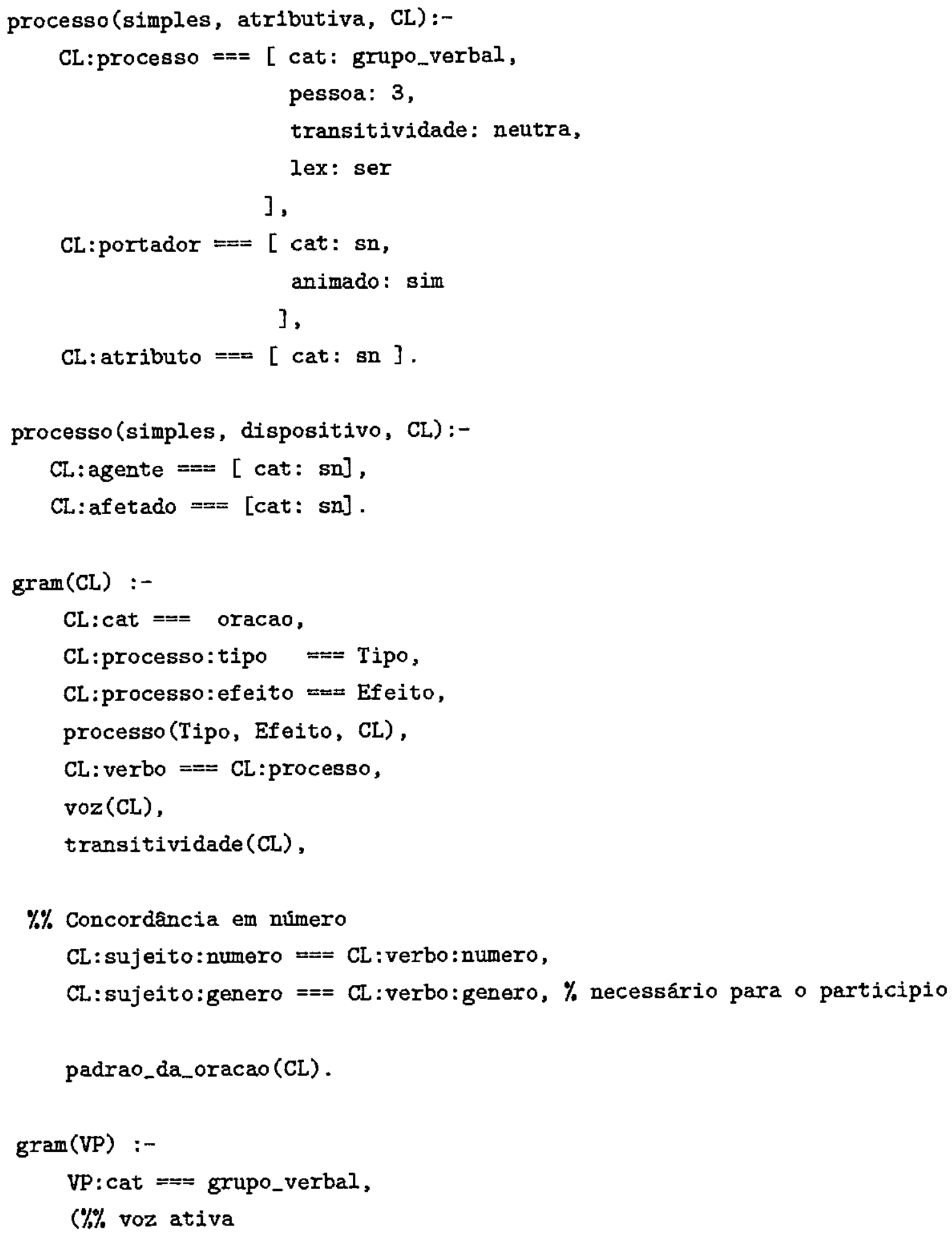


$\operatorname{gram}(\mathrm{SN}):-$

SN: cat $==\mathbf{s n}$,

$\% \%$ SN EM GERAL

$\%$ sn herda seus principais traços do nucleo e o traço definido do determinante

SN:nucleo:lex $===S N: l e x$,

$\mathrm{SN}:$ nucleo:numero $==\mathrm{SN}$ :numero,

SN:nucleo:genero $===S N$ :genero,

$\mathrm{SN}$ : numero === ( singular; plural ),

$\% \%$ QUALIFICADOR

$\mathrm{SN}===$ ( [ qualificador: none $]$

;

[ pattern: [..., nucleo, ..., qualificador], qualificador: [ cat: sp ]

]),

$\%$ SUBSTANTIVO COMUM

( $\mathrm{SN}===$ [ tipo_sn: substantivo, nucleo: [ cat: substantivo], pattern: [ determinante, ..., nucleo,...], determinante: [ cat: $\operatorname{det}]$ ],

SN: determinante: definido $===$ SN: definido,

$\mathrm{SN}$ :determinante:numero $==\mathrm{SN}$ :numero,

$\mathrm{SN}$ :determinante:genero $==\mathrm{SN}$ : genero ;

\%\% NOME PRÓPRIO

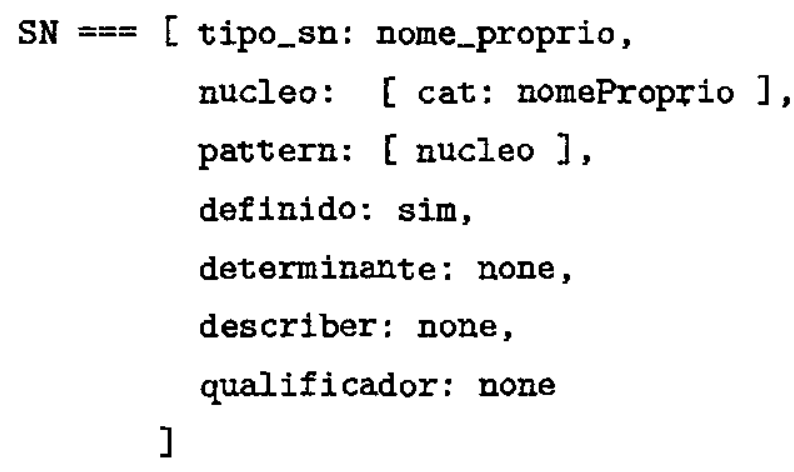


$\%$ ADJETIVOS (funcionando como predicativo do sujeito)

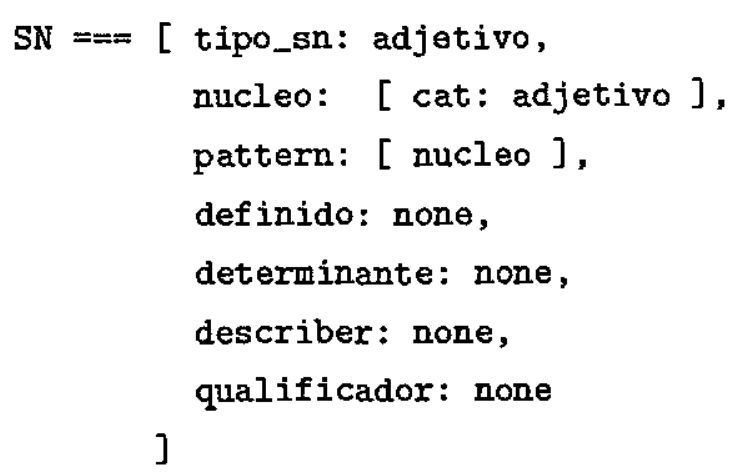

)

$\%$ DESCRIBER

( $\mathrm{SN}===[$ describer:none ];

$\mathrm{SN}===$ [pattern: $[\ldots$, nucleo, describer, ...] ],

$\mathrm{SN}$ :describer $===$ ([ cat: adjetivo ]

;

[ cat: verbo,

forma: participio

]

),

$\mathrm{SN}$ :describer: numero $=\mathrm{m}=\mathrm{SN}$ : numero,

SN:describer:genexo $==5 \mathrm{SN}$ : genero

) .

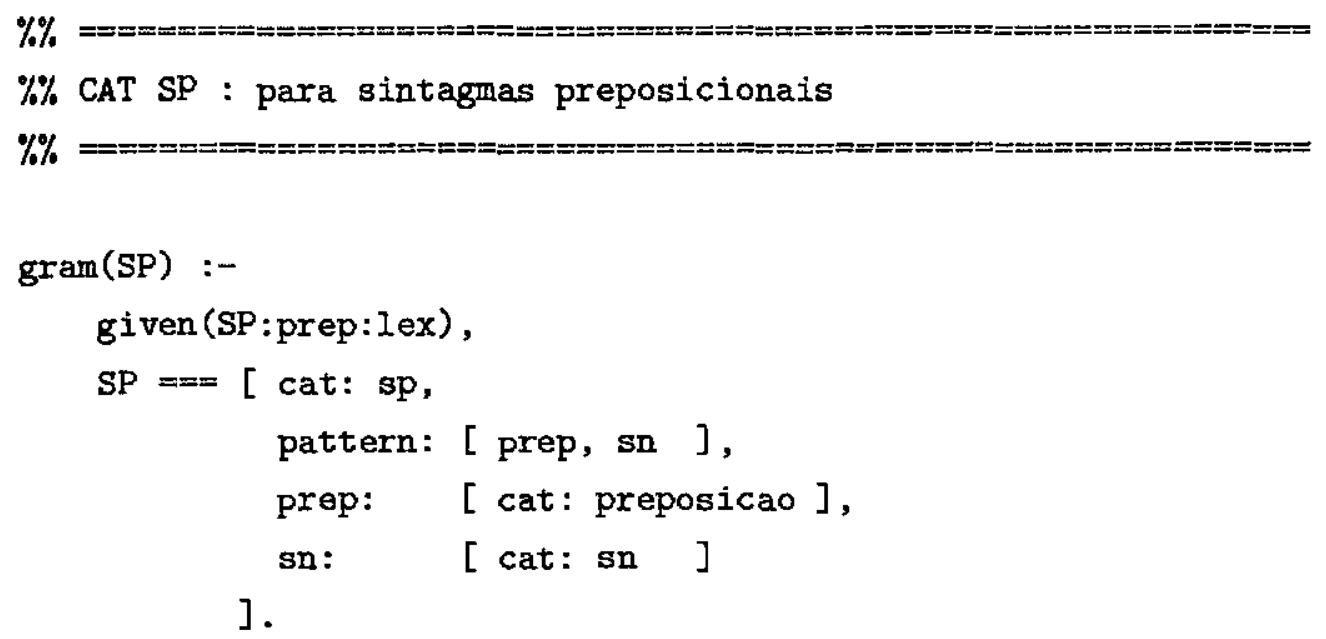




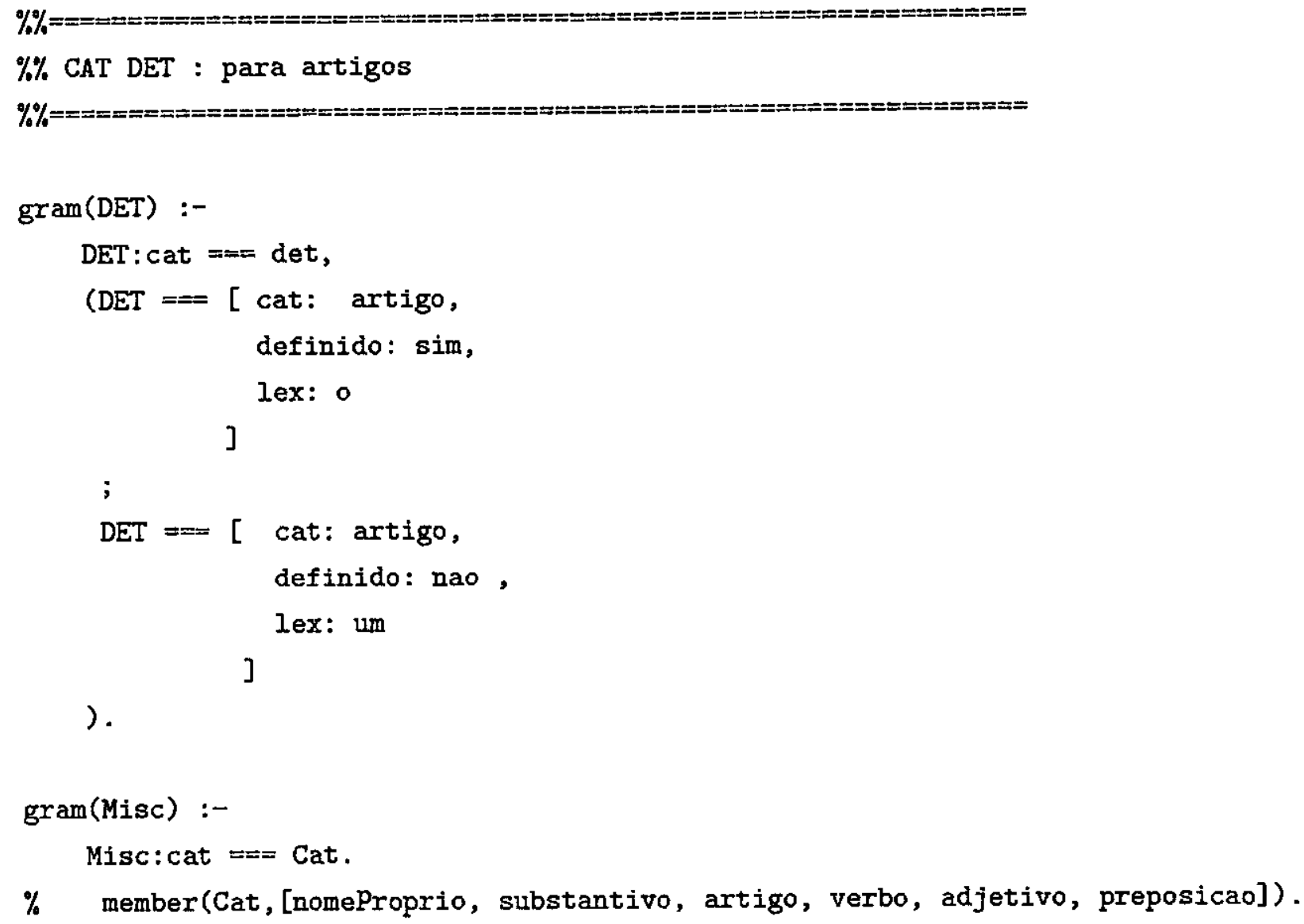




$$
\begin{aligned}
& \text { CL:sujeito }===C L \text { :agente, } \\
& C L: \text { objeto }===\text { CL:afetado. }
\end{aligned}
$$

$\%$ Número de participantes inerentes ao processo

$\%$ Baseado na classificação do verbo:

$\%$ Neutra: 1 ou 2 participantes

$\%$ Intransitivo: 1 participante

$\%$ TransDireto: 2 participantes

$\%$ Bitransitivo: 3 participantes

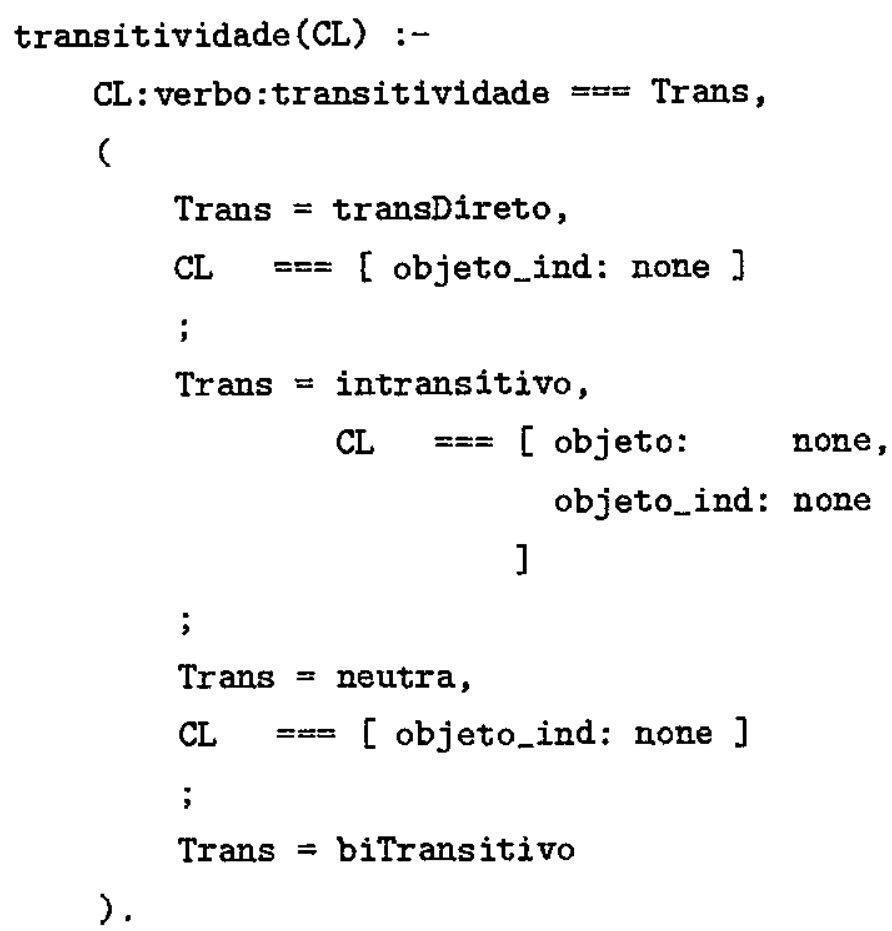

$\%$ Generalidades: reúne os papéis sintáticos e faz as concordâncias. $\%$ Os padrões estão aqui.

padrao_da_oracao(CL) :-

$\%$ Arranja a ordem dos complementos

CL:pattern $===[$ sujeito, verbo, ..., objeto, ...],

$C L:$ verbo: $\mathrm{voz}===\mathrm{Voz}$,

padrao_da_oracao(Voz, CL). 


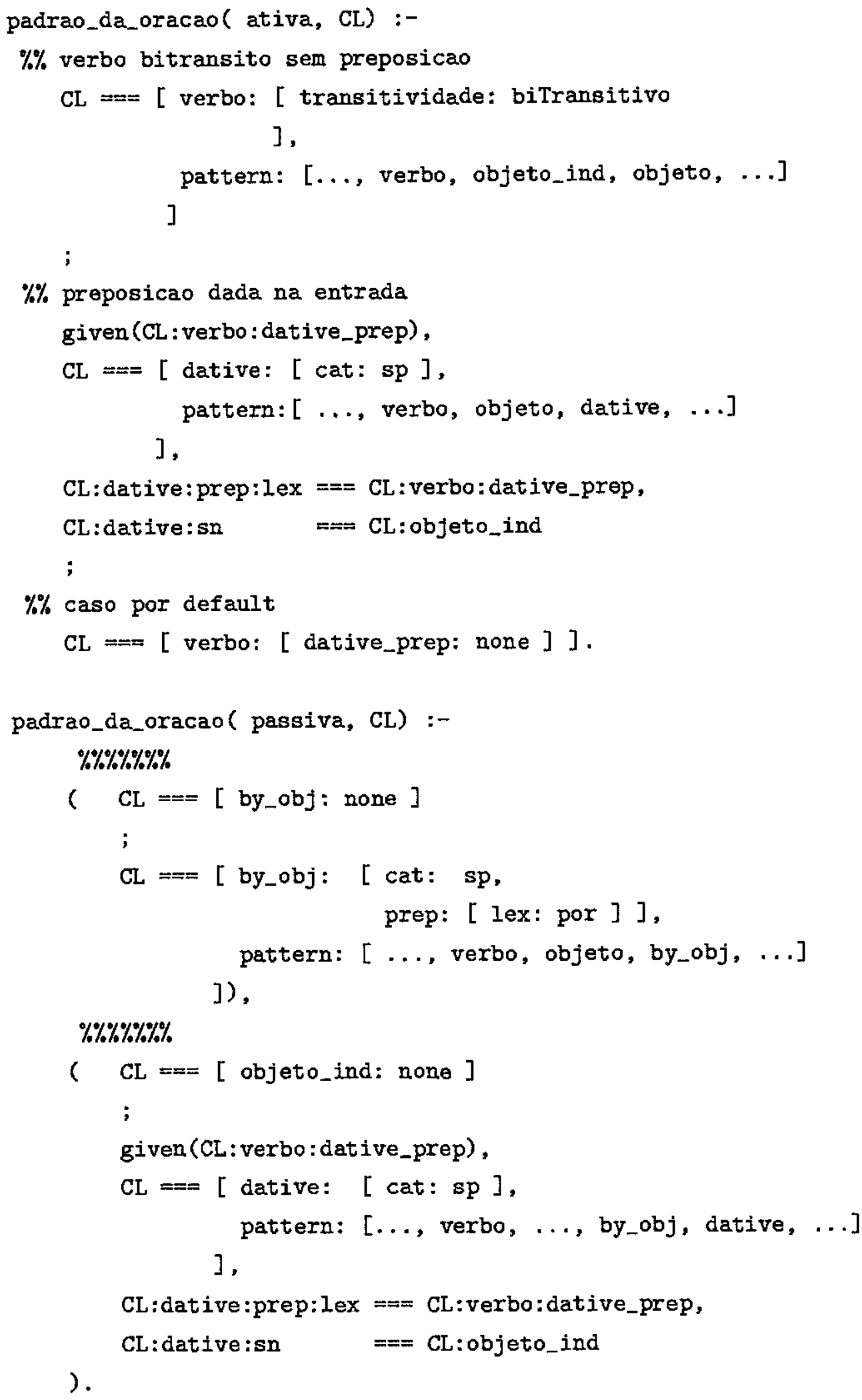




\section{A.2 Exemplos de entradas}

Exemplo 1:

Sentença original: 0 mar está calmo.

Representaçăo UNL: soj (calm, sea.Qgeneric)

Estrutura de traços (PFUF):

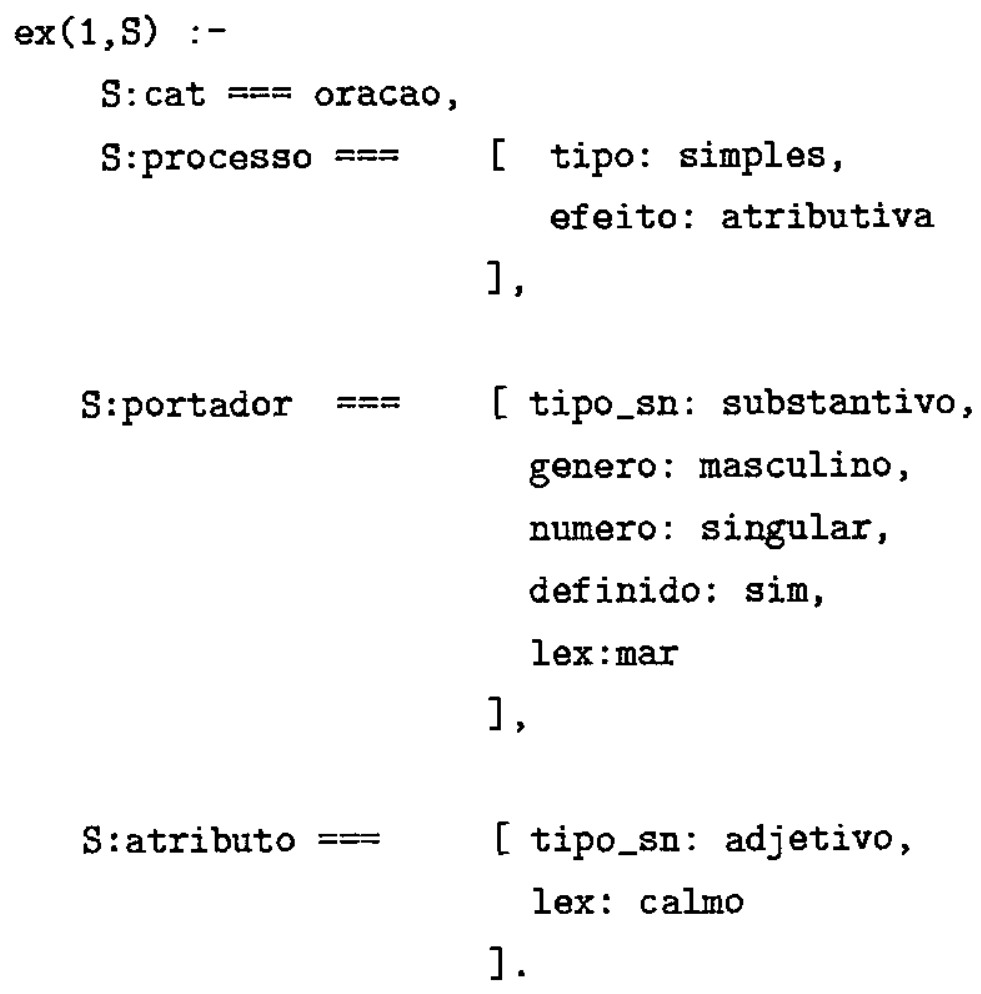

Exemplo 2:

Sentença original: Pedro come maçãs.

Representação UNL: agt (eat. Qentry. Qpred. Qpresent, Pedro), obj (eat.@entry. @pred, apple.@generic.@pl)

Estrutura de traços (PFUF):

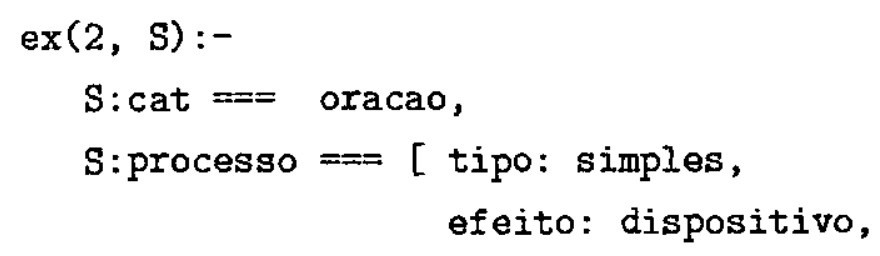




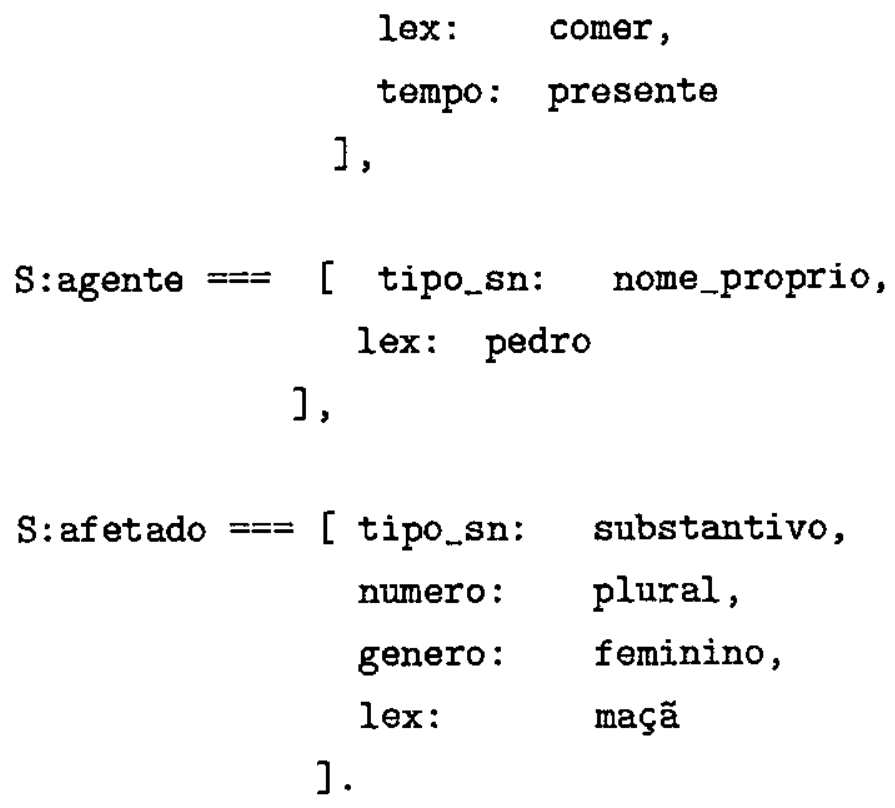




\section{Referências}

[Agu97] Alexandre Agustini. Experiência de utilização do formalismo "gramáticas síncronas de adjunção de árvores" para construção de um módulo de transferência estrutural. Dissertação de mestrado, PUCRS, Porto Alegre, 1997.

[AKP93] Hassan Ait-Kaci and Andreas Podelski. Towards a meaning of LIFE. Prl-rr-11, Digital Paris Research Laboratory, Paris, May 1993.

[App85] Douglas E. Appelt. Planning English Sentences. Studies in Natural Language Processing. Cambridge University Press, Cambridge, 1985.

[Bar00| Bar Orion Barak. The compilation of functional unification based language. Master's thesis, Ben-Gurion University, Negev, Israel, September 2000 .

[Bat97] John Bateman. Enabling technology for multilingual natural language generation: The kpml development enviroment. Natural Language Engineering, 3:15-55, 1997.

[BKNS99] Miriam Butt, Tracy Holloway King, Maria-Eugenia Niño, and Frédérique Segond. A grammar writer's cookbook. CSLI Lecture Notes No. 95. CSLI Publications, Stanford, California, 1999.

[BL90] Michael Boyer and Guy Lapalme. Text generation. In P. St-Dizier and S. Szpakowicz, editors, Logic and Logic Grammars for Language Processing, pages 255-274. Ellis Horwood, London, 1990.

[Bou98] Pierrette Bouillon. Traitement Automatique des Langues Naturelles. Collection Universités Francophones. Aupelf-Uref - Editions Duculot, Bruxelles, 1998. 
[Bra85] R. J. Brachman. On the epistemological status of semantic networks. In Readings in Knowledge Representation. Morgan Kaufman, CA, 1985.

[Cam97] Hermes A. L. Camelo. Ambientes de tradução inglês-português e ferramentas auxiliares. Dissertação de mestrado, Universidade Federal de Pernambuco, Recife, Dezembro 1997.

[E ${ }^{+}$95] Gregor Erbach et al. Extending unification formalisms. In Procceedings of the 2nd Language Engineering Convention, London, 1995.

[Eis94] Andreas Eisele. Towards probabilistic extensions of constraint-based grammars. DYANA-2, September 1994.

[Elh92] Michael Elhadad. Using Argumentation to Control Lexical Choice: A Functional Unification Implementation. $\mathrm{PhD}$ thesis, Columbia University, 1992.

[Eli99] André Eliseu. Gramática de larga escala do português. In Palmira Marrafa and Maria Antônia Mota, editors, Linguística Computacional: Investigação Fundamental e Aplicações, Lisboa, Julho 1999. Edições Colibri/Associação Portuguesa de Linguística.

[ER97] Michael Elhadad and Jacques Robin. Surge: A comprehensive plugin syntatic realisation component for text generation. Technical report, Computer Science Departament, Ben-Gurion University, Beer Sheva, Israel, 1997.

[Erb95] Gregor Erbach. Profit: Prolog with features, inheritance, and templates. EACL '95, 1995.

[FL93] Massimo Fasciano and Guy Lapalme. A prolog implementation of the functional unification grammar formalism. In Proceedings of the Fourth International Workshop on Natural Language Understanding and Logic Programming (NLULP4), pages 37-45, Nara, Japan, October 1993.

[GM89] Gerald Gazdar and Christopher S. Mellish. Natural Language Processing in Prolog: an introduction to computational linguistics. Addison-Wesley, 1989. 
[Hak96] Dilek Z. Hakkani. Design and implementation of a tactical generator for turkish, a free constituent order language. Master's thesis, Bilkent University, July 1996.

[Hal85] M.A.K. Halliday. An Introduction to Functional Grammar. Edward Arnold, London, second edition, 1985.

[Hov97] Eduard Hovy. Survey of the State of Art in Human Language Technology. Studies in Natural Language Processing. Cambridge University Press, Cambridge, 1997.

[ITT93] Kentaro Inui, Takenobu Tokunaga, and Hozumi Tanaka. Dependencydirect unification of functional unification grammar in text generation. In Proceedings of the Fourth International Workshop on Natural Language Understanding and Logic Programming (NLULP4), Nara, Japan, October 1993.

[Jes99] Marcelo A. C. Jesus. Representação de léxicos através de autômatos finitos. Master's thesis, Instituto de Ciências Matemáticas e de Computação - USP, São Carlos, Novembro 1999.

[JM00] Daniel Jurafsky and James H. Martin. Speech and Language Processing. Prentice-Hall, Inc, New Jersey, 2000.

[Jos87] Aravind K. Joshi. The relevance of tree adjoining grammar to generation. In G.Kempen, editor, Natural Language Generation, pages 233-252. Dordrecht: Martinus Nijhoff, 1987.

[Kas89] Robert Kasper. A flexible interface for linking apllications to penman's sentence generator. In Proceedings of 1989 DARPA Speech and Natural Language Workshop, pages 153-158, Philadelphia, 1989.

[Kay79] Martin Kay. Functional grammar. In Proceedings of the 5th meeting of the Berkeley Linguistics Society. Berkeley Linguistics Society, 1979.

[Kip94] Karen Kipper. Uma experiência de utilizaçāo do formalismo de gramáticas de adjunção de árvores para a língua portuguesa. Dissertação de mestrado, Universidade Federal do Rio Grande do Sul, Porto Alegre, 1994. 
[KL93] Tomasz Kowaltowski and Cláudio L. Lucchesi. Applications of finite automata representing large vocabularies. Software-Pratice and Experience, 23(1):15-20, 1993.

[KLS95] Tomasz Kowaltowski, Cláudio L. Lucchesi, and J Stolfi. Minimization of binary automata. Journal of the Brazilian Computing Society, 3(1):36-42, 1995.

[KLS98] Tomasz Kowaltowski, Cláudio L. Lucchesi, and J. Stolfi. Finite automata and efficient lexicon implementation. Technical Report DCC-92-02, January 1998.

[Kor96] Turgay Korkmaz. Turkish text generation with systemic-functional grammar. Master's thesis, Bilkent University, June 1996.

[KTIT94] Tadashi Kumano, Takenobu Tokunaga, Kentaro Inui, and Hozumi Tanaka. Genesys: An itegrated enviroment for developing systemic functional grammars. In Proceedings of International Workshop on Sharable Natural Language Resources, pages 78-85, Nara, Japan, August 1994. Nara Institute of Science and Technology.

[LS93] George F. Luger and William A. Stubblefield. Artificial intelligence: structures and strategies for complex problem solving. Benjamin/Cummings, Redwood City, California, second edition, 1993.

$\left[\mathrm{M}^{+} 87\right] \quad$ M.W. Meteer et al. Mumble-86: Design and implementation. Coins tr 87-87, University of Massachusetts, 1987.

$\left[\mathrm{M}^{+} 00\right]$ Ronaldo T. Martins et al. An interlingua aiming at communication on the web: How language-independent can it be? In Workshop on Applied Interlinguas: Practical Applications of Interlingual Approaches to NLP, Seatle, Washington, USA, April 2000.

[Mat88] C.M.I.M. Matthiessen. What's in Nigel: Lexicogrammatical cartography. Technical report, USC/ISI, 4676 Admiralty Way, Marina Del Rey, CA $90292,1988$.

[McD80] David D. McDonald. Natural Language Production as a Process of Decision Making under Constraints. $\mathrm{PhD}$ thesis, MIT Department of Electrical Engineering and Computer Science, Cambrigde, MA, 1980. 
[McD81] David D. McDonald. Language production: The source of the dictionary. In Proceedings of the 19th Annual Meeting of the ACL, pages 57-62, 1981.

[McD86] David D. McDonald. Description directed control: Its implications for the natural language generation. In K:Spark Jones B.J.Groz and B.L. Webber, editors, Readings in Natural Laǹguage Processing. Morgan Kaufmann, 1986.

[McK85] Kathleen R. McKeown. Text Generation: Using Discourse Strategies and Focus Constraints to Generate Natural Language Text. Studies in Natural Language Processing. Cambridge University Press, Cambridge, 1985.

[ME91] Kathleen R. McKeown and Michael Elhadad. A contrastive evaluation of functional unification grammar for surface language generation: a case study in choice of connectives. In In C.L.Paris; W.R.Swartout and W.C.Mann, editors, Natural Language Generation in Artificial Intelligence and Computational Linguistics, chapter 14. Kluwer Academic Publishers, 1991.

[MM83] W. C. Mann and C.M.I.M. Matthiessen. Nigel: A systemic grammar for text generation. Technical Report RS-83-105, University of Southern California, 1983.

[MRN98] Ronaldo T. Martins, Lúcia H. M. Rino, and Maria G. V. Nunes. As regras gramaticais para a decoficação UNL-português no projeto UNL. Rel. Téc. NILC-TR-98-1 67, Instituto de Ciências Matemáticas e Computação de São Carlos (ICMSC) - USP, São Carlos, Fevereiro 1998.

[MS99] Christopher D. Manning and Hinrich Schütze. Foundations of Statistical Natural Language Processing. MIT press, 1999.

[N+96] Maria G. V. Nunes et al. Desenvolvimento de um sistema de revisão gramatical automática para o português do Brasil. In Proceedings of the II Workshop on Computational Processing of Written and Spoken Portuguese, pages 71-80, Curitiba, Outubro 1996. CEFET-PR.

[N+99] Maria G. V. Nunes et al. Introdução ao Processamento das Línguas Naturais. Núcleo Interinstitucional de Linguística Computacional - NILC, São Carlos, 1999. 
$\left[\mathrm{N}^{+} 01\right] \quad$ Maria G. V. Nunes et al. The use of the Universal Networking Language for devising an automatic sentence generator for Brazilian Portuguese. Cadernos de Computação, 2(2), ICMC-USP, 2001.

[Neu98] Günter Neumann. Interleaving natural language parsing and generation through uniform processing. Journal of Artificial Intelligence, (99):121$163,1998$.

[O'D94] Michael O'Donnell. Sentence Analysis and Generation - a Systemic Perspective. PhD thesis, Linguistics Dept., University of Sydney, 1994.

[O'D95] Michael O'Donnell. Sentence generation using the systemic workbench. In Proceedings of the Fifth European Workshop on Natural Language Generation, pages 235-238, Leiden, The Netherlands, 20-22 May 1995.

[Par88] Cécile L. Paris. Tailoring object descriptions to the user's level of expertise. Computational Linguistics, 14(3):64-78, 1988.

[Per96] Mário A. Perini. Gramática Descritiva do Português. Editora Ática, 2 edition, 1996.

[PS94] Carl Pollard and Ivan A. Sag. Head-driven Phrase Structure Grammar. University of Chigago Press and Stanford: CLSI Publications, Chicago, 1994.

[Que95] Violeta S. T. D. Barbosa Quental. Uma gramática para compreensão e geração automática de textos em língua portuguesa. Tese de doutorado, PUC/RJ, Rio de Janeiro, 1995.

[RD00] Ehud Reiter and Robert Dale. Building Natural Language Generation Systems. Studies in Natural Language Processing. Cambridge University Press, New York, 2000.

[RG77] R. Roberts and I. Goldstein. The FRL Manual. MIT AI Lab, 1977.

[Rob94] Jacques Robin. Revision-Based Generation of Natural Language Summaries Providing Historical Background. PhD thesis, Columbia University, december 1994.

[Rob97] Jacques Robin. An initial UNL tool kit avoiding machine translation pitfalls. Outubro 1997. http://nilc.icmc.sc.usp.br/download/robin.html 
[SB99] Gilles Sérasset and Christian Boitet. UNL-french deconversion as transfer \& generation from an interlingua with possible quality enhancement through offline human interaction. In MT Summit, 1999.

[SB00] Gilles Sérasset and Christian Boitet. On UNL as the future "html of linguistic content" \& the reuse of existing nlp components in UNL-related applications with the example of a UNL-french deconverter. In COLING, 2000 .

[Sch93] Andreas P. Schöter. Compiling feature structures into terms: A case study in prolog. Rp-55, University of Edinburg, Centre for Cognitive Science, 1993.

[Shi86] Stuart M. Shieber. An Introduction to Unification-Based Approaches to Grammar, volume 4 of CSLI Lecture Notes. University of Chicago Press, Chicago, 1986.

[Sil96] Bento C. D. Silva. A Face Tecnológica dos Estudos da Linguagem: o processamento automático das línguas naturais. Tese de doutorado, Universidade Estadual Paulista, Araraquara, 1996.

[SvNPM90] Stuart M. Shieber, Gertjan van Noord, Fernando C. N. Pereira, and Robert C. Moore. Semantic-head-driven generation. Computational Linguistics, 16:1:30-42, 1990.

[SZRN97] C. R. C. Sossolote, C. Zavaglia, Lúcia H. M. Rino, and Maria G. V. Nunes. As manifestações morfossintáticas da língua UNL no português do Brasil. Technical Report 2, Instituto de Ciências Matemáticas e Computação de São Carlos (ICMSC) - USP, Novembro 1997.

[Tem97] Selman M. Temizsoy. Design and implementation of a system for mapping text meaning representations to f-structures of turkish sentences. Master's thesis, Bilkent University, August 1997.

[UZS99] Hiroshi Uchida, Meiying Zhu, and Tarcisio Della Senta. The UNL, a Gift for a Millennium. UNU/IAS/UNL Center, Tokyo, Japan., 1999.

[vN93] Gertjan J. M. van Noord. Reversibility in Natural Language Processing. $\mathrm{PhD}$ thesis, University of Utrecht, The Netherlands, 1993. 
[YE94] Cohen Yossi and Michael Elhadad. Implementing a FUF interpreter using. LIFE. Technical Report FC- 94-12, Ben-Gurion University, Beer-Sheva, Israel, August 1994. 